NIST Technical Note 2150

\title{
Single-Zone Simulations Using FaTIMA for Reducing Aerosol Exposure in Educational Spaces
}

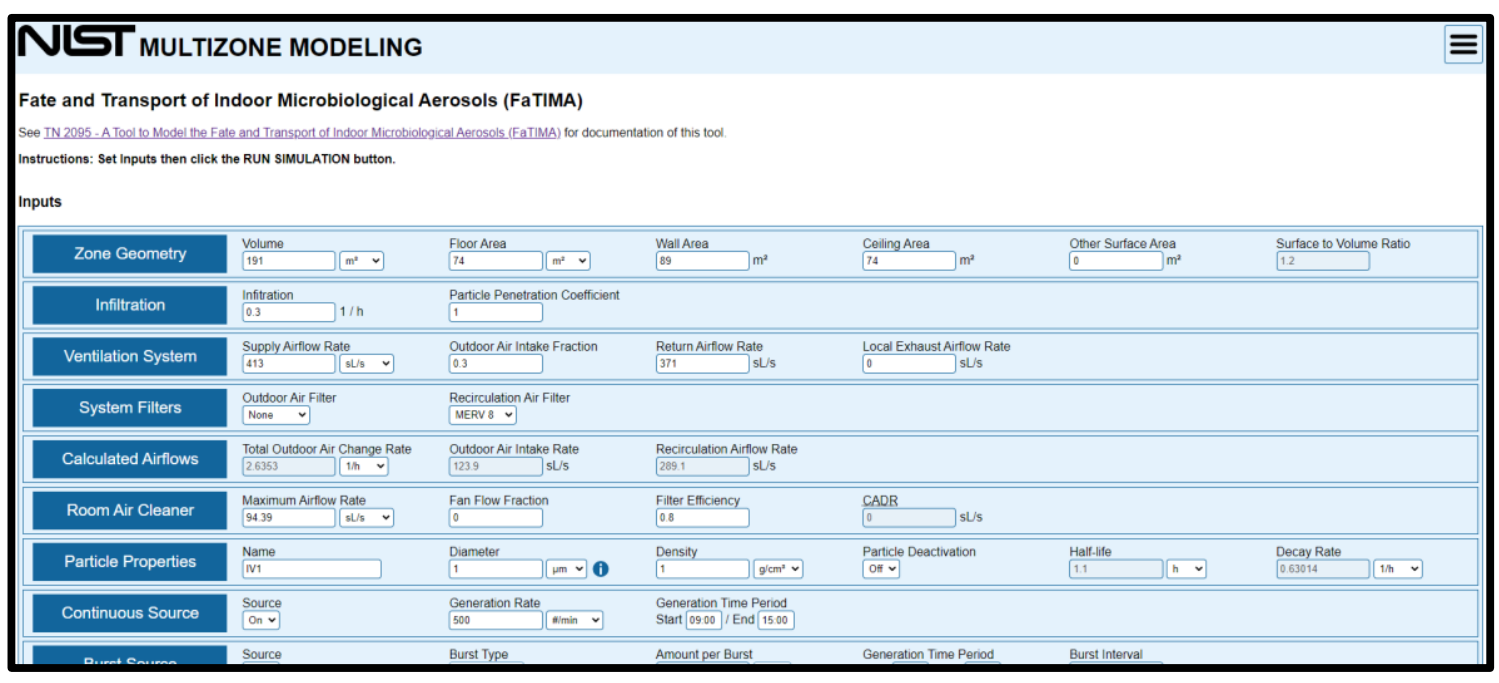

Lisa $\mathrm{Ng}$

Dustin Poppendieck Brian Polidoro W. Stuart Dols Steven Emmerich

Andrew Persily

https://doi.org/10.6028/NIST.TN.2150-upd Includes updates as of 09-02-2021. See Appendix A

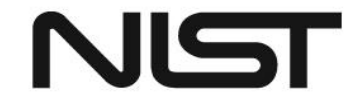

National Institute of Standards and Technology U.S. Department of Commerce 
NIST Technical Note 2150

\title{
Single-Zone Simulations Using FaTIMA for Reducing Aerosol Exposure in Educational Spaces
}

\author{
Lisa $\mathrm{Ng}$ \\ Dustin Poppendieck \\ Brian Polidoro \\ W. Stuart Dols \\ Steven Emmerich \\ Andrew Persily \\ Engineering Laboratory \\ Building, Energy, and Environment Division
}

April 2021

https://doi.org/10.6028/NIST.TN.2150-upd Includes updates as of 09-02-2021. See Appendix A

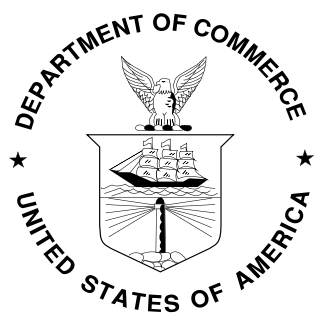

U.S. Department of Commerce Gina M. Raimondo, Secretary

National Institute of Standards and Technology

James K. Olthoff, Performing the Non-Exclusive Functions and Duties of the Under Secretary of Commerce for Standards and Technology \& Director, National Institute of Standards and Technology 
Certain commercial entities, equipment, or materials may be identified in this document in order to describe an experimental procedure or concept adequately. Such identification is not intended to imply recommendation or endorsement by the National Institute of Standards and Technology, nor is it intended to imply that the entities, materials, or equipment are necessarily the best available for the purpose.

National Institute of Standards and Technology Technical Note 2150

Natl. Inst. Stand. Technol. Tech. Note 2150, 80 pages (April 2021) CODEN: NTNOEF

https://doi.org/10.6028/NIST.TN.2150-upd Includes updates as of 09-02-2021. See Appendix A 


\section{Abstract}

On March 11, 2020, the World Health Organization declared the novel coronavirus (COVID-19) outbreak a global pandemic. Following this announcement, school closures around the United States began, and starting in June 2020, many schools decided to reopen for the next academic year or were planning to reopen. Guidance from ASHRAE and other organizations for reoccupying school buildings include wearing masks, increasing ventilation, increasing filtration, and using portable air cleaners (PAC). This report describes a simulation study that: (1) compares the relative reduction in aerosol exposure in education spaces as a result of changes to the operation of heating, ventilating, and air conditioning (HVAC) systems and inclusion of nonHVAC controls (e.g., wearing of masks and operating PAC) and (2) estimates the uncertainties in effectiveness associated with these controls and combinations of controls.

This analysis used Fate and Transport of Indoor Microbial Aerosols (FaTIMA), a tool developed by the National Institute of Standards and Technology (NIST), to evaluate aerosol exposure in ventilated spaces. FaTIMA was used to model the release of biological aerosols in two classrooms and an assembly room with four different types of HVAC systems, including central air handling systems (CAHS), dedicated outdoor air systems (DOAS), terminal unit systems (TUS), and wall unit systems (WUS). Exposure was evaluated for $1 \mu \mathrm{m}$ particles (or aerosols) by which viruses are transported. In the classrooms, exposure was evaluated for $6 \mathrm{~h}$ of continuous exposure to a continuous source. In the assembly room, exposure was evaluated for $1 \mathrm{~h}$ of continuous exposure, where the source was present for the $5 \mathrm{~h}$ prior to the exposure period.

For all the spaces and HVAC systems, the wearing of masks alone (assuming a protection efficiency of $25 \%$ for both intake and exhalation) reduced exposure by $44 \%$ relative to the base cases without masks. Masks with higher protection efficiencies (85\% to $90 \%$ ) reduced exposure $99 \%$, and masks with lower protection efficiencies reduced exposure $15 \%$. Masks with inhalation and exhalation protection efficiencies of $25 \%$ combined with MERV 13 filtration in the HVAC systems reduced exposure by an average $71 \%$ for the CAHS, DOAS, and TUS. For the CAHS, these masks combined with $100 \%$ outdoor air (OA) intake reduced exposure by an average of $70 \%$. Using either a 297 clean air delivery rate (CADR) PAC or a $569 \mathrm{~L} \cdot \mathrm{s}^{-1}$ $(1200 \mathrm{cfm})$ exhaust fan with these masks, exposure was reduced by an average of $68 \%$. Combining all these controls, exposure was reduced by an average of $85 \%$ assuming all controls were performing as intended. The results of this analysis may be useful in the selection of control options in educational facilities. 


\section{Executive Summary}

This report describes a simulation study that: (1) compares the relative reduction in aerosol exposure in education spaces as a result of changes to the operation of heating, ventilating, and air conditioning (HVAC) systems and inclusion of non-HVAC controls (e.g., wearing of masks and operating PAC) and (2) estimates the uncertainties in effectiveness associated with these controls and combinations of controls.

This analysis used Fate and Transport of Indoor Microbial Aerosols (FaTIMA), a tool developed by the National Institute of Standards and Technology (NIST), to evaluate aerosol exposure in ventilated spaces. FaTIMA was used to model the release of biological aerosols in two classrooms and an assembly room with four different types of HVAC systems, including central air handling systems (CAHS), dedicated outdoor air systems (DOAS), terminal unit systems (TUS), and wall unit systems (WUS). Exposure was evaluated for $1 \mu \mathrm{m}$ particles (or aerosols) associated with the transport of viruses. In the classrooms, exposure was evaluated for $6 \mathrm{~h}$ of continuous exposure to a continuous source. In the assembly room, exposure was evaluated for $1 \mathrm{~h}$ of continuous exposure, where the source was present for the $5 \mathrm{~h}$ prior to the exposure period. Controls such as masks for both the contagious person and receptor, increasing mechanical outdoor air intake, and upgrading recirculation filters were simulated. FaTIMA was used to generate CONTAM project files for this analysis, which are available for download on the NIST Multizone Modeling Website.

The simulated reductions in exposure achieved by each level of control are provided at the end of this report. A summary of results is as follows:

- For the base cases, i.e., no controls implemented, the CAHS had the lowest aerosol exposure, and the WUS had the highest.

- For all the spaces and HVAC systems, the wearing of masks alone (with a protection efficiency of $25 \%$ for both inhalation and exhalation) reduced exposure by a combined $44 \%$ relative to the base cases without masks. However, due to the uncertainty in protection efficiency of masks related to material, fit and actual usage, the protection efficiency of the masks is simulated over a range from $15 \%$ to $99 \%$.

- Masks with $25 \%$ inhalation and exhalation protection efficiencies combined with MERV 13 filtration reduced exposure by an average $71 \%$ for the CAHS, DOAS, and TUS in all space types simulated, and by an average $36 \%$ reduction for less efficient masks and filters.

- For the CAHS, masks with $25 \%$ inhalation and exhalation protection efficiencies combined with $100 \%$ outdoor air (OA) intake reduced exposure by an average of $70 \%$ in all space types simulated, and by an average of $44 \%$ reduction for less efficient masks and $80 \%$ OA. 


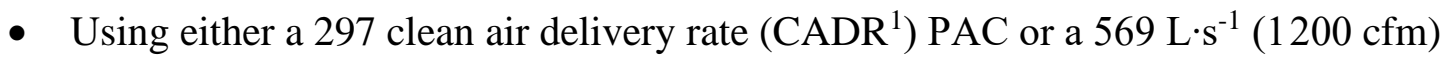
exhaust fan with masks with $25 \%$ inhalation and exhalation protection efficiencies, exposure was reduced by an average of $68 \%$ for all HVAC systems and space types simulated (40\% reduction with less efficient masks, and with PAC and exhaust fans at lower airflow rates).

- Combining all simulated controls, exposure could be reduced by an average of $85 \%$ assuming all controls were performing as intended, and by an average of $68 \%$ reduction for less effective control performance.

Multiple levels of controls were also simulated in combination with masks. For the CAHS, DOAS, and TUS, the reduction in exposure using various controls were compared with the reduction from MERV 13 filtration. This level of filtration has been recommended by ASHRAE and other organizations for reoccupying school buildings. Note that the base filtration in the CAHS was MERV 8, and in the DOAS and TUS was MERV 6.

In the classrooms, to achieve the same (or better) reduction compared with the reduction from MERV 13 filtration, the following controls would be needed:

- $93 \% \mathrm{OA}^{2}$ in the CAHS.

- PAC capacities between $4 \mathrm{~h}^{-1}$ and $5 \mathrm{~h}^{-1}$, depending on the HVAC system type.

- Exhaust fans capacities between $284 \mathrm{~L} \cdot \mathrm{s}^{-1}(3600 \mathrm{cfm})$ and $664 \mathrm{~L} \cdot \mathrm{s}^{-1}(6000 \mathrm{cfm})$, depending on the HVAC system type.

In the assembly room, to achieve the same (or better) reduction compared with the reduction from MERV 13 filtration, the following controls would be needed:

- $83 \%$ OA in the CAHS.

- The largest exhaust fan flow simulated $\left(982 \mathrm{~L} \cdot \mathrm{s}^{-1}(8400 \mathrm{cfm})\right)$ for the CAHS. For the other systems (DOAS and TUS), the equivalent reduction to MERV 13 filtration was not achieved for the exhaust fan flow capacities simulated.

- The largest PAC capacity simulated $(6 \times 297$ CADR units) was not able to reduce the exposure as much as MERV 13 filtration in the assembly room.

It should be noted that while reductions in exposure were compared with MERV 13 filtration, it is used for comparison purposes only and it is not the intent of this analysis to propose that MERV 13 is optimal for exposure reduction. This analysis shows that there are controls that could obtain potentially reductions in exposure equivalent to MERV 13 filtration, which could be useful for HVAC systems that may not be able to accommodate MERV 13 filtration.

\footnotetext{
${ }^{1}$ Portable air cleaners are often rated by the Clean Air Delivery Rate (CADR) as outlined in ANSI/AHAM Standard AC-1. CADR represents the airflow through the air cleaner (in units of cubic feet of air per minute or "cfm") multiplied by the removal efficiency associated with a type of particle. In this report, the CADR used is for smoke particles $(0.09 \mu \mathrm{m}$ to $1.0 \mu \mathrm{m})$ per the AHAM standard.

$293 \%$ OA means $93 \%$ of the total supply air is outdoor air.
} 


\section{Table of Contents}

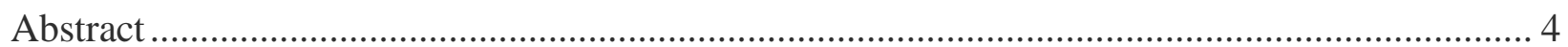

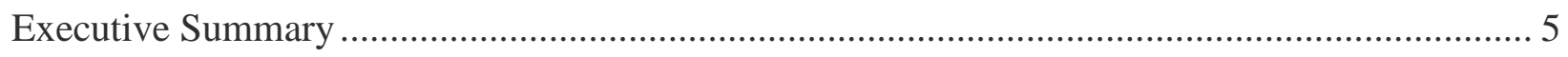

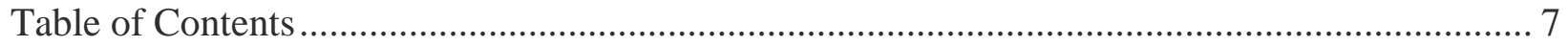

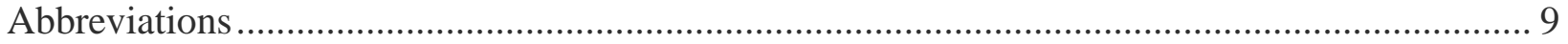

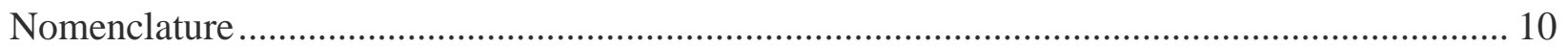

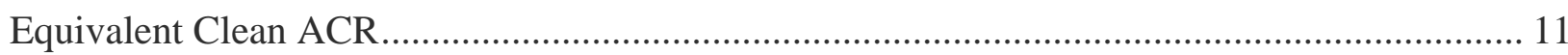

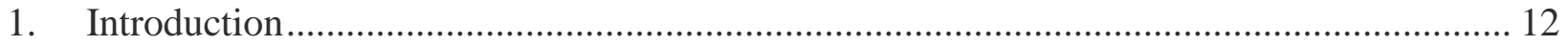

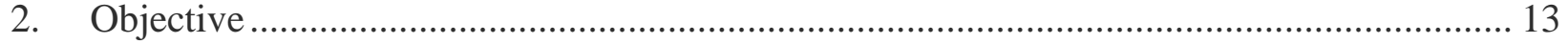

3. Modeling Tool - FaTIMA …............................................................................................ 14

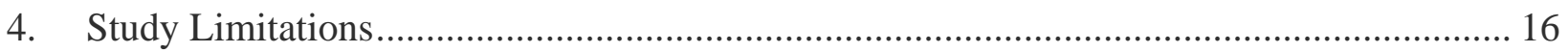

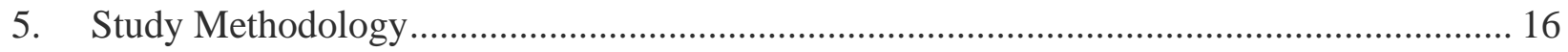

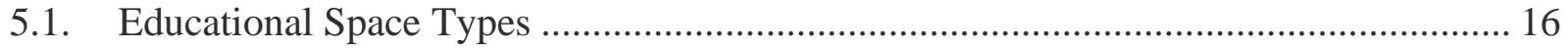

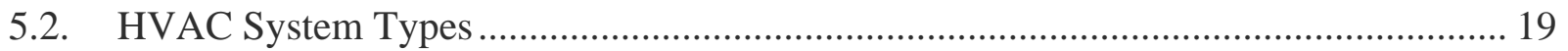

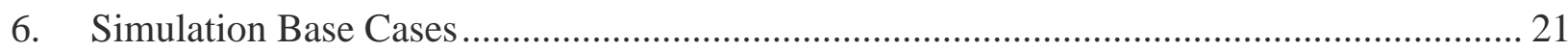

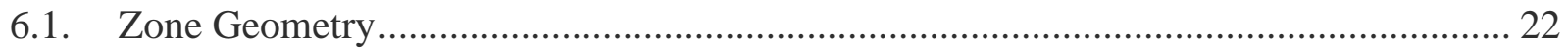

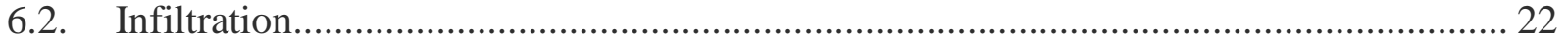

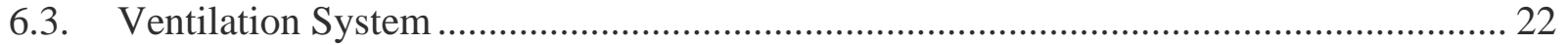

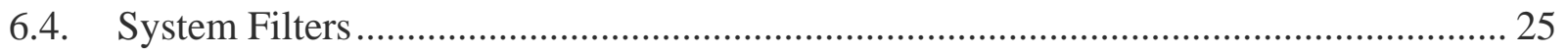

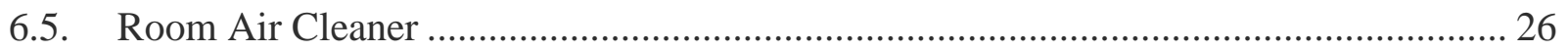

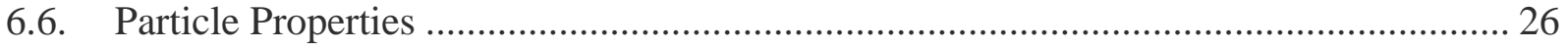

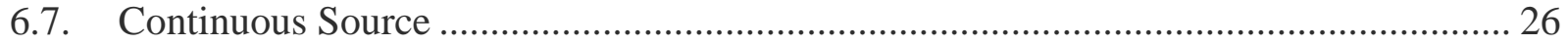

6.8. Particle Deposition Velocities ............................................................................... 27

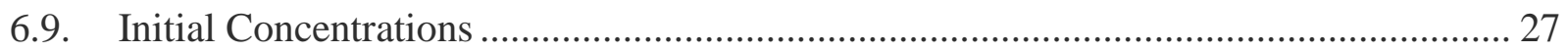

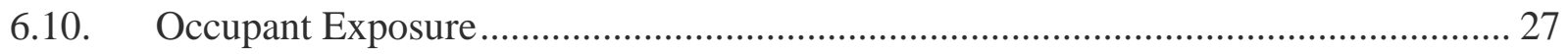

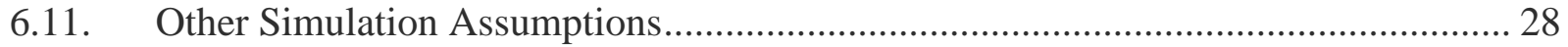

7. Simulation Cases with Controls ............................................................................................. 28

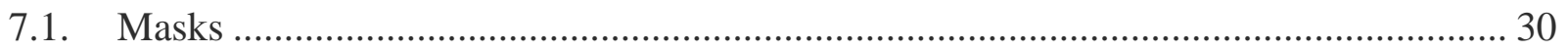

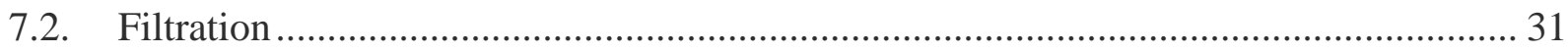

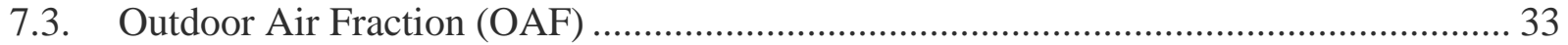




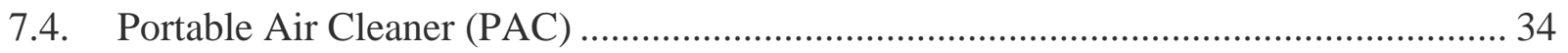

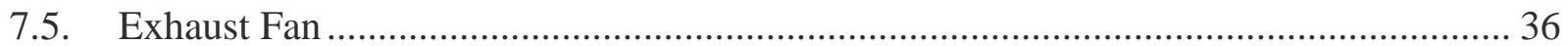

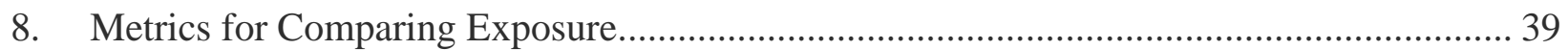

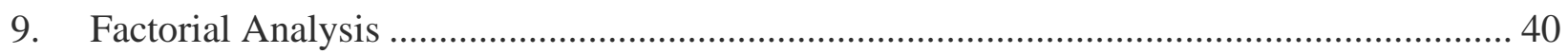

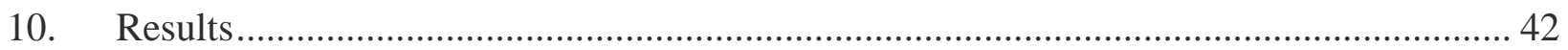

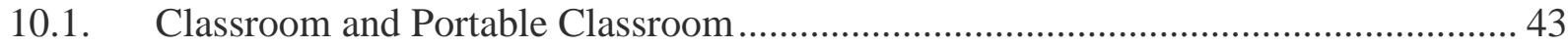

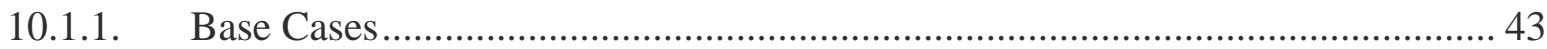

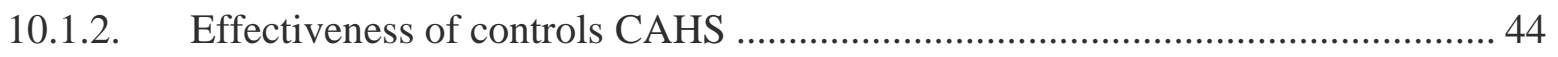

10.1.3. Effectiveness of controls DOAS …………………........................................... 47

10.1.4. Effectiveness of controls TUS ....................................................................... 49

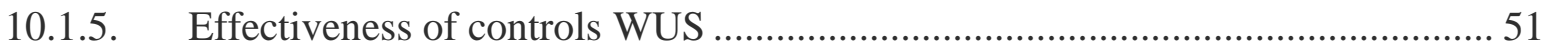

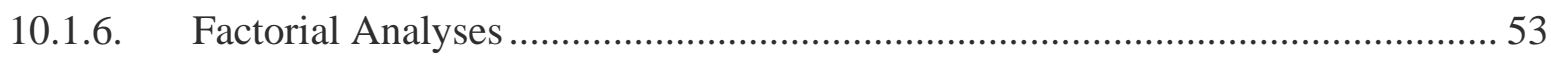

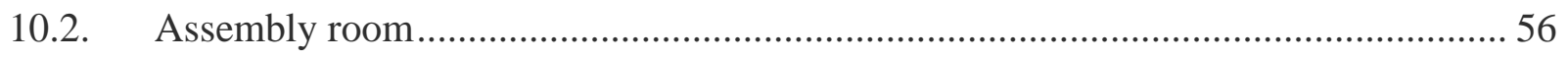

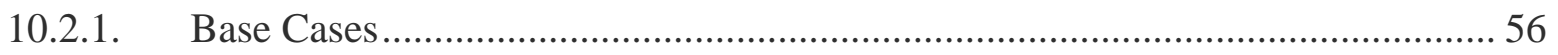

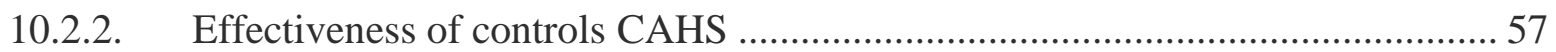

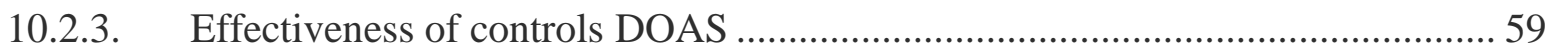

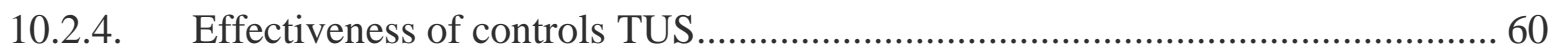

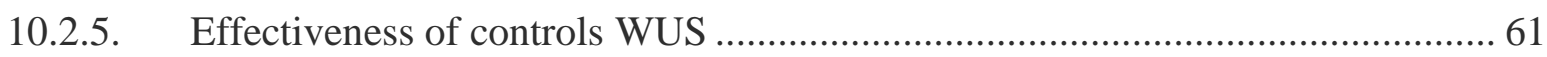

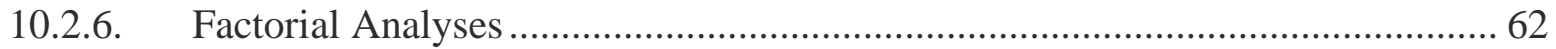

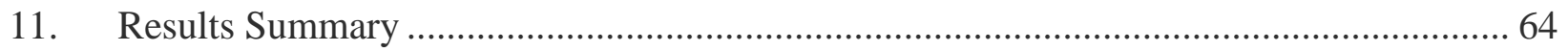

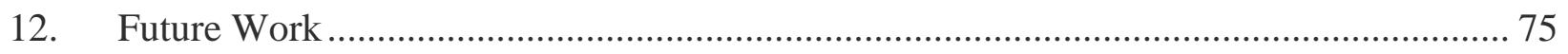

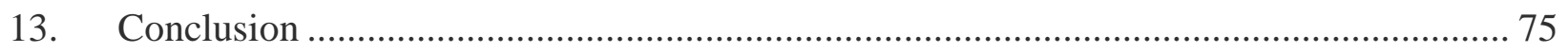

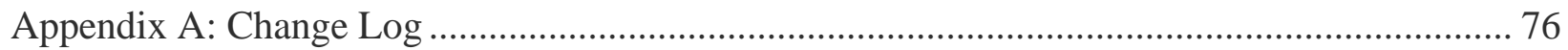

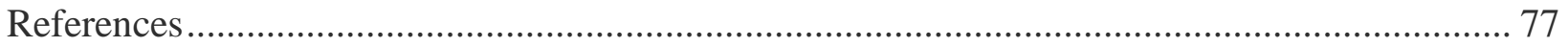




\section{Abbreviations}

$\mathrm{ACR}_{\text {infiltration }}$

$\mathrm{ACR}_{\mathrm{OA}}$

CADR

CAHS

CONTAM

COVID-19

$\mathrm{CU}$

DOAS

$\mathrm{EACR}_{\text {control }}$

Equivalent Clean ACR

FaTIMA

HVAC

IE

MERV

NASEM

NIE

$\mathrm{NIE}_{\text {CAHS }}$

$\mathrm{NIE}_{\text {DOAS }}$

NIE $_{\text {HVAC }}$

$\mathrm{NIE}_{\text {TUS }}$

NIEwUs

OA

OAF

OAU

PAC

PCO

SARS-CoV-2

TUS

UVGI

WHO

WUS
Air change rate of OA provided by infiltration $\left(\mathrm{h}^{-1}\right)$

Air change rate of OA delivered by mechanical ventilation system $\left(\mathrm{h}^{-1}\right)$

Clean air delivery rate (cubic feet per minute, $\mathrm{cfm}$ )

Central Air Handling Systems

Multizone indoor air quality and ventilation analysis program

Coronavirus disease 2019

Conditioning unit of DOAS

Dedicated Outdoor Air Systems

Equivalent air change rate delivered by a control $\left(\mathrm{h}^{-1}\right)$

Equivalent Clean Air Change Rate $\left(\mathrm{h}^{-1}\right)$

Fate and Transport of Indoor Microbiological Aerosols

Heating, ventilation, and air conditioning

Integrated exposure $\left(\# \cdot \mathrm{s} \cdot \mathrm{m}^{-3}\right)$

Minimum Efficiency Reporting Value

National Academies of Sciences, Engineering, and Medicine

Normalized integrated exposure (-)

NIE, normalized to results of a CAHS system with no controls

NIE, normalized to results of a DOAS system with no controls

NIE, normalized to results of an HVAC system(s) with no controls

NIE, normalized to results of a TUS system with no controls

NIE, normalized to results of a WUS system with no controls

Outdoor air

Outdoor Air Intake Fraction

Outdoor air unit of DOAS

Portable air cleaner(s)

Photocatalytic oxidation

Virus that causes COVID-19

Terminal Unit Systems

Ultraviolet germicidal irradiation

World Health Organization

Wall Unit Systems 


\section{Nomenclature}

$\begin{array}{ll}\mathrm{A} & \text { Floor Area } \\ \mathrm{N} & \text { Full occupancy } \\ \mathrm{Q} & \text { Volumetric airflow rate } \\ \mathrm{R}_{\mathrm{a}} & \text { OA per-floor area rate } \\ \mathrm{R}_{\mathrm{p}} & \text { OA per-person rate } \\ \mathrm{u}^{*} & \text { Friction velocity } \\ \mathrm{V} & \text { Volume }\end{array}$




\section{Equivalent Clean ACR}

The term "equivalent clean air change rate" (or equivalent clean ACR) is used in this analysis to describe the "clean" airflow provided to a space through a combination of the outdoor air delivered by the mechanical ventilation system (ACROA), outdoor air delivered through infiltration ( $\left.\mathrm{ACR}_{\text {infiltration }}\right)$, and the equivalent air change rates delivered by a control (EACR $\left.\mathrm{E}_{\text {control }}\right)$ (Eq. (1)).

$$
\text { Equivalent Clean ACR }\left(\mathrm{h}^{-1}\right)=\mathrm{ACR}_{\mathrm{OA}}+\mathrm{ACR}_{\text {infiltration }}+\mathrm{EACR}_{\text {control }}
$$

where $\mathrm{EACR}_{\text {control }}$ includes enhanced filtration, the addition of a portable air cleaner (PAC), or the addition of an exhaust fan. The Equivalent Clean ACR does not account for any deposition onto surfaces.

The term "equivalent" is used to include controls that increased outdoor airflow through the mechanical ventilation system, removed particles without increasing outdoor airflow (e.g., enhanced filtration), and removed particles by effectively increasing presumably "clean", particle-free airflow through building envelope leakage (e.g., exhaust fans).

In practice, a control may not be equally effective everywhere inside a space and depends on the location of the source, receptor, and control. Thus, Equivalent Clean ACR in this report is an idealized air change rate that does not reflect spatial variations in aerosol concentrations in the space. In other words, it assumes a uniform aerosol concentration in the zone.

At the end of this report in Sec. 11, results are presented using Equivalent Clean ACR and perperson outdoor air ventilation rates. 


\section{Introduction}

On March 11, 2020, the World Health Organization (WHO) declared the novel coronavirus (COVID-19) outbreak a global pandemic (WHO 2020). Following this announcement, school closures around the United States began. According to the National Academies of Sciences, Engineering, and Medicine (NASEM), there are approximately 50 million students and 6 million adults in 100000 school buildings across the U. S. covering $700000 \mathrm{~m}^{2}\left(7.5\right.$ million $\left.\mathrm{ft}^{2}\right)$ of floor area (NASEM 2020). The United States Government Accountability Office estimated that prior to the pandemic, $41 \%$ of districts needed to update or replace heating, ventilation, and air conditioning (HVAC) systems in at least half of their schools, representing about 36000 schools nationwide (USGAO 2020). Due to the mounting evidence that COVID-19 can be transmitted through airborne aerosols, in addition to droplet and fomite (or contact) transmission, Morawska and Milton (2020) recommended increasing outdoor air ventilation and enhanced filtration.

For school districts considering re-opening, guidance was produced by multiple organizations, including recommendations related to ventilation as summarized by Persily and $\mathrm{Ng}$ (2020). The ASHRAE Epidemic Task Force recommended increasing outdoor ventilation, disabling demandcontrolled systems, and flushing buildings prior to occupancy at least two hours daily (or three "clean" air changes), and upgrading to filters with a Minimum Efficiency Reporting Value (MERV) of 13 if the existing equipment has the capacity (ASHRAE 2020). Both ASHRAE and the Harvard School of Public Health (Jones et al. 2020) recommended supplementing these measures with portable air cleaners (PAC) as needed.

There have been several outbreaks of COVID-19 in indoor environments reported in the literature. A call center in South Korea reported 97 confirmed cases out of 1143 employees, residents, and visitors to the building during the time of interest (Park et al. 2020). The first confirmed case was on the $9^{\text {th }}$ floor of the 19 -floor building, then two more cases on the $10^{\text {th }}$ floor and the remaining cases on the $11^{\text {th }}$ floor (call center). Park et al. (2020) concluded that these cases were due to close contact and not primarily through the ventilation system. While Park et al. (2020) did note that the ventilation system was inspected, no details were given on that inspection or about the building ventilation system. Another relevant transmission event was the outbreak in a restaurant in Guangzhou, China (Lu et al. 2020). At this restaurant, it was assumed that a patron at a middle table transmitted COVID-19 to those at their table and to those at two adjacent tables that were within the supply airstream of a room air conditioner. There was little information on whether mechanical ventilation was provided to this space and if any filtration was present in the room air conditioner. Miller et al. (2020) concluded that a superspreader event occurred at a Skagit Valley Chorale rehearsal due possibly to low outdoor ventilation rates, greater aerosol generation from singing while also not wearing masks, and an occupancy time of $2.5 \mathrm{~h}$. The authors recommended increasing the aerosol loss rate (or total equivalent outdoor air change rates) to $5 \mathrm{~h}^{-1}$ and reducing the rehearsal time to $1 \mathrm{~h}$ to reduce the probability of infection by $80 \%$.

CDPH (2020) performed a simulation analysis in a classroom and estimated that masks reduced risk by more than half. When combined with a PAC having a clean air delivery rate (CADR) that was at least 2/3 of the floor area (as recommended by the Association of Home Appliance 
Manufacturers (AHAM) in (AHAM 2006)), exposure was reduced by more than $70 \%$. Using this 2/3 factor, the Harvard-University of Colorado (UC) Boulder Air Cleaner Calculator for Schools v1.2 (Allen et al. 2020) calculated that a classroom with a floor area of $46.4 \mathrm{~m}^{2}\left(500 \mathrm{ft}^{2}\right)$ with "typical" mechanical ventilation and a 333 CADR could achieve an "ideal $\left(6 \mathrm{~h}^{-1}\right)$ ") level of air changes. Though the tool is not able to estimate reduction in exposure, it can be helpful in selecting PAC capacity for a space.

Jimenez (2020) developed the COVID-19 Aerosol Transmission Estimator. Inputting the same space as above $\left(46.4 \mathrm{~m}^{2}\left(500 \mathrm{ft}^{2}\right)\right)$ with a 333 CADR PAC (and everyone wearing a mask), the tool estimates a $58 \%$ reduction in the probability that one person would become infected in a classroom with 16 people and one infector. Jimenez (2020) states that the development of the tool was based on available knowledge at the time. Two major assumptions were the infectious dose (or "quanta") and how much quanta are exhaled during various activities (Buonanno et al. 2020a; Buonanno et al. 2020b; Miller et al. 2020).

While SARS-CoV-2 (the virus that causes COVID) itself is smaller than $1 \mu \mathrm{m}$, it typically is present in respiratory aerosols that also contain water, salts and proteins. According to Liu et al. (2020), the peak concentrations of SARS-CoV-2 occur in aerosols in two size ranges. One range was between $0.25 \mu \mathrm{m}$ and $1.0 \mu \mathrm{m}$, and the other was larger than $2.5 \mu \mathrm{m}$. (In the analysis described in this report, a single particle size of $1 \mu \mathrm{m}$ representing a typical respiratory aerosol that may contain SARS-CoV-2 was simulated based on the findings in Liu et al. (2020) as well as the limitation to simulate only one particle size in FaTIMA at the time of publication.)

It has been shown that activities such as breathing, speaking, and singing may generate different amounts and sizes of aerosols (Alsved et al. 2020; Asadi et al. 2019). Some studies have shown that increasing the relative humidity indoors can reduce the transmission of influenza (Kudo et al. 2019; Noti et al. 2013). While higher relative humidity outdoors was correlated to a reduction in the spread of COVID-19 indoors (Mecenas et al. 2020; Ward et al. 2020), there was limited evidence that low relative humidity indoors $(<40 \%)$ increases the airborne transmissions of SARS-CoV-2 (Ahlawat et al. 2020). Horve et al. (2020) found the presence of SARS-CoV-2 ribonucleic acid (RNA) in approximately $25 \%$ of the samples taken from nine different filters in air handlers throughout a hospital building. However, the infectivity of the samples was not analyzed.

While the relative contribution of aerosols, droplets, and fomites to SARS-CoV-2 transmission is still being studied, improving ventilation performance in buildings has been a key strategy in minimizing outbreaks of other airborne diseases (Li et al. 2007) and is a common recommendation for opening buildings during the COVID-19 pandemic (ASHRAE 2020).

\section{Objective}

The objective of this analysis was to compare the relative reduction in aerosol exposure in educational spaces as a result of changes to the operation of HVAC systems and the inclusion of non-HVAC controls (e.g., wearing of masks and PAC) using FaTIMA (Fate and Transport of Indoor Microbiological Aerosols) and to estimate the uncertainties in the effectiveness of these 
controls. This analysis used the ventilation-related recommendations published by organizations such as ASHRAE to guide the selection of simulation inputs.

This analysis examined the impact of the controls in reducing airborne exposure to aerosols of a single size $(1 \mu \mathrm{m})$, as described below. The analysis did not explore the effects of relative humidity on airborne transmission, the impacts of technologies such as ultraviolet germicidal irradiation (UVGI) or photocatalytic oxidation (PCO) or other, non-airborne routes of exposure.

\section{Modeling Tool - FaTIMA}

FaTIMA is a free, online tool that allows for the analysis of the indoor fate of aerosols accounting for ventilation, filtration, deposition, and deactivation mechanisms. FaTIMA uses a model of a single zone with a uniform aerosol concentration that is served by a mechanical ventilation system and incorporates aerosol source and removal mechanisms. The mechanical ventilation system model implemented within FaTIMA allows specification of supply, return, and outdoor air intake fraction to represent either a positive, negative, or balanced ventilation system. An exhaust fan can also be included independently of the mechanical ventilation system. Particle sources are provided to enable a combination of continuous, e.g., breathing-related emissions, or intermittent, e.g., coughing-related, emissions. Particle removal mechanisms include filters within the ventilation system, a PAC, surface deposition, and virus deactivation. Simulations are run for a $24-\mathrm{h}$ period, with the results provided as the time history of the airborne concentration and surface loading as well as integrated exposure that an occupant would experience within the zone (Dols et al. 2020).

Inputs to FaTIMA include room dimensions, infiltration rate, HVAC airflow rates, exhaust fan flow rates, PAC specifications, aerosol characteristics, deactivation rate, sources, surface deposition rates, and room occupancy schedule. Numerical and graphical outputs include airborne aerosol concentration, surface loading, filter loading, and occupant exposure. Examples of the input screen and graphical outputs are shown in Figure 1.

FaTIMA is a simplified, web-based front end to CONTAM (Dols and Polidoro 2020). CONTAM is a multizone indoor air quality and ventilation analysis program developed to estimate airflows, contaminant concentrations, and occupant exposure in buildings. For some of the analyses described below, the FaTIMA-generated CONTAM project file (.prj) was manipulated in CONTAM prior to simulation. When CONTAM was used in this way, it is noted in the report. 


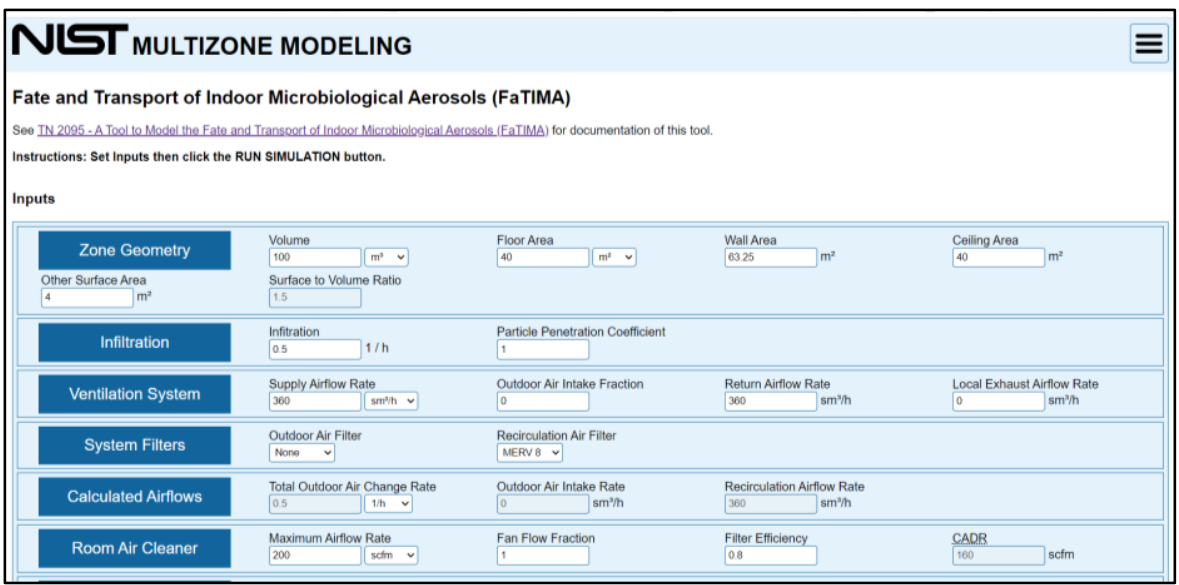

(a)

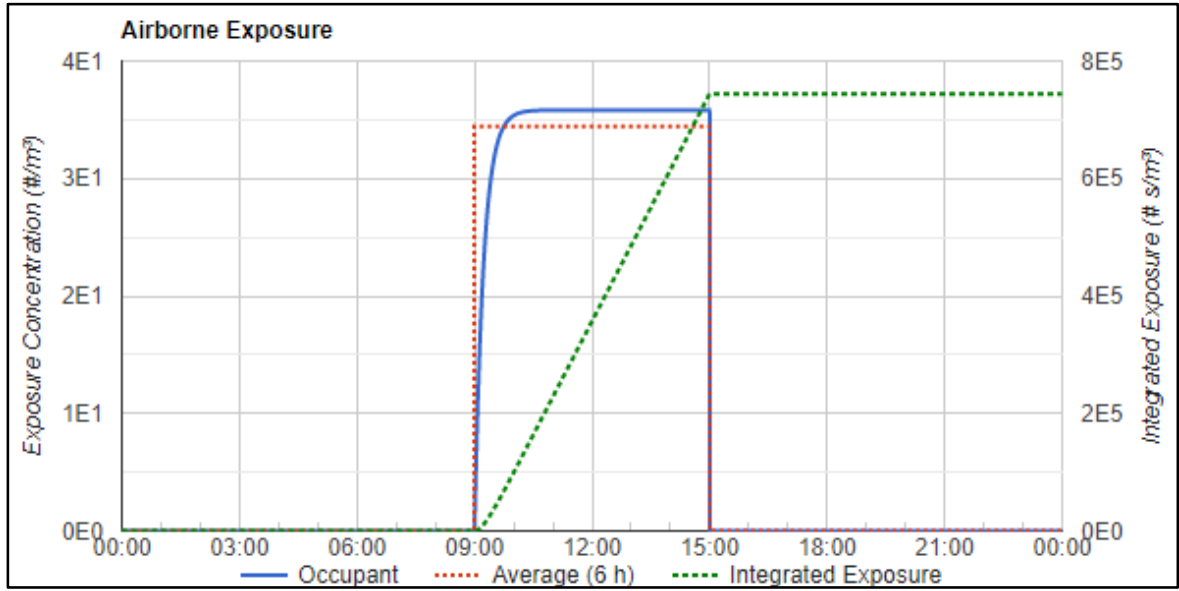

(b)

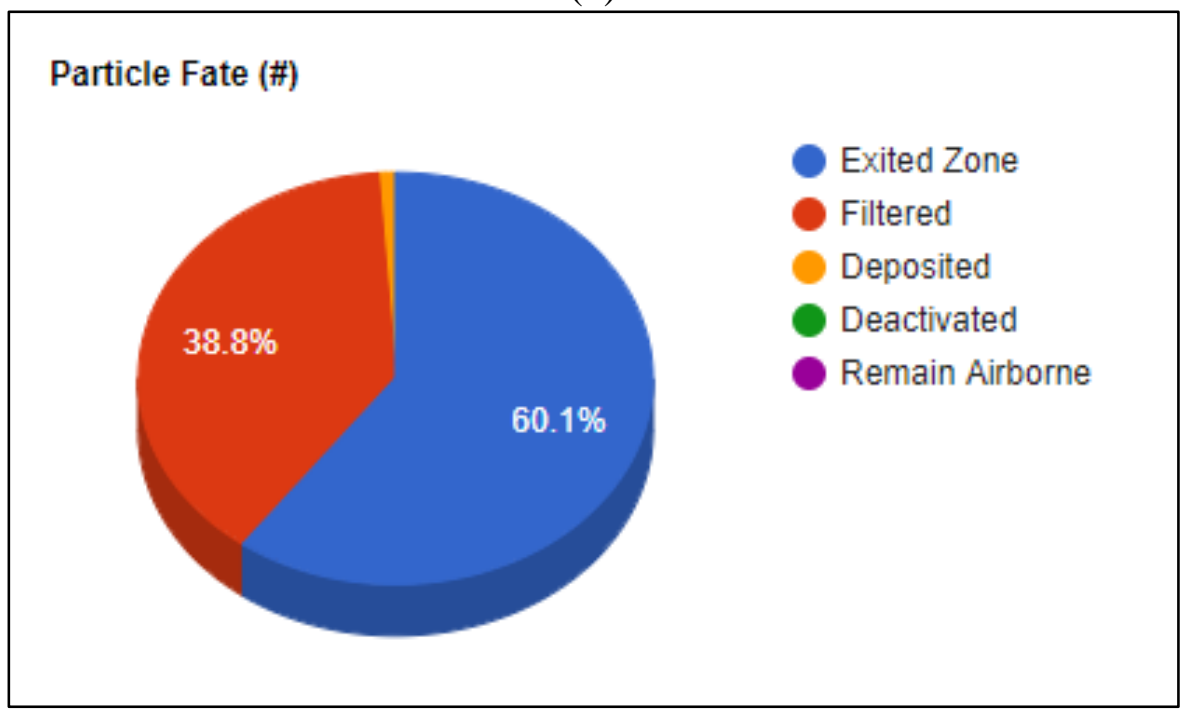

(c)

Figure 1. Example FaTIMA inputs and outputs: (a) input screen, (b) output showing time series of occupancy, average hourly exposure, and integrated exposure and (c) output showing fate of aerosols (or "particles") 


\section{Study Limitations}

This analysis characterized the relative reduction in aerosol exposure as a result of applying various controls using FaTIMA. The analysis was performed assuming a single contagious occupant within a zone and a uniform aerosol concentration throughout the zone. The predicted impact of these controls will be different for other buildings, occupancies, HVAC systems and other input parameters. Nevertheless, the results of this analysis could help decision makers when considering the application of such controls, including changes to HVAC system operation. This analysis did not define levels of exposure considered to be safe or healthy, nor consider the impacts of these controls as part of a broader risk reduction strategy that might be pursued by a building owner or operator. As noted by ASHRAE, the controls considered here should be part of a larger risk reduction strategy that includes hand washing, surface cleaning, social distancing, and reduced occupant density (ASHRAE 2021).

\section{Study Methodology}

This analysis was conducted for three educational space types described in Sec. 5.1 and four HVAC system types described in Sec. 5.2. The base HVAC operation without controls is presented in Sec. 5.2. The FaTIMA inputs for the base case are presented in Sec. 6. Methods used to model controls are described in Sec. 7. Integrated exposure (an output of FaTIMA) was used to calculate a metric to compare results as described in Sec. 8. Post-processing and normalization was performed to account for the exposure of a receptor wearing a mask with $25 \%$ inhalation and exhalation protection efficiency over the same time interval as the contagious occupant is also wearing one, as described in Sec. 8. To assess the uncertainty in exposure reduction associated with the controls, a two-level factorial test is presented in Sec. 9.

Results are presented in Sec. 10.1 for the classrooms and Sec. 10.2 for the assembly room. Note that the base case results (Sec. 10.1.1 and 10.2.1) are presented without masks. The results by HVAC system type (Sec. 10.1.2 to Sec. 10.1.5, and Sec. 10.2.2 to Sec. 1.1.1) are presented with masks having a $25 \%$ inhalation and exhalation protection efficiency. The results of the factorial analyses are presented for individual controls at selected levels with and without masks (Sec. 10.1.6 and Sec. 1.1.1).

\subsection{Educational Space Types}

This analysis was conducted for three educational space types: classroom, portable classroom and an assembly room. ASHRAE 62.1-2019 (ASHRAE 2019) lists a default occupancy in units of occupants divided by floor area for classrooms and an assembly room but does not provide ceiling height values needed to fully describe room dimensions. Dimensions for the three space types used in this study were determined using a combination of sources.

The "standard" size for a classroom (no age distinction) in the emission testing method for California Specification 01350 (CDPH 2017) was $12.2 \mathrm{~m}(40 \mathrm{ft}) \times 7.32 \mathrm{~m}(24 \mathrm{ft}) \times 2.59 \mathrm{~m}$ $(8.5 \mathrm{ft})$ with an occupancy of 27 people. This equates to 30 people $/ 100 \mathrm{~m}^{2}\left(28\right.$ people/1000 $\left.\mathrm{ft}^{2}\right)$. The room area and occupancy of the "standard classroom" in California Specification 01350 was 
scaled to match the default occupancy of the "classroom (ages 5 to 8)" category listed in ASHRAE $62.1-2019$ (25 people/100 $\mathrm{m}^{2}$ or 25 people/1000 $\left.\mathrm{ft}^{2}\right)$. Thus, the classroom in this analysis was assumed to have a square floor area with dimensions: $8.6 \mathrm{~m}(28 \mathrm{ft}) \times 8.6 \mathrm{~m}(28 \mathrm{ft}) \times$ $2.6 \mathrm{~m}(8.5 \mathrm{ft})$.

The size of the portable classroom ${ }^{3}$ was based on Thomas-Rees et al. (2009), which reported that most portable classrooms are one of two sizes. The larger one was selected for this analysis: $12.2 \mathrm{~m}(40 \mathrm{ft}) \times 7.3 \mathrm{~m}(24 \mathrm{ft})$, with an assumed ceiling height of $2.6 \mathrm{~m}(8.5 \mathrm{ft})$. The portable classroom used the default occupancy of the "classroom (ages 9+)" category listed in ASHRAE 62.1-2019.

No guidance was found on the size of an assembly room. Therefore, it was assumed that the area of the assembly room was four times the area of the classroom in CDPH (2017) and two times its height: $18.9 \mathrm{~m}(62 \mathrm{ft}) \times 18.9 \mathrm{~m}(62 \mathrm{ft}) \times 5.2 \mathrm{~m}(17 \mathrm{ft})$. The assembly room used the default occupancy of the "lecture classroom" category listed in ASHRAE 62.1-2019.

The area $(A)$, volume $(V)$, default occupancy, and full occupancy $(N)$ of each space type in this analysis are listed in Table 1. The full occupancy was used to determine the total mechanical outdoor air (OA) ventilation required for each space type per ASHRAE 62.1-2019.

Table 1. Size, occupancy, default, and full occupancies for simulated space types

\begin{tabular}{|l|c|c|c|c|}
\hline Space type & $\begin{array}{c}\text { Floor Area } \\
(\boldsymbol{A}) \mathbf{(} \\
\mathbf{m}^{\mathbf{2}}\left(\mathbf{f t}^{\mathbf{2}}\right)\end{array}$ & $\begin{array}{c}\text { Volume }(\boldsymbol{V}), \\
\mathbf{m}^{\mathbf{3}}\left(\mathbf{f t}^{\mathbf{3}}\right)\end{array}$ & $\begin{array}{c}\text { Default } \\
\text { occupancy } \\
\left(\# \cdot \mathbf{1 0 0} \mathbf{~ m}^{\mathbf{2}} \mathbf{~ o r}\right. \\
\# \cdot \mathbf{1 0 0 0} \mathbf{f t}^{-\mathbf{2}} \mathbf{)}\end{array}$ & $\begin{array}{c}\mathbf{1} \\
\text { Full occupancy } \\
(\boldsymbol{N})^{\mathbf{2}}\end{array}$ \\
\hline Classroom & $74(793)$ & $191(6739)$ & 25 & 18 \\
\hline Portable classroom & $89(960)$ & $231(8158)$ & 35 & 31 \\
\hline Assembly room & $357(3841)$ & $1848(65270)$ & 65 & 232 \\
\hline
\end{tabular}

1. Default occupancy is from ASHRAE 62.1-2019. The "lecture classroom" space type in the standard was used for the assembly room.

2. Full occupancy is the default occupancy multiplied by the floor area.

The supply airflow rates for each space type were based on Informative Appendix $F$ in ASHRAE 62.1-2019 (ASHRAE 2019) and are listed in Table 2 in units of $\mathrm{L} \cdot \mathrm{s}^{-1} \mathrm{~m}^{-2}$ and $\mathrm{cfm} \cdot \mathrm{ft}^{-2}$, where "cfm" is a commonly used acronym in the industry for cubic feet per minute. Airflow rates expressed in $\mathrm{h}^{-1}$ (or air changes per hour) were calculated by dividing the volumetric airflow rate by the space volume.

\footnotetext{
${ }^{3}$ Portable classrooms are typically trailers and other temporary facilities used for schools in the U. S. and possibly elsewhere.
} 
The total mechanical OA ventilation requirements in ASHRAE 62.1-2019 are given in two parts: OA per-person rates $\left(R_{\mathrm{p}}\right)$ and OA per-floor area rates $\left(R_{\mathrm{a}}\right)$, which are combined to determine the total mechanical OA ventilation rate requirement using Eq. (2):

$$
\text { Total mechanical OA ventilation rate }=R_{\mathrm{p}} \times N+R_{\mathrm{a}} \times A
$$

where $A$ is the floor area and $N$ is full occupancy. The total OA rates simulated are listed in Table 2 for each space type.

The portable classroom had the highest required total mechanical OA ventilation rate per volume $\left(\mathrm{h}^{-1}\right)$, and the assembly room had the lowest. However, on a per-person basis, the classroom had the highest total mechanical OA ventilation rate. It should be noted that Haverinen-Shaughnessy et al. (2011) have shown that schools in the U. S. are often under-ventilated compared to the version of ASHRAE Standard 62.1 to which they were designed. They showed that $80 \%$ of the schools in their analysis were ventilating below the rate required at the time of their analysis $\left(7.1 \mathrm{~L} \cdot \mathrm{s}^{-1} \cdot\right.$ person $\left.^{-1}\right)$ with a median ventilation rate of $3.6 \mathrm{~L} \cdot \mathrm{s}^{-1} \cdot$ person $^{-1}$. This median value was $16 \%$ to $51 \%$ lower than the total mechanical OA ventilation rate required in the space types simulated in this study using the rates required by ASHRAE Standard 62.1-2019 (and shown in Table 2).

Table 2. Simulated supply airflow rates and total mechanical OA ventilation rate

\begin{tabular}{|c|c|c|c|c|c|c|c|c|}
\hline \multirow[b]{2}{*}{ Space Type } & \multicolumn{3}{|c|}{ Supply Airflow Rate a } & \multicolumn{3}{|c|}{$\begin{array}{c}\text { Total Mechanical OA } \\
\text { Ventilation Rate }\end{array}$} & \multicolumn{2}{|c|}{$\begin{array}{c}\text { Total Mechanical OA } \\
\text { Ventilation Rate per } \\
\text { person }\end{array}$} \\
\hline & $\mathbf{L} \cdot \mathbf{S}^{-1} \cdot \mathbf{m}^{-2}$ & $\mathbf{c f m} \cdot \mathbf{f t}^{-2}$ & $\mathbf{h}^{-1}$ & $L \cdot \mathbf{s}^{-1}$ & cfm & $\mathbf{h}^{-1}$ & $\mathbf{L} \cdot \mathbf{S}^{-1}$ & cfm \\
\hline Classroom & 5.60 & 1.10 & 7.8 & 136 & 289 & 2.6 & 7.4 & 15.7 \\
\hline Portable classroom & 7.05 & 1.39 & 9.8 & 210 & 444 & 3.3 & 6.7 & 14.2 \\
\hline Assembly Room & 12.25 & 2.41 & 4.9 & 988 & 2094 & 1.9 & 4.3 & 9.0 \\
\hline
\end{tabular}

a. Supply airflow rates from Informative Appendix F in ASHRAE 62.1-2019 for classrooms (ages 5 to 8), classrooms (ages 9 plus), and multiuse assembly respectively.

The infiltration rate was assumed to be $0.30 \mathrm{~h}^{-1}$ in all space types simulated, which was the average infiltration rate for the primary and secondary schools prototype models simulated previously by the authors ( $\mathrm{Ng}$ et al. 2019; $\mathrm{Ng}$ et al. 2018; Shrestha et al. 2019).

For the classrooms, the occupancy interval for exposure was selected to be from 9 a.m. to 3 p.m. For the assembly room, it was assumed that $1 \mathrm{~h}$ classes rotated throughout the day between 9 a.m. to 3 p.m. and a single aerosol source was always present. The occupancy interval for exposure in the assembly room was selected to be from 2 p.m. to 3 p.m., which was assumed to be the last class of the day. While in reality students in classrooms may leave their classrooms for activities, such as lunch, FaTIMA is only able to simulate continuous and intermittent schedules at regular intervals. Thus, FaTIMA was unable to simulate exposure with a single $1 \mathrm{~h}$ break in the middle of the day at the time of this analysis. 


\subsection{HVAC System Types}

Four types of HVAC systems were simulated: Central Air Handling Systems (CAHS), Dedicated Outdoor Air Systems (DOAS), Terminal Unit Systems (TUS), and Wall Unit Systems (WUS). The systems differ in how and if outdoor air was mechanically provided. Schematics of the four HVAC systems are shown in Figure 2, with airflow rates shown for the classroom only. Values for the airflow rates for the other space types are provided in Sec. 6.3.

CAHS in this study were assumed to be rooftop units that supplied the required OA and returned $90 \%$ of the supply airflow rate. A portion of the return air was exhausted, and the required OA was mixed with the remaining return air (recirculated air) before being supplied to the space. For the DOAS, an outdoor air unit (OAU) delivered the required OA directly to the space, and a thermal conditioning system (CU) recirculated, conditioned, and filtered the air in the space. TUS in this study were assumed to be fan coil units or unit ventilators. It was assumed that they delivered the required OA mixed with return air. Unlike the CAHS, the TUS did not mechanically exhaust any of the return air. WUS in this study were assumed to be through-thewall room air conditioners that provided no mechanical OA. In Figure 2, the WUS had no heating coil because in these spaces, heat is assumed to be provided by separate equipment such as baseboard heaters or radiators. These WUS typically rely on convection for moving air, and convective airflow is neither modeled in FaTIMA nor affects the outdoor ventilation rate.

Figure 2 also shows the base filtration level of recirculation filters. The base filters were MERV 8 for the CAHS, MERV 6 for the DOAS and TUS, and none for WUS. More detailed discussion on how filters were modeled in FaTIMA is provided in Sec. 7.2.

In FaTIMA, infiltration was modeled as a Constant Volume Flow fan ("Infiltration fan" in (Figure 2). An "air balance" element was included in FaTIMA (Figure 2) to account for imbalances between the air entering and leaving the zone through the HVAC system, exhaust fan, and the infiltration fan. Details of the infiltration and air balance terms are presented in Sec. 6.2 and Sec. 6.3, respectively. 


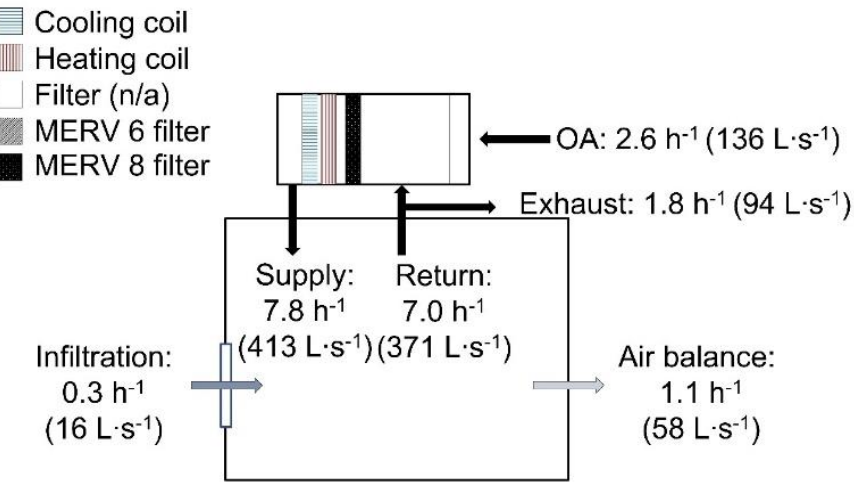

(a) CAHS

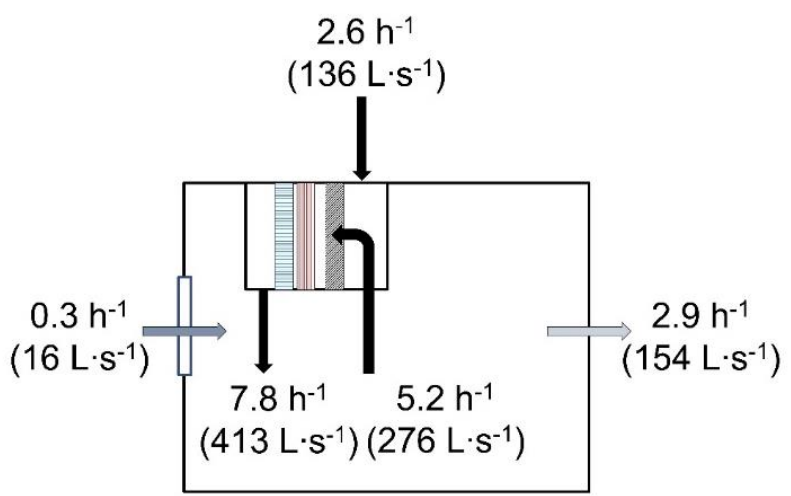

(c) TUS

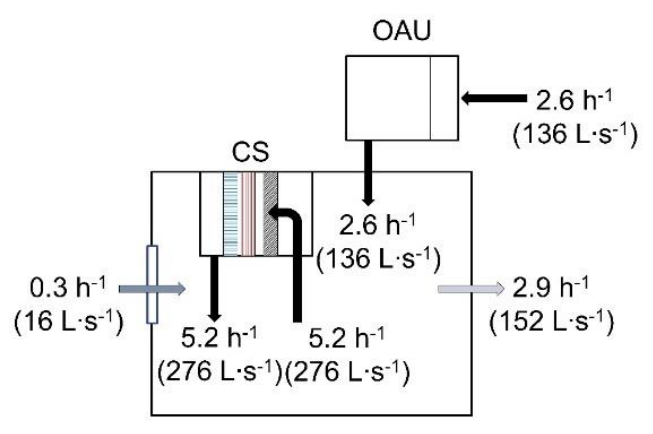

(b) DOAS

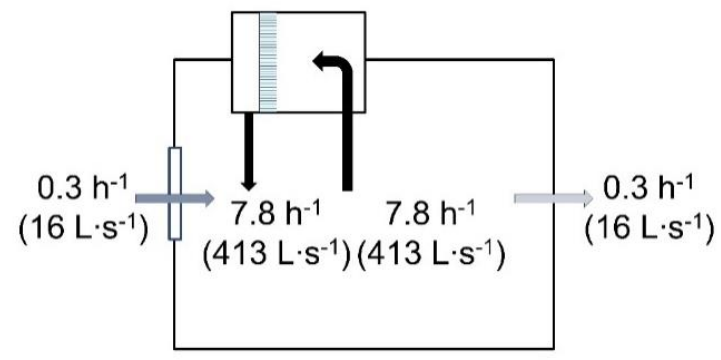

(d) WUS

Figure 2. Schematics of HVAC system types simulated (a) CAHS (b) DOAS (c) TUS and (d) WUS. Airflow rates shown are for the classroom. 


\section{Simulation Base Cases}

This section provides a description of the simulation inputs and how they were implemented in FaTIMA for the base cases. Sec. 1.1 to Sec. 6.10 follow the order of inputs in the FaTIMA interface (Figure 3).

\section{NUT MULtizone modeling}

Fate and Transport of Indoor Microbiological Aerosols (FaTIMA)

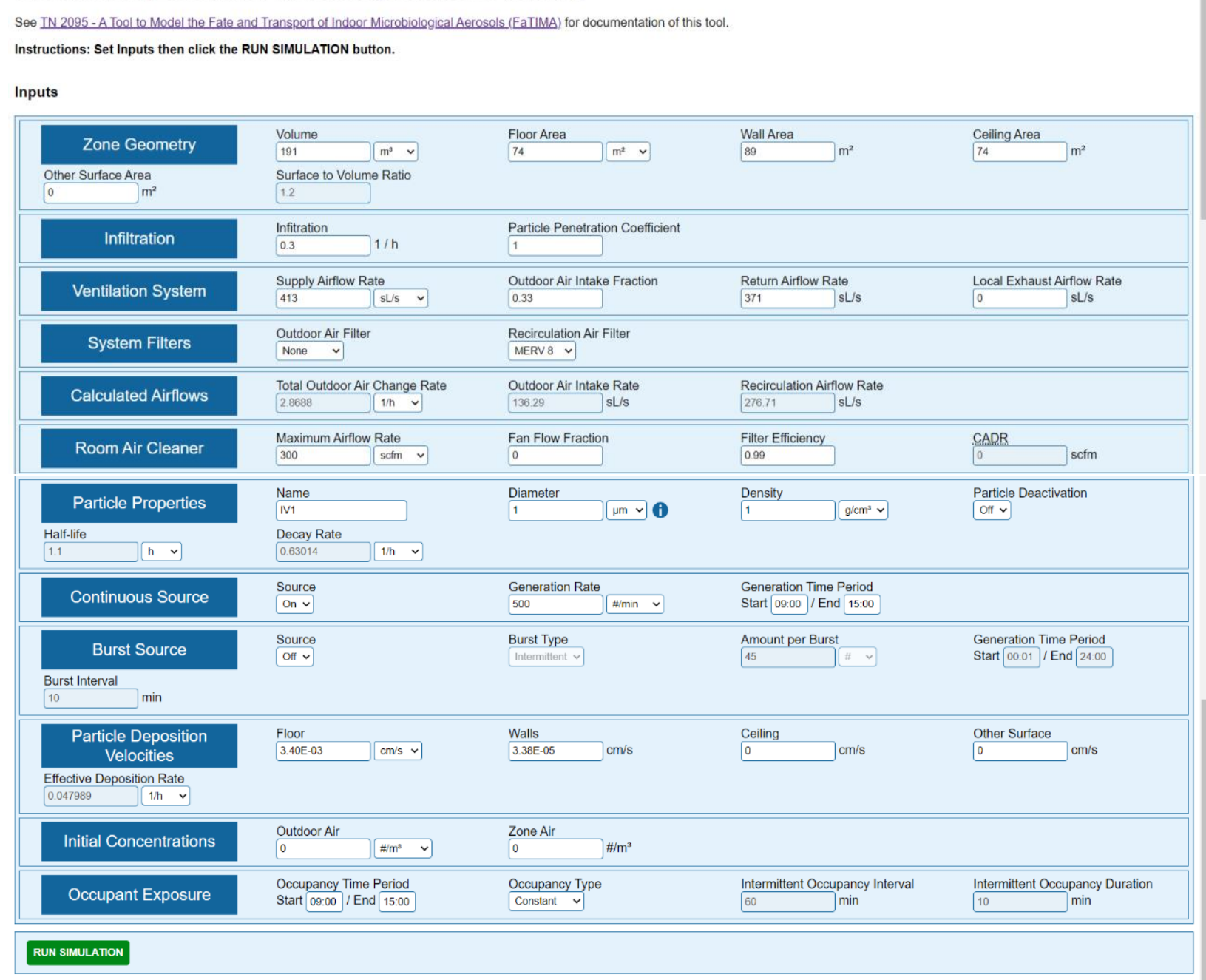

Figure 3. Screenshot of FaTIMA inputs (values are for classroom CAHS) 


\subsection{Zone Geometry}

The Zone Geometry section of FaTIMA includes fields for Volume, Floor Area, Wall Area, Ceiling Area, and Other Surface Area. The assumed volume and floor areas of each space were defined in Sec. 5.1. The Wall Area for each space type was calculated using the dimensions presented in Sec. 5.1. The Ceiling Area was assumed to be equal to the Floor Area. It was assumed that no other surfaces were present, so the Other Surface Area was set to zero. The zone geometry inputs for the space types are listed in Table 3.

Table 3. Zone geometry inputs

\begin{tabular}{|l|c|c|c|c|}
\hline Space type & $\begin{array}{c}\text { Volume, } \\
\mathbf{m}^{\mathbf{3}}\left(\mathbf{f t}^{\mathbf{3}}\right)\end{array}$ & $\mathbf{A r e a}, \mathbf{m}^{\mathbf{2}}\left(\mathbf{f t}^{\mathbf{2}}\right)$ & $\begin{array}{c}\text { Wall area, } \\
\mathbf{m}^{\mathbf{2}}\left(\mathbf{f t}^{\mathbf{2}}\right)\end{array}$ & $\begin{array}{c}\text { Ceiling Area, } \\
\mathbf{m}^{\mathbf{2}}\left(\mathbf{f t}^{\mathbf{2}}\right)\end{array}$ \\
\hline Classroom & $191(6739)$ & $74(793)$ & $89(958)$ & $74(793)$ \\
\hline Portable classroom & $231(8158)$ & $89(960)$ & $101(1087)$ & $89(960)$ \\
\hline Assembly room & $1848(65270)$ & $357(3841)$ & $391(4209)$ & $357(3841)$ \\
\hline
\end{tabular}

\subsection{Infiltration}

The Infiltration section of FaTIMA has fields for Infiltration and Particle Penetration Coefficient. Particle Penetration Coefficient is the fraction of particles in the outdoor air that will penetrate the building envelope through infiltration. See Dols et al. (2020) for more information.

Infiltration was set to $0.3 \mathrm{~h}^{-1}$, and the Particle Penetration Coefficient was assumed to be 1 .

If a user wants to account for weather impacts in a simulation, they can adjust the infiltration rate. However, weather and infiltration are both dynamic. Therefore, even if infiltration was changed to a different constant value, the impacts of weather would not be fully captured.

\subsection{Ventilation System}

The Ventilation System section of FaTIMA had fields for Supply Airflow Rate, Return Airflow Rate and Outdoor Air Intake Fraction (OAF). The Local Exhaust Airflow Rate input was used to define exhaust fans as control measures (Sec. 7.5). For the base case, the Local Exhaust Airflow Rate was input as zero. Note that the Local Exhaust Airflow Rate is separate from the exhausted air in the CAHS (Figure 2 in Sec. 5.2). The Ventilation System could only be simulated as always on for the $24 \mathrm{~h}$ simulation at the time of this analysis.

The values for each HVAC system and space type are given in Table 4 in SI units and Table 5 in IP units. This table also shows the air balance, which is the sum of the Supply Airflow Rate and Infiltration Rate minus the Return Airflow Rate. The DOAS and TUS had the same air balance.

For the DOAS, which was composed of an OAU and CU, the Total OA Rate from the OAU was added to the assumed infiltration rate, and the sum was input into the Infiltration field of FaTIMA. For the DOAS, the OAF was zero. 
Table 4. Ventilation system inputs and air balance for the base case of each HVAC system type (SI units)

\begin{tabular}{|c|c|c|c|c|c|c|c|}
\hline $\begin{array}{l}\text { HVAC } \\
\text { System } \\
\text { Type }\end{array}$ & $\begin{array}{c}\text { Supply } \\
\text { Airflow } \\
\text { Rate }\left(\mathbf{L} \cdot \mathbf{s}^{-1}\right)\end{array}$ & $\begin{array}{c}\text { Return } \\
\text { Airflow } \\
\text { Rate }\left(L \cdot \mathbf{s}^{-1}\right)\end{array}$ & $\begin{array}{l}\text { Outdoor } \\
\quad \text { Air } \\
\text { Fraction } \\
\text { (OAF, -) }\end{array}$ & $\begin{array}{c}\text { Total Mechanical } \\
\text { OA Ventilation } \\
\text { Rate }\left(\mathbf{L} \cdot \mathbf{s}^{-1}\right)^{\mathbf{b}}\end{array}$ & Infiltration $\left(\mathbf{L} \cdot \mathbf{s}^{-1}\right)$ & $\begin{array}{c}\text { Recirculation } \\
\text { Filter (-) }\end{array}$ & $\begin{array}{c}\text { Air } \\
\text { Balance } \\
\left(\mathbf{L} \cdot \mathbf{s}^{-1}\right)^{\mathrm{a}}\end{array}$ \\
\hline \multicolumn{8}{|c|}{ Classroom } \\
\hline CAHS & 413 & 371 & 0.33 & 136 & 16 & MERV 8 & 58 \\
\hline DOAS & $276^{\mathrm{a}}$ & 276 & 0 & 0 & $152(16+136)^{\mathrm{c}}$ & MERV 6 & 152 \\
\hline TUS & 413 & 276 & 0.33 & 136 & 16 & MERV 6 & 152 \\
\hline WUS & 413 & 413 & 0 & 0 & 16 & None & 16 \\
\hline \multicolumn{8}{|c|}{ Portable classroom } \\
\hline CAHS & 629 & 566 & 0.33 & 210 & 19 & MERV 8 & 82 \\
\hline DOAS & $419^{a}$ & 419 & 0 & 0 & $229(210+19)^{b}$ & MERV 6 & 229 \\
\hline TUS & 629 & 419 & 0.33 & 210 & 19 & MERV 6 & 229 \\
\hline WUS & 629 & 629 & 0 & 0 & 19 & None & 19 \\
\hline \multicolumn{8}{|c|}{ Assembly room } \\
\hline CAHS & 4371 & 3934 & 0.23 & 988 & 154 & MERV 8 & 591 \\
\hline DOAS & $3382^{a}$ & 3382 & 0 & 0 & $1142(988+154)^{\mathrm{b}}$ & MERV 6 & 1142 \\
\hline TUS & 4371 & 3382 & 0.23 & 988 & 154 & MERV 6 & 1142 \\
\hline WUS & 4371 & 4371 & 0 & 0 & 154 & None & 154 \\
\hline
\end{tabular}

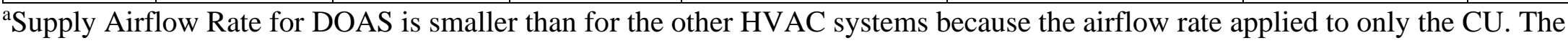
remainder of the supply air was delivered by the OAU and input as infiltration (see note c).

${ }^{\mathrm{b}}$ Total Mechanical OA Ventilation Rate and Air Balance were not FaTIMA inputs; they are presented to clarify the difference between the simulated HVAC systems.

${ }^{c}$ FATIMA infiltration input values for DOAS include total outdoor mechanical airflow rate and infiltration. 
Table 5. Ventilation system inputs and air balance for the base case of each HVAC system type (IP units)

\begin{tabular}{|c|c|c|c|c|c|c|c|}
\hline $\begin{array}{l}\text { HVAC } \\
\text { System } \\
\text { Type }\end{array}$ & $\begin{array}{c}\text { Supply } \\
\text { Airflow } \\
\text { Rate }(\mathrm{cfm}) \\
\end{array}$ & $\begin{array}{c}\text { Return } \\
\text { Airflow } \\
\text { Rate (cfm) } \\
\end{array}$ & $\begin{array}{l}\text { Outdoor } \\
\text { Air } \\
\text { Fraction } \\
\text { (OAF, -) }\end{array}$ & $\begin{array}{c}\text { Total Mechanical } \\
\text { OA Ventilation } \\
\text { Rate (cfm) }\end{array}$ & Infiltration (cfm) & $\begin{array}{c}\text { Recirculation } \\
\text { Filter (-) }\end{array}$ & $\begin{array}{c}\text { Air } \\
\text { Balance } \\
(\mathbf{c f m})\end{array}$ \\
\hline \multicolumn{8}{|c|}{ Classroom } \\
\hline CAHS & 888 & 799 & 0.33 & 279 & 34 & MERV 8 & 123 \\
\hline DOAS & 752 & 752 & 0 & 0 & $313(279+34)$ & MERV 6 & 313 \\
\hline TUS & 888 & 595 & 0.33 & 279 & 34 & MERV 6 & 327 \\
\hline WUS & 888 & 888 & 0 & 0 & 34 & None & 34 \\
\hline \multicolumn{8}{|c|}{ Portable classroom } \\
\hline CAHS & 1354 & 1218 & 0.33 & 427 & 40 & MERV 8 & 176 \\
\hline DOAS & 1144 & 1144 & 0 & 0 & $467(427+40)$ & MERV 6 & 467 \\
\hline TUS & 1354 & 902 & 0.33 & 427 & 40 & MERV 6 & 492 \\
\hline WUS & 1354 & 1354 & 0 & 0 & 40 & None & 40 \\
\hline \multicolumn{8}{|c|}{ Assembly room } \\
\hline CAHS & 9409 & 8469 & 0.23 & 1970 & 326 & MERV 8 & 1266 \\
\hline DOAS & 8421 & 8421 & 0 & 0 & $2296(1970+326)$ & MERV 6 & 2296 \\
\hline TUS & 9409 & 7282 & 0.23 & 1970 & 326 & MERV 6 & 2453 \\
\hline WUS & 9409 & 9409 & 0 & 0 & 326 & None & 326 \\
\hline
\end{tabular}




\subsection{System Filters}

ASHRAE 52.2-2017 (ASHRAE 2017) defines a MERV 13 filter as having an average efficiency of $50 \%$ for particles between $0.3 \mu \mathrm{m}$ and $1 \mu \mathrm{m}$ and an average efficiency of $85 \%$ for particles between $1 \mu \mathrm{m}$ and $3 \mu \mathrm{m}$. However, FaTIMA can only model a single particle diameter rather than a range. This requires greater resolution filter models than the requirements presented in ASHRAE 52.2-2017 (ASHRAE 2017). The filter models utilized by FaTIMA were based on the work of Kowalski et al. (1999), who developed models of MERV filters as recreated in Figure 4. In their work, a MERV 13 filter was predicted to remove $90 \%$ of $1 \mu \mathrm{m}$ diameter aerosols. The use of these filter models may yield different results compared with using the minimum requirements in ASHRAE 52.2-2017. However, the models were validated against experimental data in Kowalski et al. (1999). Reported filter performance depend on many factors including face velocity and the media length. As installed, filter performance will also depend on installation, filter loading, and other factors.

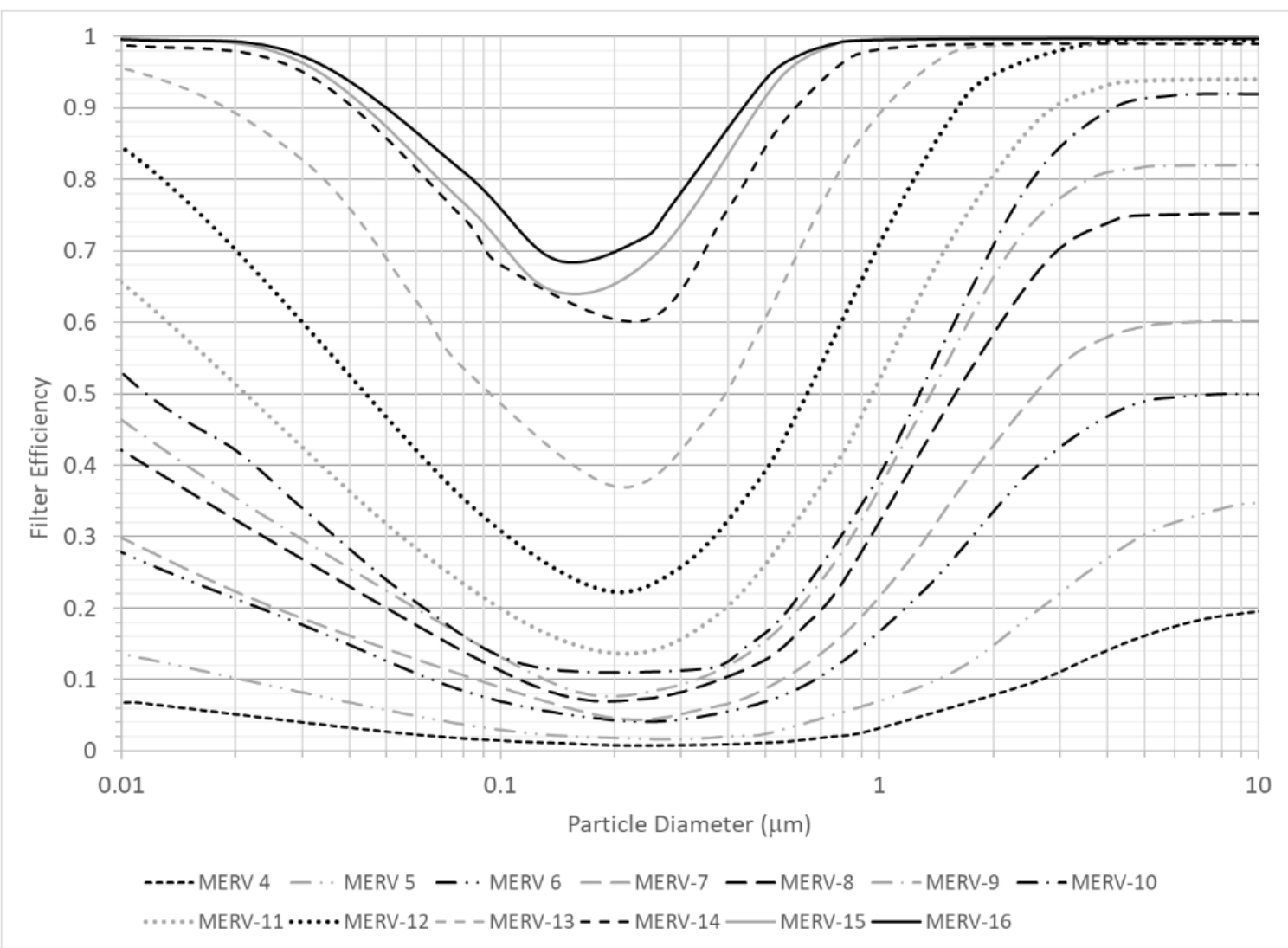

Figure 4. Filter efficiencies of different MERV filters at different particle diameters. Recreated by Dols et al. (2020) based on work by Kowalski et al. (1999) 
The System Filters section of FaTIMA has dropdown menus for Outdoor Air Filter and Recirculation Air Filter. For this analysis, no Outdoor Air Filter was used because it was assumed that the outdoor concentration of the aerosol of interest was zero. For the CAHS, the Recirculation Air Filter field of FaTIMA was set as MERV 8, and that of the DOAS and TUS was set as MERV 6. For the WUS, the Recirculation Air Filter field was set as None. From Figure 4, at $1 \mu \mathrm{m}$, the filtration efficiency for a MERV 6 filter is approximately 0.16 and for a MERV 8 filter is approximately 0.32 .

\subsection{Room Air Cleaner}

The Room Air Cleaner section of FaTIMA has fields for Maximum Airflow Rate, Fan Flow Fraction, and Filter Efficiency. In this study, the room air cleaner is referred to as a PAC. The base cases did not include a PAC. The Maximum Airflow Rate must be greater than zero in order for FaTIMA to run and is set to $142 \mathrm{~L} \cdot \mathrm{s}^{-1}(300 \mathrm{cfm})$. For the base cases, the Fan Flow Fraction was set to 0 (indicating the PAC was not operating). The Filter Efficiency was set to 0.99.

\subsection{Particle Properties}

The Particle Properties section of FaTIMA has fields for Name, Diameter, Density, and HalfLife (if Particle Deactivation is selected as On). The diameter was entered as $1 \mu \mathrm{m}$, and the density was entered as $1.0 \mathrm{~g} \cdot \mathrm{cm}^{-3}$. The Particle Deactivation was set to Off even though viruses could decay in aerosols in the timeframe (e.g., $6 \mathrm{~h}$ ) analyzed in this report (Niazi et al. 2020).

\subsection{Continuous Source}

The Continuous Source section of FaTIMA has fields for Generation Rate and Generation Time Period Start/End, if the Source is selected as On. For this analysis, the Continuous Source was set to On and was assumed to be a single contagious occupant continuously emitting aerosols without wearing a mask for the base cases. The Generation Rate was input as 500 particles per minute $\left(\# \cdot \mathrm{min}^{-1}\right)$. It does not assume that all of these particles contain virus or that any specific concentration of particles in a space causes COVID-19. This particle generation rate also does not take into account differences in breathing rates between adults and children, or between different people or activities. For all space types, the Generation Time Period Start Time was set to 09:00 and the End Time was set to 15:00. The Burst Source feature of FaTIMA (e.g., coughing) was not used for this analysis.

Although the literature does identify aerosol generation rates related to viruses in human exhaled breath (Duguid 1946; Leconte et al. 2011; Milton et al. 2013), the aerosol generation rate in this study was arbitrary because all reported results were normalized as described in Sec. 8. When a mask was worn by the contagious occupant, the aerosol source in FaTIMA was reduced by the assumed protection efficiency of the mask (Sec. 7.1). 


\subsection{Particle Deposition Velocities}

The Particle Deposition Velocities section of FaTIMA has fields for Floor, Walls, Ceiling, and Other Surface. Particle size-dependent deposition rates are a function of the friction velocity $\left(\mathrm{u}^{*}\right)$ as reviewed in Dols et al. (2020). In this analysis it was assumed that deposition rates were correlated to HVAC supply airflow rates, meaning the space type with the highest supply airflow rate had the highest deposition rates as reported in Dols et al. (2020). Conversely, the space type with the lowest supply airflow rate had the lowest deposition rates.

The classroom had the lowest supply airflow rates, and the portable classroom had the highest. Based on the $\mathrm{u}^{*}$ values reported in Dols et al. (2020), it was assumed that for the classroom $\mathrm{u}^{*}=$ $0.003 \mathrm{~m} \cdot \mathrm{s}^{-1}$ (the lowest reported $\mathrm{u}^{*}$ in Dols et al. (2020)), the assembly room $\mathrm{u}^{*}=0.03 \mathrm{~m} \cdot \mathrm{s}^{-1}$, and the portable classroom $\mathrm{u}^{*}=1.0 \mathrm{~m} \cdot \mathrm{s}^{-1}$ (the highest reported $\mathrm{u}^{*}$ in Dols et al. (2020)). Assuming these $\mathrm{u}^{*}$ values and the deposition data in Dols et al. (2020), the deposition rates used in this analysis are listed in Table 6.

The total deposition rate in the space (the last column of Table 6) was calculated based on the combination of all deposition velocities and surface areas (Dols et al. 2020). The rates are given in $\mathrm{h}^{-1}$ and are almost an order of magnitude lower than the outdoor ventilation rates. Thus, in this analysis, the deposition was not likely to be a significant removal mechanism of airborne $1 \mu \mathrm{m}$ particles. The deposition onto Other Surfaces (e.g., desks and shelves) was input as zero.

Table 6. Aerosol deposition rates used in this analysis

\begin{tabular}{|c|c|c|c|c|c|}
\hline \multirow[b]{2}{*}{ Space } & \multirow{2}{*}{$\begin{array}{c}\text { Supply airflow } \\
\text { rate }\left(h^{-1}\right)\end{array}$} & \multicolumn{3}{|c|}{ Deposition velocity $\left(\mathrm{cm} \cdot \mathrm{s}^{-1}\right)$} & \multirow{2}{*}{$\begin{array}{c}\text { Total } \\
\text { deposition rate } \\
\left(\mathbf{h}^{-1}\right)\end{array}$} \\
\hline & & Floors & Walls & Ceiling & \\
\hline Classroom & 7.8 & $3.40 \mathrm{E}-03$ & $3.38 \mathrm{E}-06$ & 0 & 0.048 \\
\hline Portable classroom & 9.8 & $3.40 \mathrm{E}-03$ & $1.13 \mathrm{E}-03$ & $1.75 \mathrm{E}-04$ & 0.067 \\
\hline Assembly room & 8.5 & $3.40 \mathrm{E}-03$ & $3.38 \mathrm{E}-05$ & 0 & 0.024 \\
\hline
\end{tabular}

\subsection{Initial Concentrations}

The Initial Concentrations section of FaTIMA has fields for Outdoor Air and Zone Air concentrations. The initial concentration of the aerosol was assumed to be zero in both the outdoor air and inside the zone.

\subsection{Occupant Exposure}

The Occupant Exposure section of FaTIMA has fields for Occupancy Type and Occupancy Time Period. For this analysis, the Occupancy Type was set to Constant. For the analyses of the classrooms, the Occupancy Time Period Start Time was set to 09:00 and the End Time was set to 15:00. For the analyses of the assembly room, the Occupancy Time Period Start Time was set to 14:00 and the End Time was set to 15:00. 


\subsection{Other Simulation Assumptions}

FaTIMA assumes that the indoor temperature is held constant at $20^{\circ} \mathrm{C}\left(68^{\circ} \mathrm{F}\right)$ for the entire simulation. Also, outdoor weather data could not be employed to FaTIMA at the time of analysis. To account for weather effects on infiltration and ventilation system operation, the user should download the CONTAM project file associated with the user inputs and simulate those impacts in CONTAM using.

All of the CONTAM project files used in this analysis are available for download on the NIST Multizone Modeling Website.

\section{Simulation Cases with Controls}

Five controls were simulated for each HVAC system, as summarized in Table 7. The icons in Table 7 represent each control and are used throughout this document. The controls under filtration (Sec. 7.2) and OAF (Sec. 7.3) varied depending on the HVAC system. PAC (Sec. 7.4) and exhaust fans (Sec. 7.5) were simulated with every HVAC system.

Table 7. Controls implemented by HVAC system type

\begin{tabular}{|llllll|}
\hline HVAC system & Yes \\
type
\end{tabular}

Table 8 summarizes how the controls were simulated at various levels by HVAC system. Mask efficiency was held constant while the other controls were individually varied (Sec. 7.1). The incremental levels simulated for the other controls are described in Sec. 7.4 to Sec. 7.5. After evaluating the reduction in exposure at various levels of controls, Sec. 9 describes how the controls were simulated using a two-level factorial analysis in order to assess the uncertainty associated with the controls.

FaTIMA outputs several metrics for exposure. The main criteria used in this analysis to evaluate simulation results was the Integrated Exposure $\left(\# \cdot s \cdot \mathrm{m}^{-3}\right.$ ) (IE) (Sec. 8), which were normalized to yield an NIE value as described in Sec. 8. The reduction in IE with controls was plotted against the Equivalent Clean ACR achieved with each control. 
Table 8. Controls varied incrementally by HVAC system type with masks

\begin{tabular}{|c|c|c|c|c|c|c|c|}
\hline $\begin{array}{c}\text { Space } \\
\text { Type }\end{array}$ & Level & Mask efficiency & $\begin{array}{c}\text { CAHS } \\
\text { MERV } \\
\text { rating (-) }\end{array}$ & $\begin{array}{c}\text { DOAS/TUS } \\
\text { MERV rating } \\
(-)\end{array}$ & $\begin{array}{c}\text { OAF } \\
(-) \\
\end{array}$ & 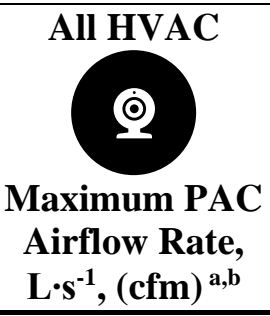 & 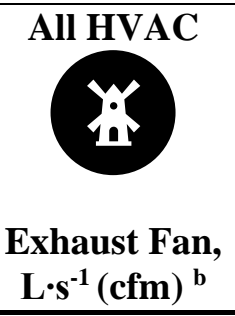 \\
\hline \multirow{8}{*}{ 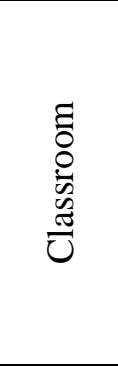 } & 0 (base operation) & $25 \%$ & 8 & 6 & 0.33 & 0 & 0 \\
\hline & 1 & $25 \%$ & 9 & 7 & 0.43 & $53(112)$ & $95(200)$ \\
\hline & 2 & $25 \%$ & 10 & 8 & 0.53 & $106(225)$ & $284(600)$ \\
\hline & 3 & $25 \%$ & 11 & 9 & 0.63 & $159(337)$ & $474(1000)$ \\
\hline & 4 & $25 \%$ & 12 & 10 & 0.73 & $212(449)$ & $664(1400)$ \\
\hline & 5 & $25 \%$ & 13 & 11 & 0.83 & $265(562)$ & $853(1800)$ \\
\hline & 6 & $25 \%$ & 14 & 12 & 0.93 & $318(674)$ & $1043(2200)$ \\
\hline & 7 & $25 \%$ & 15 & 13 & 1.00 & N/A & N/A \\
\hline \multirow{8}{*}{ 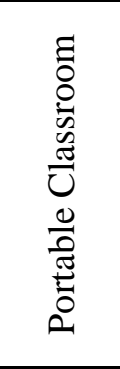 } & 0 (base operation) & $25 \%$ & 8 & 6 & 0.33 & 0 & 0 \\
\hline & 1 & $25 \%$ & 9 & 7 & 0.43 & $64(136)$ & $95(200)$ \\
\hline & 2 & $25 \%$ & 10 & 8 & 0.53 & $128(272)$ & $284(600)$ \\
\hline & 3 & $25 \%$ & 11 & 9 & 0.63 & $192(408)$ & $474(1000)$ \\
\hline & 4 & $25 \%$ & 12 & 10 & 0.73 & $257(544)$ & $664(1400)$ \\
\hline & 5 & $25 \%$ & 13 & 11 & 0.83 & $321(680)$ & $853(1800)$ \\
\hline & 6 & $25 \%$ & 14 & 12 & 0.93 & $385(816)$ & $1043(2200)$ \\
\hline & 7 & $25 \%$ & 15 & 13 & 1.00 & N/A & N/A \\
\hline \multirow{8}{*}{ 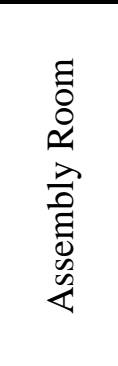 } & 0 (base operation) & $25 \%$ & 8 & 6 & 0.23 & 0 & 0 \\
\hline & 1 & $25 \%$ & 9 & 7 & 0.33 & $142(300)$ & $1138(2400)$ \\
\hline & 2 & $25 \%$ & 10 & 8 & 0.43 & $284(600)$ & $1706(3600)$ \\
\hline & 3 & $25 \%$ & 11 & 9 & 0.53 & $427(900)$ & $2275(4800)$ \\
\hline & 4 & $25 \%$ & 12 & 10 & 0.63 & $569(1200)$ & $2844(6000)$ \\
\hline & 5 & $25 \%$ & 13 & 11 & 0.73 & $711(1500)$ & $3413(7200)$ \\
\hline & 6 & $25 \%$ & 14 & 12 & 0.83 & $853(1800)$ & $3982(8400)$ \\
\hline & 7 & $25 \%$ & 15 & 13 & 1.00 & N/A & N/A \\
\hline
\end{tabular}

${ }^{\text {a. }}$ For CADR, see Sec. 7.4; ${ }^{\text {b. }}$ Only six levels simulated for PAC and exhaust fans. 


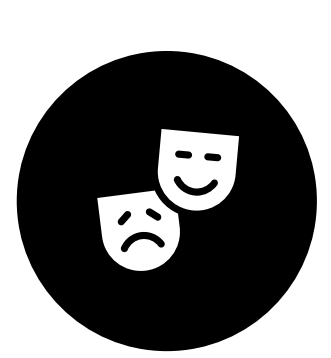

\subsection{Masks}

In this analysis, due to the limited availability of N95 masks, the single contagious occupant and single receptor were assumed to be wearing cloth masks. While not as effective as N95 masks, cloth masks provide a level of source control for the infected individual and reduced exposure for other occupants (Pan et al. 2021).

Many factors that impact the efficiency of masks in reducing exposure to aerosols including the pressure difference across the mask, the direction of flow through a mask (inhalation versus exhalation), filter efficiency, pliability of mask material, and the fit of the mask on the user's head (Lindsley et al. 2021; Pan et al. 2021). The last two factors can influence the amount of leakage around the mask. Inhalation and exhalation protection efficiencies are metrics that are intended to account for these all factors for a breath drawn in or exhaled through a mask, respectively. Measured inhalation and exhalation protection efficiency values can be different for the same mask due to variation in pressure differences and sealing when inhaling and exhaling.

Prior to the 2020 pandemic there was limited data on the protection efficiency of cloth masks. Makison Booth et al. (2013) demonstrated a ten-fold reduction in exposure to infectious influenza virus for people wearing surgical masks (i.e., inhalation protection) for aerosols that averaged $60 \mu \mathrm{m}$ in diameter. Milton et al. (2013) demonstrated exhalation protection efficiency for influenza virus in fine $(\leq 5 \mu \mathrm{m})$ aerosols of $64 \%$. van der Sande et al. (2008) tested homemade masks made from teacloths on children and adults for aerosols between $0.02 \mu \mathrm{m}$ and $1 \mu \mathrm{m}$. Inhalation protection efficiency was $60 \%$ for the adults and $52 \%$ for the children.

More studies have been done recently on the filtration efficiencies of cloth mask materials (not accounting for fit). Mueller et al. (2018) showed that bandana, t-shirt, handkerchief and shawl fabrics had filtration efficiencies by mass of $18 \%$ to $43 \%$ for volcanic ash. Rengasamy et al. (2010) examined cloth sweatshirt, t-shirt, towel and scarf materials for filtration efficiency for aerosols between $0.02 \mu \mathrm{m}$ and $1 \mu \mathrm{m}$. The cloth masks had average filtration efficiencies ranging from $10 \%$ to $26 \%$, while the other materials (t-shirts, sweatshirts, bandanas) ranged from $11 \%$ to $60 \%$. They also found that filtration efficiency was lower at $1 \mu \mathrm{m}$ than for smaller aerosols.

Given 1) the limited data for inhalation and exhalation protection efficiencies, 2) the range of filtration efficiencies in the literature, and 3) the lack of information on mask fit for children over the time periods studied in this analysis, it was assumed for this analysis that the simulated mask would provide inhalation and exhalation protection efficiencies of $25 \%$ at $1.0 \mu \mathrm{m}$.

In simulating masks, the Generation Rate under the Continuous Source section in FaTIMA (Sec. 6.7) was reduced by $25 \%$ (i.e., from $500 \# \cdot \mathrm{min}^{-1}$ to $375 \# \cdot \mathrm{min}^{-1}$ ) to account for source reduction from an infected occupant wearing a mask. To account for an exposed occupant also wearing a mask, the results from FaTIMA were reduced by another $25 \%$ in post-processing as will be described in Sec. 8 .

The effect of inhalation and exhalation protection efficiencies of cloth masks on exposure is examined in the factorial analysis section of this report (Sec. 9). 


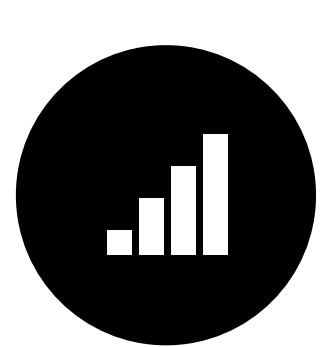

\subsection{Filtration}

It was assumed that the recirculation filter in the CAHS, CU of the DOAS, and in the TUS could be upgraded. The enhanced filtration was simulated at seven increments above the base case with masks (Table 8). For the CAHS, the filter was increased from MERV 8 to MERV 15. For the CU of the DOAS and TUS, the filter was increased from MERV 6 to MERV 13. Since the base WUS had no recirculation filter, none was added as a control. The filtration was varied under the Recirculation Air Filter of section in FaTIMA (Sec. 6.4). Table 8 summarized the controls and their incremental values for each HVAC system type. The other values in Table 8 will be described in later sections.

The effectiveness of these incremental MERV improvements was reported using the Equivalent Clean ACR after the filtration was improved. The Equivalent Clean ACR for each filtration upgrade (Table 9) was determined by comparing the NIE of the filtration upgrade and finding the OAF (and associated Equivalent Clean ACR) that achieved the same (or lower) NIE. Note that in Table 9, the Equivalent Clean ACR for the DOAS and TUS are listed in a single column because the rates were the same. 
Table 9. Filter efficiencies and resulting Equivalent Clean ACR

\begin{tabular}{|c|c|c|c|c|c|c|c|}
\hline \multirow[b]{2}{*}{ MERV level } & \multirow{2}{*}{$\begin{array}{c}\text { Filter Efficiency } \\
\text { at } 1 \mu \mathrm{m}^{\text {a }}\end{array}$} & \multicolumn{2}{|c|}{$\begin{array}{c}\text { Classroom } \\
\text { Equivalent Clean ACR }\left(h^{-1}\right)\end{array}$} & \multicolumn{2}{|c|}{$\begin{array}{l}\text { Portable classroom } \\
\text { Equivalent Clean ACR }\left(h^{-1}\right)\end{array}$} & \multicolumn{2}{|c|}{$\begin{array}{c}\text { Assembly room } \\
\text { Equivalent Clean ACR }\left(h^{-1}\right)\end{array}$} \\
\hline & & CAHS & DOAS/TUS & CAHS & DOAS/TUS & CAHS & DOAS/TUS \\
\hline 6 & 0.16 & $\mathrm{~N} / \mathrm{A}^{\mathrm{c}}$ & $2.9^{\mathrm{b}}$ & $\mathrm{N} / \mathrm{A}^{\mathrm{c}}$ & $3.6^{\mathrm{b}}$ & $\mathrm{N} / \mathrm{A}^{\mathrm{c}}$ & $2.2^{\mathrm{b}}$ \\
\hline 7 & 0.21 & $\mathrm{~N} / \mathrm{A}^{\mathrm{c}}$ & 4.7 & $\mathrm{~N} / \mathrm{A}^{\mathrm{c}}$ & 4.8 & $\mathrm{~N} / \mathrm{A}^{\mathrm{c}}$ & 3.4 \\
\hline 8 & 0.32 & 2.9 & 5.5 & 3.6 & 6.8 & 2.2 & 5.1 \\
\hline 9 & 0.38 & 3.9 & 6.3 & 4.8 & 7.8 & 3.4 & 5.9 \\
\hline 10 & 0.38 & 3.9 & 6.3 & 5.8 & 7.8 & 4.2 & 5.9 \\
\hline 11 & 0.52 & 5.5 & 7.1 & 6.8 & 8.8 & 5.1 & 7.6 \\
\hline 12 & 0.70 & 7.1 & 8.4 & 8.8 & $10.4+$ & 6.8 & $9.1+$ \\
\hline 13 & 0.90 & 7.8 & $8.4+{ }^{\mathrm{d}}$ & 9.7 & $10.4+$ & 7.6 & $9.1+$ \\
\hline 14 & 0.98 & $8.4+$ & $\mathrm{N} / \mathrm{A}^{\mathrm{e}}$ & $10.4+$ & N/A ${ }^{\mathrm{e}}$ & $9.1+$ & N/A ${ }^{\mathrm{e}}$ \\
\hline 15 & 0.99 & $8.4+$ & $\mathrm{N} / \mathrm{A}^{\mathrm{e}}$ & $10.4+$ & $\mathrm{N} / \mathrm{A}^{\mathrm{e}}$ & $9.1+$ & N/A ${ }^{\mathrm{e}}$ \\
\hline
\end{tabular}

${ }^{a}$ Based on MERV curves in Figure 4.

${ }^{b}$ MERV 6 is the base filtration for DOAS and TUS.

${ }^{c}$ MERV 8 is the base filtration for the CAHS for there are no Equivalent Clean ACR values for MERV 6 and MERV 7.

$\mathrm{d}$ " +" indicates that Equivalent Clean ACR was not simulated above this value. A larger Equivalent Clean ACR would be needed to achieve the NIE HVAC $_{\text {that was equal or less than the NIE }}$ HVAC achieved by the level of filtration listed.

${ }^{\mathrm{e}}$ Not simulated 


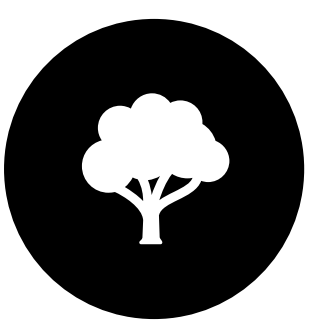

\subsection{Outdoor Air Fraction (OAF)}

It was assumed that the DOAS and TUS could not increase the base OA delivered to the simulated spaces. On the other hand, it was assumed that the CAHS could increase its base OAF to 1.0, meaning the mechanical OA supplied would be equal to the supply rate (see Table 2).

As mentioned above, the OAF was simulated at seven increments above the base with masks (Table 8). Thus, for the classroom and portable classroom CAHS, the OA intake fraction was increased from 0.33 to 1.0 in increments of 0.1 . For the assembly room CAHS, the OA intake fraction was increased from 0.23 to 1.0 in increments of 0.1 ( 0.93 was skipped in order to keep the number of incremental changes to seven as it was in the classrooms). The OAF input was varied under the Ventilation System section in FaTIMA (Sec. 6.3). The Equivalent Clean ACR of each OAF simulated is listed in Table 10 for the classrooms and Table 11 for the assembly room. The OAF for the DOAS was not incrementally varied because DOAS typically deliver the required OA rate with no modulation. The OAF for the TUS was not incrementally varied. The $\mathrm{EACR}_{\mathrm{OAF}}=\mathrm{OAF} \times Q_{\text {supply }} / V$, where $Q_{\text {supply }}$ for CAHS is listed in Table 4 and Table 5.

Table 10. OAF and resulting Equivalent Clean ACR in classrooms for CAHS only

\begin{tabular}{|c|c|c|}
\hline $\begin{array}{c}\text { OAF } \\
\text { classrooms }\end{array}$ & $\begin{array}{c}\text { Classroom } \\
\text { Equivalent Clean ACR }\left(\mathbf{h}^{-\mathbf{1}}\right)\end{array}$ & $\begin{array}{c}\text { Portable classroom } \\
\text { Equivalent Clean ACR }\left(\mathbf{h}^{\mathbf{- 1}}\right)\end{array}$ \\
\hline Base: 0.33 & 2.9 & 3.6 \\
\hline 0.43 & 3.9 & 4.8 \\
\hline 0.53 & 4.7 & 5.8 \\
\hline 0.63 & 5.5 & 6.8 \\
\hline 0.73 & 6.3 & 7.8 \\
\hline 0.83 & 7.1 & 8.8 \\
\hline 0.93 & 7.8 & 9.7 \\
\hline 1.00 & 8.4 & 10.4 \\
\hline
\end{tabular}

Table 11. OAF and resulting Equivalent Clean ACR in assembly room for CAHS only

\begin{tabular}{|c|c|}
\hline OAF assembly room & $\begin{array}{c}\text { Assembly room } \\
\text { Equivalent Clean ACR (h-1) }\end{array}$ \\
\hline Base: 0.23 & 2.2 \\
\hline 0.33 & 3.4 \\
\hline 0.43 & 4.2 \\
\hline 0.53 & 5.1 \\
\hline 0.63 & 5.9 \\
\hline 0.73 & 6.8 \\
\hline $0.83^{\text {a }}$ & 7.6 \\
\hline 1.00 & 9.1 \\
\hline
\end{tabular}




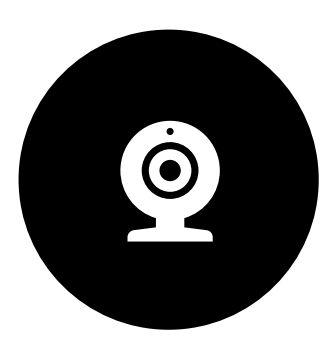

\subsection{Portable Air Cleaner (PAC)}

It was assumed that each space type could accommodate PACs, which were rated by the Clean Air Delivery Rate (CADR) as outlined in ANSI/AHAM Standard AC-1 (AHAM 2006). CADR represents the airflow through the air cleaner (in units of cubic feet of air per minute or $\mathrm{cfm}$ ) multiplied by the removal efficiency associated with three different types of particles: smoke $0.09 \mu \mathrm{m}$ to $1.0 \mu \mathrm{m}$, dust $0.5 \mu \mathrm{m}$ to $3 \mu \mathrm{m}$ and pollen $5 \mu \mathrm{m}$ to $11 \mu \mathrm{m}$. The CADR rating for smoke was used in this analysis.

As mentioned above, the PAC was modeled at six increments above the base (no PAC) case with masks (Table 8). It was assumed that the simulated PAC contained a high-efficiency particulate air (HEPA) filter with a filter efficiency of $99 \%$ for $1 \mu \mathrm{m}$ particles. For the classroom and portable classroom, the maximum airflow rate of the PAC was increased from $1 \mathrm{~h}^{-1}$ to $6 \mathrm{~h}^{-1}$ in increments of $1 \mathrm{~h}^{-1}$. These air change rates $\left(\mathrm{h}^{-1}\right)$ were converted to the volumetric flow rate by multiplying $\mathrm{h}^{-1}$ by the volume of each space type. Table 12 and Table 13 list the CADR of the PAC unit(s) needed to achieve the listed air change rates.

For the assembly room, which had a larger volume, there was no single available PAC in the Association of Home Appliance Manufacturers (AHAM) directory (AHAM 2020) that had a maximum airflow rate equal to an air change rate of $1.0 \mathrm{~h}^{-1}$. Thus, the number of 297 CADR units were increased from one to six in increments of one unit. A PAC with a maximum airflow rate of $142 \mathrm{~L} \cdot \mathrm{s}^{-1}(300 \mathrm{cfm})$ and filter efficiency of 0.99 has a CADR of 297 in units of $\mathrm{cfm}$. Because the EACR PAC $_{\text {did not depend on the air balance of the HVAC system, EACR }}$ PAC is equal to the CADR (converted to $\mathrm{m}^{3} \cdot \mathrm{s}^{-1}$ ) divided by $V\left(\mathrm{~m}^{3}\right)$.

The Maximum Airflow Rate of the Room Air Cleaner section in FaTIMA (Sec. 6.5) was set to the values in Table 12 and Table 13, and the Fan Flow Fraction was set to 1.0. The Equivalent Clean ACR of each PAC simulated is listed in Table 12 for the classrooms and Table 13 for the assembly room. Because the CAHS, DOAS, and TUS had the same mechanical OA, the Equivalent Clean ACR of an added PAC was the same for these systems. 
Table 12. PAC capacities and resulting Equivalent Clean ACR in classrooms

\begin{tabular}{|c|c|c|c|c|c|c|c|}
\hline $\begin{array}{c}\text { PAC in } \\
\text { classrooms } \\
(\text { level }) \\
\end{array}$ & $\begin{array}{c}\text { PAC in } \\
\text { classrooms } \\
\left(\mathbf{h}^{-1}\right) \\
\end{array}$ & $\begin{array}{c}\text { PAC CADR } \\
\text { Classroom } \\
(\text { cfm }) \\
\end{array}$ & \multicolumn{2}{|c|}{\begin{tabular}{|c|} 
Classroom \\
Equivalent Clean $\operatorname{ACR}\left(h^{-1}\right)$
\end{tabular}} & $\begin{array}{c}\text { PAC CADR } \\
\text { Portable Classroom } \\
(\mathrm{cfm})\end{array}$ & \multicolumn{2}{|c|}{$\begin{array}{c}\text { Portable classroom } \\
\text { Equivalent Clean ACR }\left(h^{-1}\right)\end{array}$} \\
\hline 0 & Base: 0 & 0 & 2.9 & 0.3 & 0 & 3.6 & 0.3 \\
\hline 2 & 2 & 222 & 4.8 & 2.3 & 269 & 5.5 & 2.3 \\
\hline 3 & 3 & 334 & 5.8 & 3.3 & 404 & 6.5 & 3.3 \\
\hline 4 & 4 & 445 & 6.8 & 4.3 & 538 & 7.5 & 4.3 \\
\hline
\end{tabular}

Table 13. PAC capacities and resulting Equivalent Clean ACR in assembly room

\begin{tabular}{|c|c|c|c|c|}
\hline $\begin{array}{c}\text { PAC in } \\
\text { assembly room } \\
(\mathbf{l e v e l})\end{array}$ & $\begin{array}{c}\text { PAC in } \\
\text { assembly room }\end{array}$ & $\begin{array}{c}\text { PAC CADR in } \\
\text { assembly Room }\end{array}$ & \multicolumn{2}{|c|}{$\begin{array}{c}\text { Assembly room } \\
\text { Equivalent Clean ACR (h-1) }\end{array}$} \\
\cline { 4 - 5 } & $(\mathbf{c} \mathbf{- 1})$ & 0 & 2.2 & WUS \\
\hline 0 & Base: 0 & 297 & 2.5 & 0.3 \\
\hline 1 & 0.3 & 594 & 2.8 & 0.6 \\
\hline 2 & 0.5 & 891 & 3.0 & 1.1 \\
\hline 3 & 0.8 & 1188 & 3.3 & 1.4 \\
\hline 4 & 1.1 & 1485 & 3.6 & 1.7 \\
\hline 5 & 1.4 & 1782 & 3.9 & 1.9 \\
\hline 6 & 1.6 & & & \\
\hline
\end{tabular}




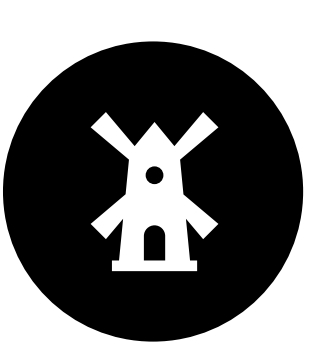

\subsection{Exhaust Fan}

Exhaust fans were assumed to be commercially available box fans that can be installed in windows or doorways in each space. As mentioned above, the addition of an exhaust fan was simulated at six increments above the base (no exhaust fan) with masks (Table 8). Thus, for the classrooms, the exhaust fan airflow rate was increased from $95 \mathrm{~L} \cdot \mathrm{s}^{-1}(200 \mathrm{cfm})$ to $1043 \mathrm{~L} \cdot \mathrm{s}^{-1}(2200 \mathrm{cfm})$ in increments of $190 \mathrm{~L} \cdot \mathrm{s}^{-1}(400 \mathrm{cfm})$. For the assembly room, the exhaust fan airflow rate was increased from $1138 \mathrm{~L} \cdot \mathrm{s}^{-1}(2400 \mathrm{cfm})$ to $3938 \mathrm{~L} \cdot \mathrm{s}^{-1}(8400 \mathrm{cfm})$ in increments of $569 \mathrm{~L} \cdot \mathrm{s}^{-1}(1200 \mathrm{cfm})$. The capacity of exhaust fans was varied under the Local Exhaust Airflow Rate of the Ventilation System section in FaTIMA (Sec. 6.3).

The EACR of each exhaust fan simulated is listed in Table 14 for the classroom, Table 15 for the portable classroom, and Table 16 for the assembly room. The EACR exhaustfan for this analysis are specific to the space types and HVAC systems modeled. There may be cases where EACR exhaustfan equals the exhaust fan capacity $\left(\mathrm{m}^{3} \cdot \mathrm{s}^{-1}\right)$ divided by $V$, but for the cases studied here it did not. This was due to the air balance (actually imbalance) created by the simulated HVAC systems and the assumed infiltration rates which would require an exhaust fan with a large enough capacity to overcome the imbalance to increase the clean ACR of the space by the amount specified for the exhaust fan.

For each space and HVAC type, the resulting Equivalent Clean ACR from the same exhaust fan capacity would differ. For example, an exhaust fan with a capacity of $284 \mathrm{~L} \cdot \mathrm{s}^{-1}(600 \mathrm{cfm})$ in the classroom has an air change rate $(Q / V)$ of $5.4 \mathrm{~h}^{-1}$. In the CAHS, the air balance was $1.1 \mathrm{~h}^{-1}$, meaning the CAHS plus the modeled infiltration would result in $1.1 \mathrm{~h}^{-1}$ of air leaving space. Since the $1.1 \mathrm{~h}^{-1}$ of air is already leaving the space, a $5.4 \mathrm{~h}^{-1}$ exhaust fan would only remove an

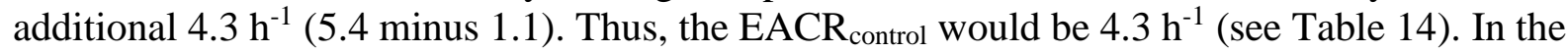
WUS, where the air balance was $0.3 \mathrm{~h}^{-1}$, the EACR $\mathrm{E}_{\text {control }}$ for this same $5.4 \mathrm{~h}^{-1}$ exhaust fan would be $5.1 \mathrm{~h}^{-1}$ (5.4 minus 0.3$)$.

Thus, only when the exhaust fan flow exceeded the air balance of the HVAC system would the exhaust fan increase the Equivalent Clean ACR of a space. As an example, for the smallest capacity exhaust fan for the DOAS and TUS systems, EACR exhaustfan $=0$ because the air balance was not exceeded and thus, the Equivalent Clean ACR did not change from the base case. The DOAS and TUS had the same air balance and were listed in a single column of the tables because the EACR exhaustfan and Equivalent Clean ACR were the same. 
Table 14. Exhaust fan capacities and resulting Equivalent Clean ACR in classroom

\begin{tabular}{|c|c|c|c|c|c|c|c|c|}
\hline \multirow{2}{*}{$\begin{array}{l}\text { Exhaust } \\
\text { fan in } \\
\text { classroom } \\
\left(\mathrm{L} \cdot \mathrm{s}^{-1}\right)\end{array}$} & \multirow{2}{*}{$\begin{array}{l}\text { Exhaust } \\
\text { fan in } \\
\text { classroom } \\
\text { (cfm) }\end{array}$} & \multirow{2}{*}{$\begin{array}{l}\text { Exhaust } \\
\text { fan in } \\
\text { classroom } \\
\left(\mathbf{h}^{-1}\right)\end{array}$} & \multicolumn{3}{|c|}{$\begin{array}{c}\text { Classroom } \\
\text { EACRexhaustfan }\left(h^{-1}\right)\end{array}$} & \multicolumn{3}{|c|}{$\begin{array}{c}\text { Classroom } \\
\text { Equivalent Clean ACR }\left(h^{-1}\right)\end{array}$} \\
\hline & & & CAHS & DOAS/TUS & WUS & CAHS & DOAS/TUS & WUS \\
\hline Base: 0 & Base: 0 & Base: 0 & N/A & N/A & N/A & 2.9 & 2.9 & 0.3 \\
\hline 95 & 200 & 1.8 & 0.7 & 0.0 & 1.5 & 3.6 & 2.9 & 1.8 \\
\hline 284 & 600 & 5.4 & 4.3 & 2.5 & 5.1 & 7.2 & 5.4 & 5.4 \\
\hline 474 & 1000 & 8.9 & 7.9 & 6.1 & 8.6 & 10.7 & 8.9 & 8.9 \\
\hline 664 & 1400 & 12.5 & 11.4 & 9.7 & 12.2 & 14.3 & 12.5 & 12.5 \\
\hline 853 & 1800 & 16.1 & 15.0 & 13.2 & 15.8 & 17.9 & 16.1 & 16.1 \\
\hline 1043 & 2200 & 19.7 & 18.6 & 16.8 & 19.4 & 21.5 & 19.7 & 19.7 \\
\hline
\end{tabular}

Table 15. Exhaust fan capacities and resulting Equivalent Clean ACR in portable classroom

\begin{tabular}{|l|l|l|c|c|c|c|c|c|}
\hline $\begin{array}{l}\text { Exhaust } \\
\text { fan in } \\
\text { portable } \\
\text { classroom } \\
\left(\mathbf{L} \cdot \mathbf{s}^{-1}\right)\end{array}$ & $\begin{array}{l}\text { Exhaust } \\
\text { fan in } \\
\text { portable } \\
\text { classroom } \\
\text { (cfm) }\end{array}$ & $\begin{array}{l}\text { Exhaust } \\
\text { fan in } \\
\text { portable } \\
\text { classroom } \\
\text { (h-1) }\end{array}$ & \multicolumn{2}{|c|}{$\begin{array}{l}\text { Portable classroom } \\
\text { EACRexhaustfan (h-1) }\end{array}$} & \multicolumn{3}{|c|}{$\begin{array}{l}\text { Portable classroom } \\
\text { Equivalent Clean ACR (h-1) }\end{array}$} \\
\cline { 5 - 10 } & CAHS & DOAS/TUS & WUS & CAHS & DOAS/TUS & WUS \\
\hline Base: 0 & Base: 0 & Base: 0 & N/A & N/A & N/A & 3.6 & 3.6 & 0.3 \\
\hline 95 & 200 & 1.5 & 0.2 & 0.0 & 1.2 & 3.8 & 3.6 & 1.5 \\
\hline 284 & 600 & 4.4 & 3.2 & 0.9 & 4.1 & 6.7 & 4.4 & 4.4 \\
\hline 474 & 1000 & 7.4 & 6.1 & 3.8 & 7.1 & 9.7 & 7.4 & 7.4 \\
\hline 664 & 1400 & 10.3 & 9.1 & 6.8 & 10.0 & 12.6 & 10.3 & 10.3 \\
\hline 853 & 1800 & 13.3 & 12.0 & 9.7 & 13.0 & 15.6 & 13.3 & 13.3 \\
\hline 1043 & 2200 & 16.3 & 15.0 & 12.7 & 16.0 & 18.5 & 16.3 & 16.3 \\
\hline
\end{tabular}


Table 16. Exhaust fan capacities and resulting Equivalent Clean ACR in assembly room

\begin{tabular}{|l|l|l|c|c|c|c|c|c|}
\hline \multirow{2}{*}{$\begin{array}{l}\text { Exhaust } \\
\text { fan in } \\
\text { assembly } \\
\text { room }\left(\mathbf{L} \cdot \mathbf{s}^{-1}\right)\end{array}$} & $\begin{array}{l}\text { Exhaust } \\
\text { fan in } \\
\text { assembly } \\
\text { room }(\mathbf{c f m})\end{array}$ & $\begin{array}{l}\text { Exhaust } \\
\text { fan in } \\
\text { assembly } \\
\text { room }\left(\mathbf{h}^{-1}\right)\end{array}$ & \multicolumn{3}{|c|}{$\begin{array}{c}\text { Assembly room } \\
\text { EACRexhaustfan (h-1) }\end{array}$} & \multicolumn{3}{|c|}{$\begin{array}{l}\text { Assembly room } \\
\text { Equivalent Clean ACR (h-1) }\end{array}$} \\
\cline { 3 - 10 } & CAHS & DOAS/TUS & WUS & CAHS & DOAS/TUS & WUS \\
\hline Base: 0 & Base: 0 & Base: 0 & N/A & N/A & N/A & 2.2 & 2.2 & 0.3 \\
\hline 1138 & 2400 & 2.2 & 1.1 & 0.0 & 1.9 & 3.3 & 2.2 & 2.2 \\
\hline 1706 & 3600 & 3.3 & 2.2 & 1.1 & 3.0 & 4.4 & 3.3 & 3.3 \\
\hline 2275 & 4800 & 4.4 & 3.3 & 2.2 & 4.1 & 5.5 & 4.4 & 4.4 \\
\hline 2844 & 6000 & 5.5 & 4.4 & 3.3 & 5.2 & 6.6 & 5.5 & 5.5 \\
\hline 3413 & 7200 & 6.6 & 5.5 & 4.4 & 6.4 & 7.7 & 6.6 & 6.6 \\
\hline 3982 & 8400 & 7.8 & 6.6 & 5.5 & 7.5 & 8.8 & 7.8 & 7.8 \\
\hline
\end{tabular}




\section{Metrics for Comparing Exposure}

The Integrated Exposure highlighted in Figure 5 was used in this analysis to compare exposure between cases. IE was calculated by FaTIMA using trapezoidal integration to perform a summation of the product of the airborne aerosol concentration and the simulation time step over the user-defined occupancy interval.

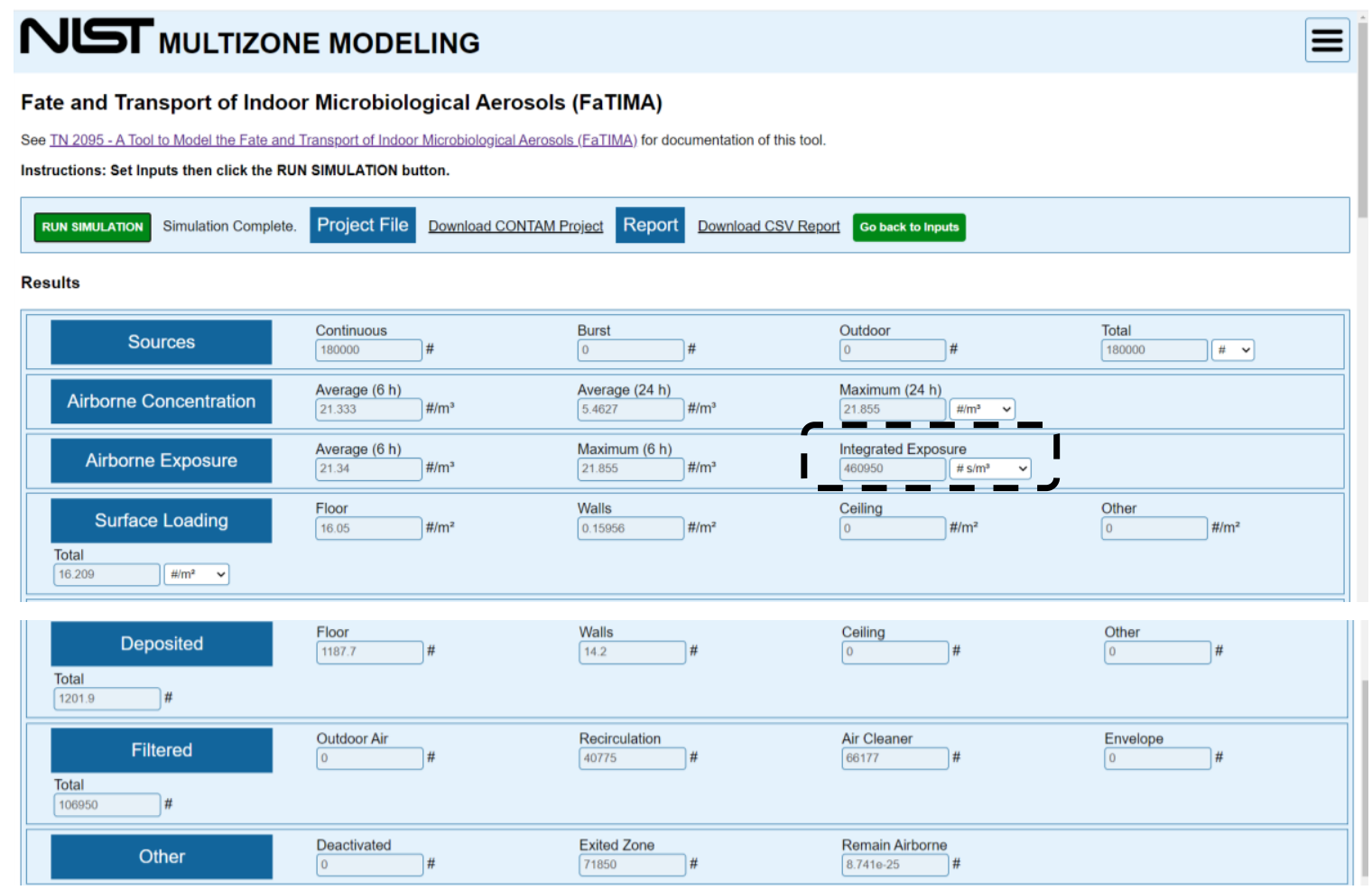

Figure 5. Screenshot of FaTIMA numerical outputs for classroom CAHS

Since the goal of this analysis was to evaluate the relative reduction in aerosol exposure, a Normalized Integrated Exposure (NIE) was used. The term "NIEHVAC" was used to represent simulation results normalized to the results of the corresponding HVAC system with no controls (Eq. (3)). In the results presented, the subscript "HVAC" will be replaced by the specific system type to indicate which results were used for normalization. For example, results presented as NIE ${ }_{\text {CAHS }}$ were normalized with respect to the CAHS with no controls. As mentioned above, to account for an exposed occupant also wearing a mask, the IE result from FaTIMA was reduced by the protection efficiency of the mask (Eq. (3)).

$\mathrm{NIE}_{\mathrm{HVAC}}=\mathrm{IE}_{\mathrm{HVAC}, \text { control }} \times(1-$ protection efficiency mask $) / \mathrm{IE}_{\mathrm{HVAC}}$, no control

In the results, reductions in exposure were compared with MERV 13 filtration. However, it is not the intent of this analysis to conclude that this is a target for optimal exposure reduction. It is used for comparison purposes only. This analysis shows that there are controls that could potentially obtain reductions in exposure equivalent to MERV 13 filtration, which could be useful for HVAC systems that may not be able to accommodate MERV 13 filtration. 


\section{Factorial Analysis}

To assess the uncertainty in exposure reduction associated with the controls, a two-level factorial test was performed. Table 17 presents the values used in this two-level factorial test. Values for a plus level (+) and a minus level (-) were assigned for the controls based on a literature review and market research.

The (+) and (-) values represented controls that performed at "base levels" or "less than base", respectively, except for the masks. FaTIMA was used to implement the (+) and (-) values of the selected controls except for the filter (-) value. For the filter (-) value, a Constant Efficiency filter model in CONTAM was used because filters could only be selected in FaTIMA according to MERV rating. Another approach could have been to select a MERV rating for which the efficiency at $1 \mu \mathrm{m}$ was equal to the filter (-) value. For the masks, three levels were evaluated - a base level (Sec. 7.1), a set of (+) values using higher inhalation and exhalation efficiencies reported, and a set of (-) values using lower inhalation and exhalation efficiencies reported. 
Table 17. Two-level factorial parameters for sensitivity analysis

\begin{tabular}{|c|c|c|}
\hline $\begin{array}{l}\text { Control } \\
\text { (HVAC system applied) }\end{array}$ & $(+)$ value $^{a}$ & $(-)$ value $^{b}$ \\
\hline Mask inhalation protection efficiency ${ }^{c}$ & $90 \%$ & $0 \%$ \\
\hline Mask exhalation protection efficiency ${ }^{c}$ & $85 \%$ & $15 \%$ \\
\hline HVAC filter efficiency (CAHS, DOAS, TUS) & MERV $13(90 \%)$ & $50 \%$ \\
\hline OA intake fraction (CAHS) & 1.00 & 0.80 \\
\hline PAC maximum airflow rate (all) & $142 \mathrm{~L} \cdot \mathrm{s}^{-1}(300 \mathrm{cfm})$ & $47 \mathrm{~L} \cdot \mathrm{s}^{-1}(99 \mathrm{cfm})$ \\
\hline Local exhaust airflow rate (all) & $569 \mathrm{~L} \cdot \mathrm{s}^{-1}(1200 \mathrm{cfm})$ & $512 \mathrm{~L} \cdot \mathrm{s}^{-1}(1080 \mathrm{cfm})$ \\
\hline
\end{tabular}

${ }^{a}$ Base value for the control except for masks.

${ }^{\mathrm{b}}$ Less than base value for the control except for mask.

${ }^{\mathrm{c}}$ For masks, the base case assumed that the inhalation and exhalation protection efficiency were both $25 \%$ (Sec. 7.1). For the sensitivity analysis, the (+) and (-) values for the inhalation and exhalation protection efficiencies were from high and low values reported in the literature.

While there has been research investigating filtration efficiencies of mask materials, to date only one study has investigated both inhalation and exhalation protection efficiencies of cloth and surgical masks (Pan et al. 2021). Their research demonstrated a wide range of inhalation and exhalation protection efficiencies due to both material filtration efficiencies, material pliability, and mask fit. While filtration efficiencies for $1 \mu \mathrm{m}$ aerosols of mask materials alone ranged from $5 \%$ to $95 \%$, the inhalation protection efficiency (inward, accounting for fit) for 11 materials ranged from $0 \%$ to $85 \%$. The exhalation protection efficiency (outward, accounting for fit) for 11 materials ranged from $15 \%$ to $90 \%$.

The upper and lower protection efficiencies from Pan et al. (2021) were used in the factorial analysis. Hence, the (+) value for the masks was assumed to be $90 \%$ inhalation protection efficiency and $85 \%$ exhalation protection efficiency. The (-) values were assumed to be $0 \%$ inhalation protection efficiency and $15 \%$ exhalation protection efficiency.

The (+) value for filtration, MERV 13, was selected based on the filtration guidance in ASHRAE (2020). For $1 \mu \mathrm{m}$ particles, MERV 13 filtration in this analysis was assumed to have a filter efficiency of $90 \%$ from Kowalski et al. (1999). The (-) value for the filtration, $50 \%$, was selected based on the minimum requirements for MERV 13 filters in ASHRAE 52.2-2017 (ASHRAE 2017).

The (+) value for OAF was selected based on guidance to "increase ventilation" when appropriate (ASHRAE 2020). The (-) value for the OAF was selected to be $20 \%$ less than the $(+)$ value in an attempt to account for system performance not matching intent.

The (+) level for the PAC was selected based on available capacities in the Association of Home Appliance Manufacturers (AHAM) directory (AHAM 2020). The (-) value for the PAC was selected based on the assumption that the speed setting on a PAC might be lowered to reduce noise in a classroom.

The (+) level for the exhaust fan was selected based on market research of available capacities in box fans. The (-) value for the exhaust fan $10 \%$ less than the (+) value. 


\section{Results}

The results for the two classrooms are presented in Sec. 10.1 and the results for the assembly room in Sec. 10.2. The two classrooms are presented together because their results are similar. Within the results section for each space type, the base case results are presented first (Sec. 10.1.1 and Sec. 10.2.1). The results after varying the value of controls (plotted using Equivalent Clean ACR) are presented in Sec. 10.1.2 to Sec. 10.1.5 for the classrooms and in Sec. 10.2.2 to Sec. 1.1.1 for the assembly room. The results presented in these sections include masks with $25 \%$ inhalation and exhalation protection efficiency by the infectious occupant and the receptor for whom the exposure is calculated.

The results of the factorial analyses are presented in Sec. 10.1.6 for both the classroom and portable classroom and Sec. 1.1.1 for the assembly room. Factorial results are reported as $\mathrm{NIE}_{\text {HVAC }}$ with an uncertainty value (e.g., $0.81(0.91)$ ). The value reported first was the NIE calculated from the simulation results using the level (+) value in Table 17. The value inside the parenthesis is the NIEHVAC calculated from the simulation results using the level (-) value in Table 17. Only for the masks were three values presented - the NIE reported for the base inhalation/exhalation protection efficiency of $25 \%$, the NIE using the (+) values for inhalation and exhalation protection efficiency in Table 17, and the NIE using the (-) values. 


\subsection{Classroom and Portable Classroom}

\subsubsection{Base Cases}

Figure 6 shows the IE values of the base cases (no controls) for the classrooms and for each HVAC system type. These values were listed to show that the base operation of the HVAC system type affected the base exposure. The base IE values for the WUS were eight to ten times higher than for other HVAC systems depending on the space type. However, these values were not a direct metric of infection risk. The results for the DOAS and TUS are similar because both systems have the same air balance as discussed in Sec. 6.3 and listed in Table 4. The IEs for the portable classroom were lower than for the classroom because the portable classroom had more mechanical OA intake per ASHRAE 62.1-2019 (Table 2).

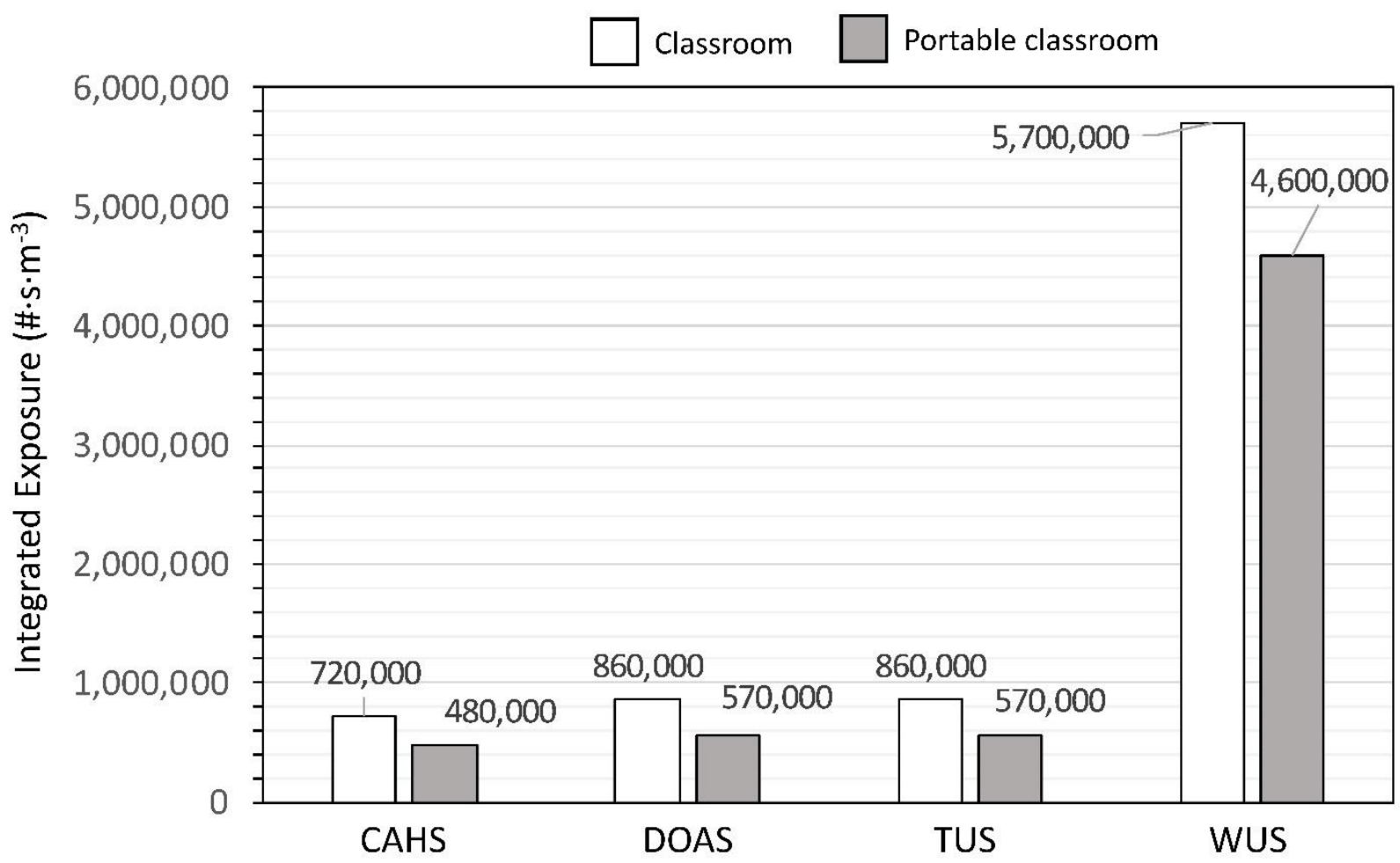

Figure 6. Base IE for classroom and portable classroom

Figure 7 show the classroom IE values normalized to the results of the CAHS (NIE CAHS $_{\text {, which }}$ had the lowest IE of the HVAC system types simulated for the space types simulated. The effect of not having any mechanical OA ventilation is apparent in the WUS. 


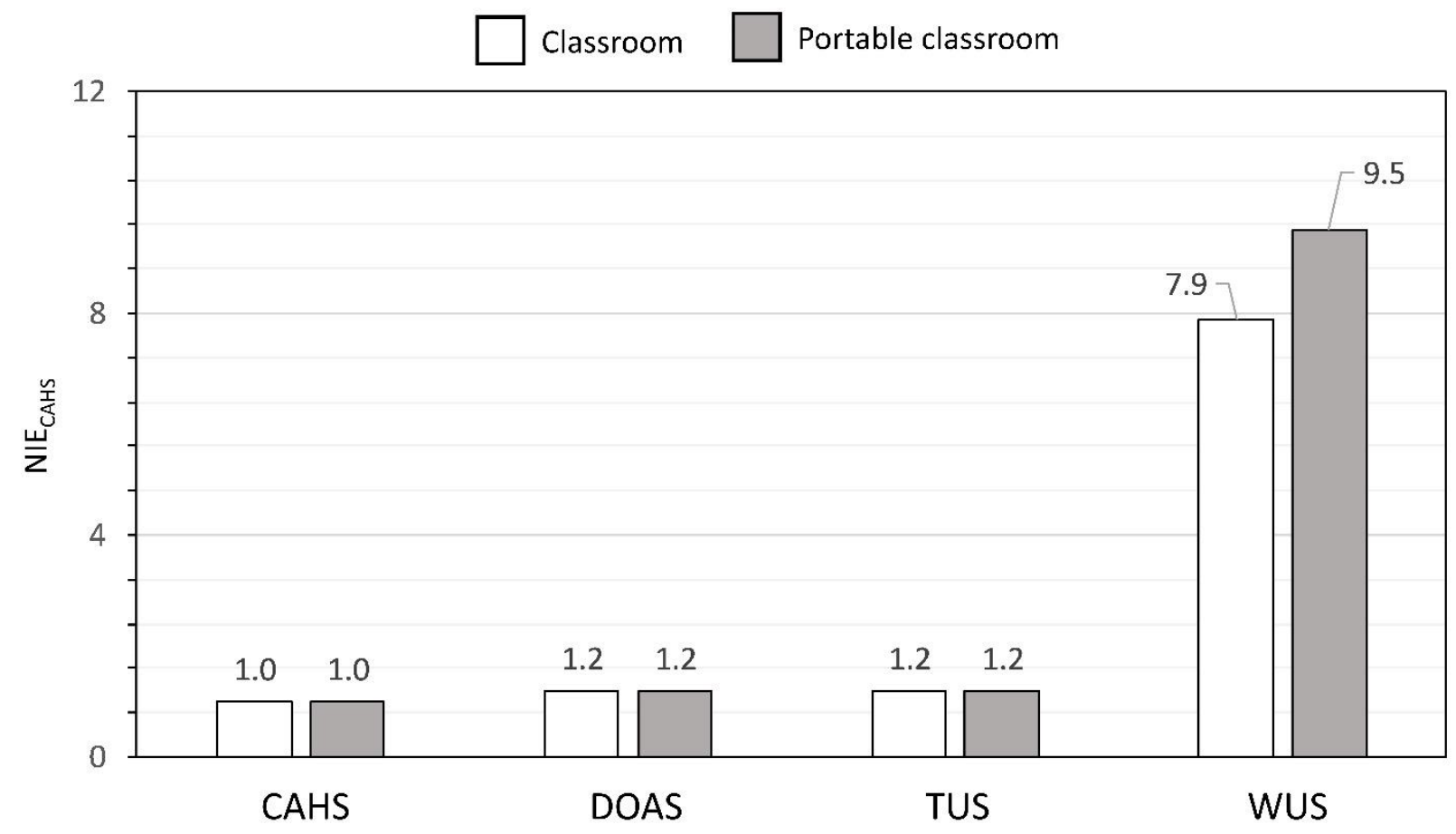

Figure 7. NIEcAHS for HVAC system types (both classrooms).

The NIE ${ }_{\text {CAHS }}$ for the DOAS and TUS without any controls were both 1.2 for both classrooms, meaning that the IE for classrooms using DOAS and TUS were $20 \%$ greater than the IE for a classroom using CAHS.

\subsubsection{Effectiveness of controls CAHS}

Figure 8 shows the effectiveness of four controls (filtration, OAF, PAC, and exhaust fan) with masks versus Equivalent Clean ACR for the classrooms with CAHS. Each level of control and

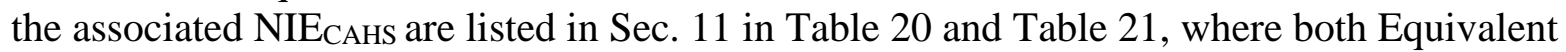
Clean ACR and per-person outdoor air ventilation rates are listed. 
The solid horizontal line indicates the NIE factorial analysis, MERV 13 filtration is the filtration guidance in ASHRAE (2020). To achieve reductions equal to (or greater than) MERV 13 filtration $\left(\mathrm{NIE}_{\mathrm{CAHS}}=0.34\right)$ using other simulated controls individually would require the following controls:

- $\mathrm{OAF}$ of $93 \%$ in either classroom $\left(\mathrm{NIE}_{\mathrm{CAHS}}=0.33\right)^{4}$

or:

- PAC with a maximum airflow rate of $4 \mathrm{~h}^{-1}\left(212 \mathrm{~L} \cdot \mathrm{s}^{-1}, 449 \mathrm{cfm}\right)$ which is $445 \mathrm{CADR}$ and has a resulting Equivalent Clean $\mathrm{ACR}=6.8 \mathrm{~h}^{-1}$ in the classroom $\left(\mathrm{NIE}_{\mathrm{CAHS}}=0.31\right)$

- PAC with a maximum airflow rate of $4 \mathrm{~h}^{-1}\left(257 \mathrm{~L} \cdot \mathrm{s}^{-1}, 544 \mathrm{cfm}\right)$ which is $538 \mathrm{CADR}$ and has a resulting Equivalent Clean $\mathrm{ACR}=7.5 \mathrm{~h}^{-1}$ in the portable classroom $\left(\mathrm{NIE}_{\mathrm{CAHS}}=\right.$ $0.33)$

or:

- $284 \mathrm{~L} \cdot \mathrm{s}^{-1}(600 \mathrm{cfm})$ exhaust fan (resulting Equivalent Clean ACR $\left.=7.2 \mathrm{~h}^{-1}\right)$ in the classroom $\left(\mathrm{NIE}_{\mathrm{CAHS}}=0.29\right)$

- $\quad 474 \mathrm{~L} \cdot \mathrm{s}^{-1}(1000 \mathrm{cfm})$ exhaust fan (resulting Equivalent Clean ACR $\left.=9.7 \mathrm{~h}^{-1}\right)$ in the portable classroom $\left(\mathrm{NIE}_{\mathrm{CAHS}}=0.27\right)$

${ }^{4}$ The base OAF of the CAHS in the classrooms is 0.33 . 


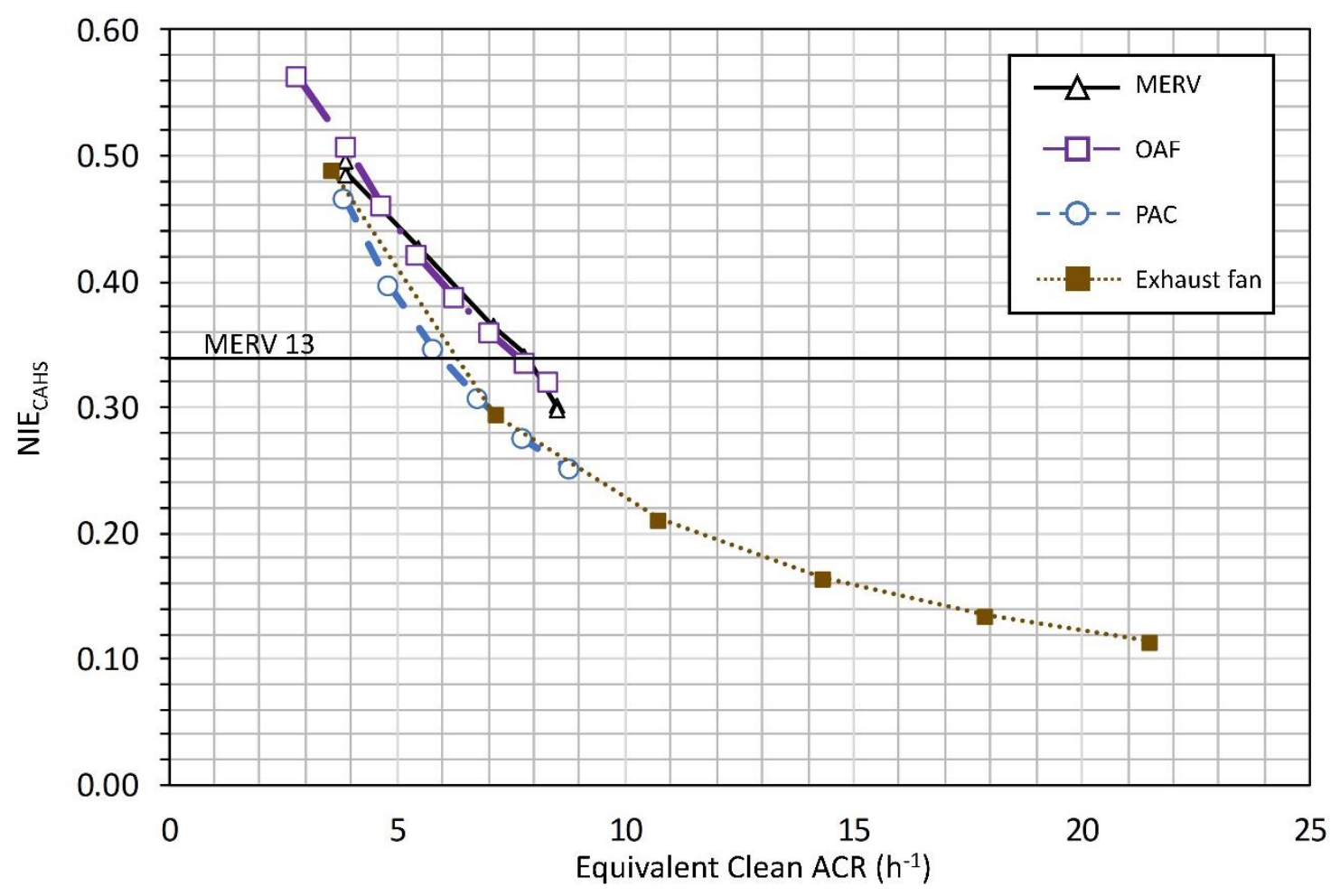

(a) Classroom

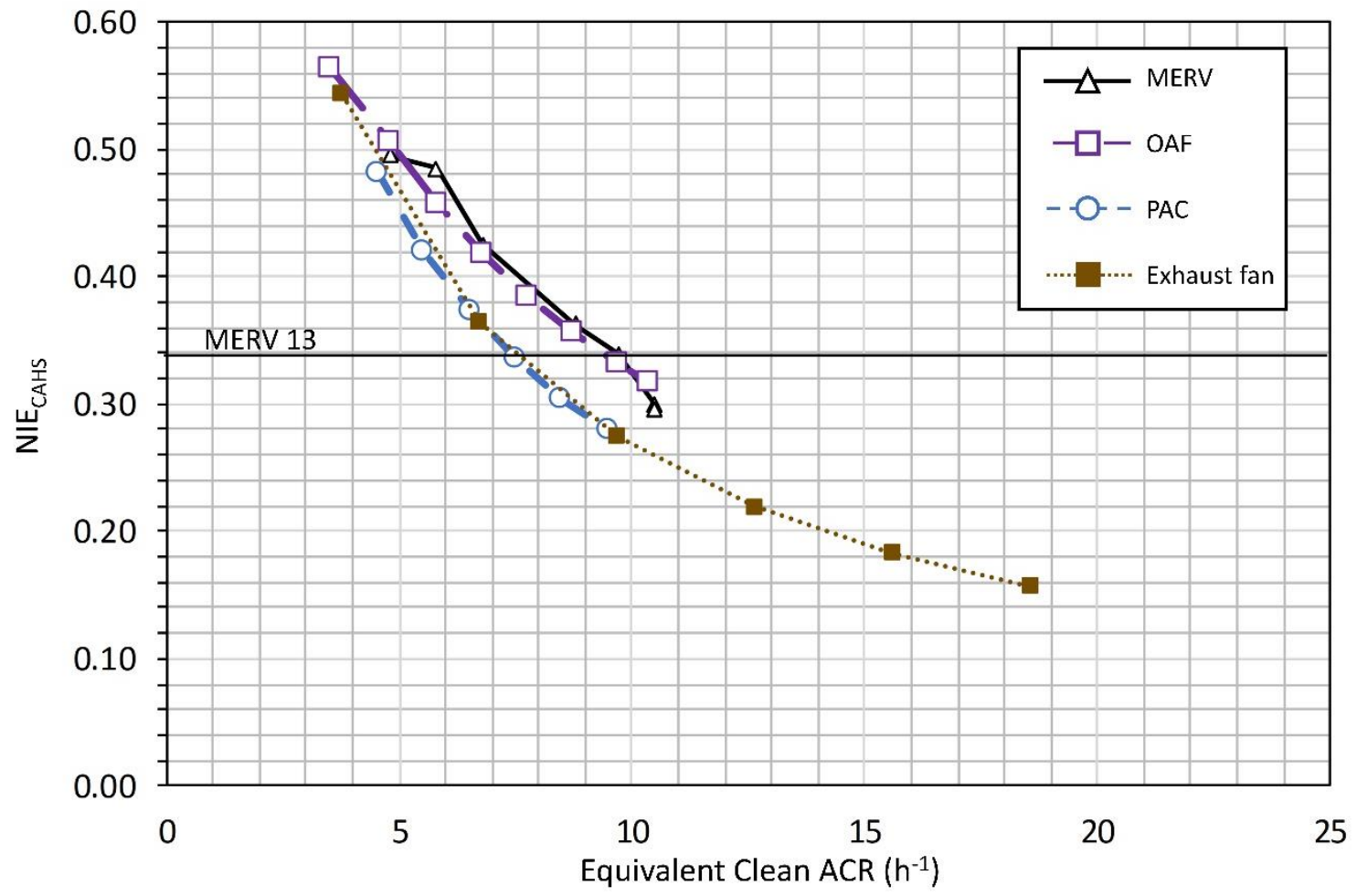

(b) Portable classroom

Figure 8. NIEcaHs with varying controls for (a) classroom and (b) portable classroom with masks 


\subsubsection{Effectiveness of controls DOAS}

Figure 9 shows the effectiveness of three controls (filtration, PAC, and exhaust fan) with masks versus Equivalent Clean ACR for the classrooms with DOAS. Each level of control and the

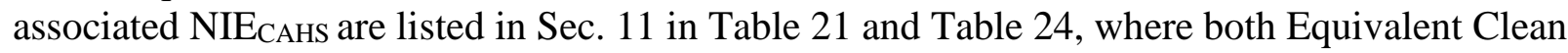
ACR and per-person outdoor air ventilation rates are listed.

The solid horizontal line indicates the NIE ${ }_{\text {DOAS }}$ at MERV 13 filtration. To achieve reductions equal to (or greater than) MERV 13 filtration $\left(\mathrm{NIE}_{\mathrm{DOAS}}=0.29\right)$, would require:

- PAC with a maximum airflow rate of $4 \mathrm{~h}^{-1} \mathrm{PAC}\left(212 \mathrm{~L} \cdot \mathrm{s}^{-1}, 449 \mathrm{cfm}\right)$ which is 445 $\mathrm{CADR}$ and has a resulting Equivalent Clean ACR of $6.8 \mathrm{~h}^{-1}$ in the classroom $\left(\mathrm{NIE}_{\mathrm{DOAS}}=\right.$ $0.28)$

- PAC with a maximum airflow rate of $5 \mathrm{~h}^{-1} \mathrm{PAC}\left(321 \mathrm{~L} \cdot \mathrm{s}^{-1}, 680 \mathrm{cfm}\right)$ which is 673 $\mathrm{CADR}$ and has a resulting Equivalent Clean ACR $=8.5 \mathrm{~h}^{-1}$ in the portable classroom $\left(\mathrm{NIE}_{\mathrm{DOAS}}=0.28\right)$

or:

- $\quad 474 \mathrm{~L} \cdot \mathrm{s}^{-1}(1000 \mathrm{cfm})$ exhaust fan (resulting Equivalent Clean ACR $\left.=8.9 \mathrm{~h}^{-1}\right)$ in the classroom $\left(\mathrm{NIE}_{\mathrm{DOAS}}=0.22\right)$

- $664 \mathrm{~L} \cdot \mathrm{s}^{-1}(1400 \mathrm{cfm})$ exhaust fan (resulting Equivalent Clean ACR $=10.3 \mathrm{~h}^{-1}$ ) in the portable classroom $\left(\mathrm{NIE}_{\mathrm{DOAS}}=0.24\right)$ 


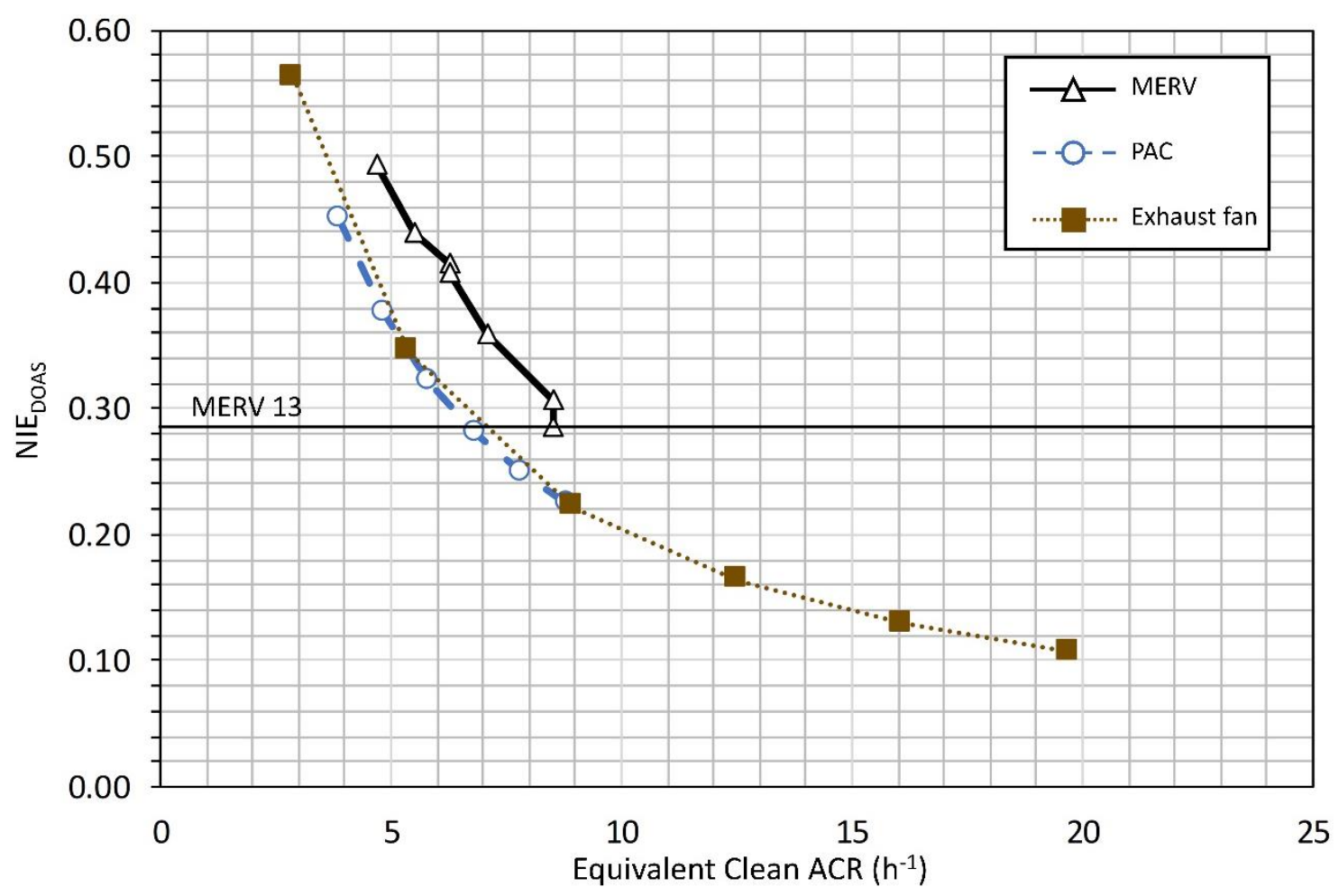

(a) Classroom

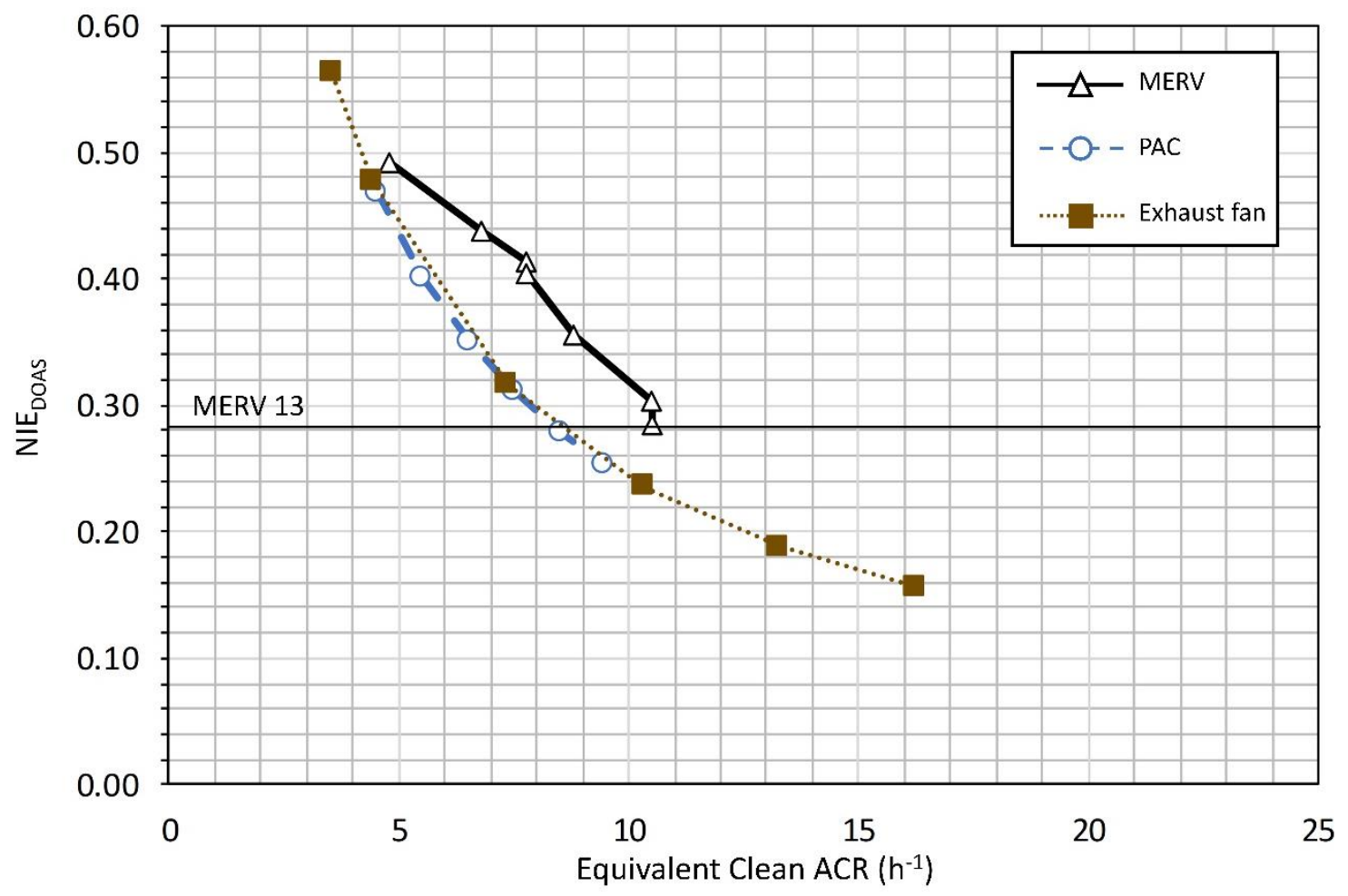

(b) Portable classroom

Figure 9. NIEDoAs with varying controls for (a) classroom and (b) portable classroom with masks 


\subsubsection{Effectiveness of controls TUS}

Figure 10 shows the effectiveness of three controls (filtration, PAC, and exhaust fan) with masks versus Equivalent Clean ACR for the classrooms with TUS. Each level of control and the

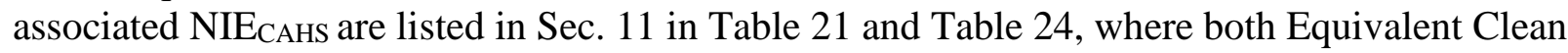
ACR and per-person outdoor air ventilation rates are listed.

The solid horizontal line indicates the NIETUS at MERV 13 filtration. To achieve reductions equal to (or greater than) MERV 13 filtration $\left(\mathrm{NIE}_{\mathrm{TUS}}=0.29\right)$, would require:

- PAC with a maximum airflow rate of $4 \mathrm{~h}^{-1} \mathrm{PAC}\left(212 \mathrm{~L} \cdot \mathrm{s}^{-1}, 449 \mathrm{cfm}\right)$ which is 445 $\mathrm{CADR}$ and has a resulting Equivalent Clean $\mathrm{ACR}=6.8 \mathrm{~h}^{-1}$ in the classroom (NIETUS $=$ $0.28)$

- PAC with a maximum airflow rate of $5 \mathrm{~h}^{-1} \mathrm{PAC}\left(321 \mathrm{~L} \cdot \mathrm{s}^{-1}, 680 \mathrm{cfm}\right)$ which is 673 $\mathrm{CADR}$ and has a resulting Equivalent Clean ACR $=8.5 \mathrm{~h}^{-1}$ in the portable classroom $\left(\mathrm{NIE}_{\mathrm{TUS}}=0.28\right)$

or:

- $474 \mathrm{~L} \cdot \mathrm{s}^{-1}(1000 \mathrm{cfm})$ exhaust fan (resulting Equivalent Clean ACR $\left.=8.9 \mathrm{~h}^{-1}\right)$ in the classroom

$\left(\mathrm{NIE}_{\mathrm{TUS}}=0.22\right)$

- $664 \mathrm{~L} \cdot \mathrm{s}^{-1}(1400 \mathrm{cfm})$ exhaust fan (resulting Equivalent Clean ACR $=10.3 \mathrm{~h}^{-1}$ ) in the portable classroom $\left(\mathrm{NIE}_{\mathrm{TUS}}=0.24\right)$ 


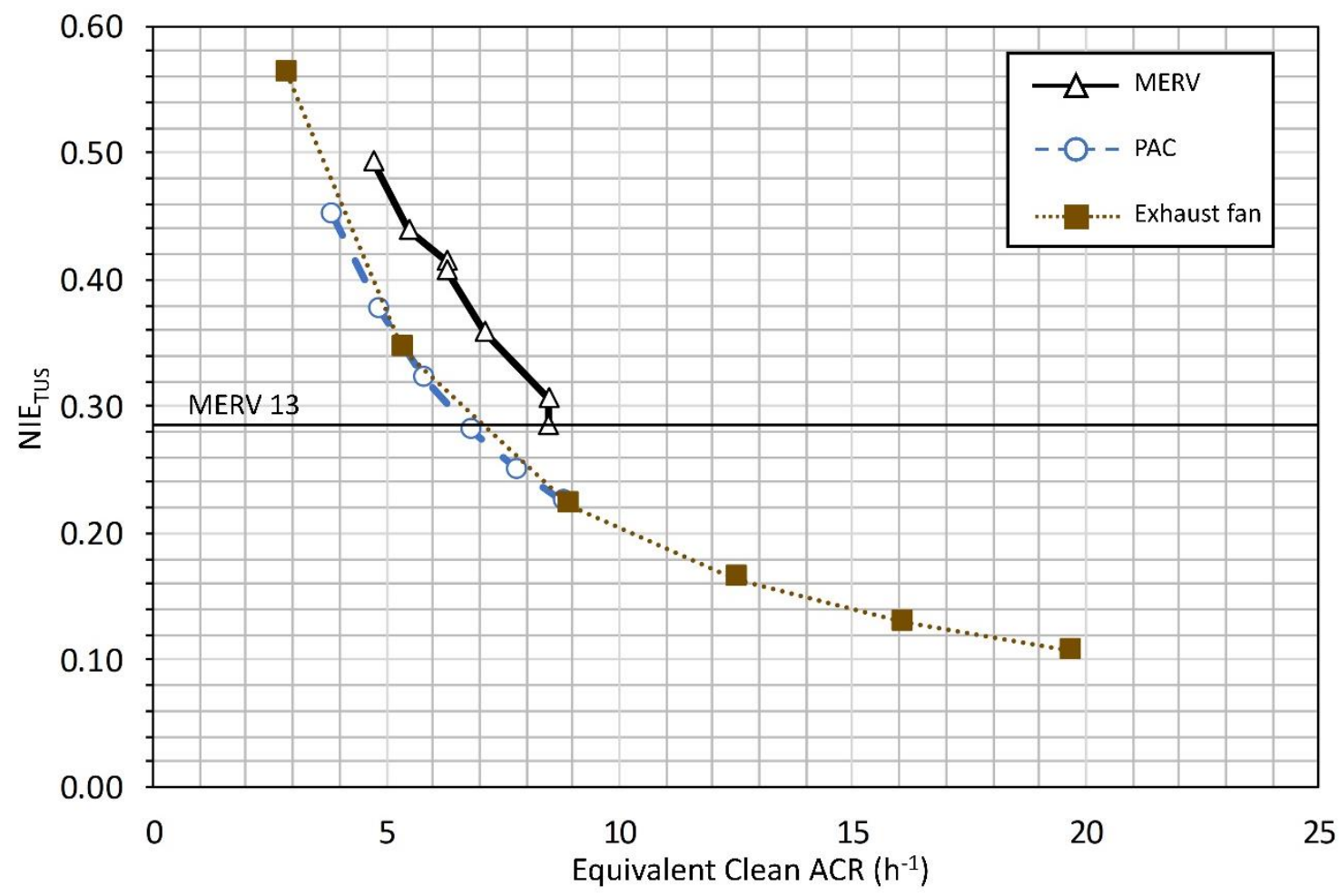

(a) Classroom

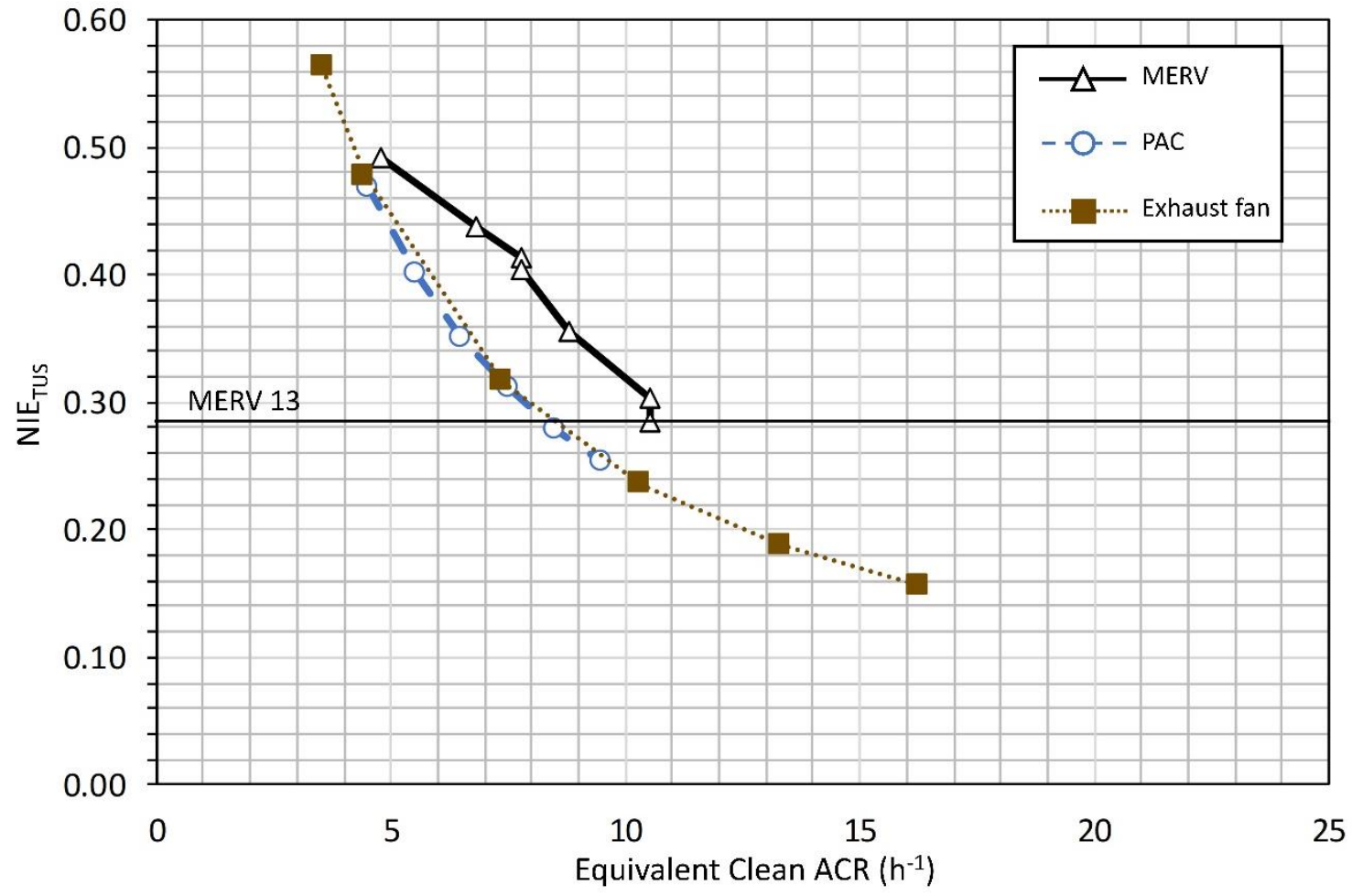

(b) Portable classroom

Figure 10. NIEtus with varying controls for (a) classroom and (b) portable classroom with masks 


\subsubsection{Effectiveness of controls WUS}

Figure 11 shows the effectiveness of three controls (filtration, PAC, and exhaust fan) with masks versus Equivalent Clean ACR for the classrooms with WUS. Each level of control and the

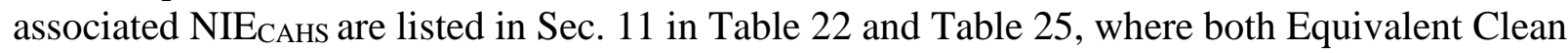
ACR and per-person outdoor air ventilation rates are listed.

The selected PAC capacities and exhaust fan flow rates resulted in similar Equivalent Clean ACR for each space type (Figure 11) up to $6 \mathrm{~h}^{-1}$. Up to this air change rate, the reduction in NIE wus was similar ( $2 \%$ differences on average). The relative reductions in the classrooms with WUS were greater compared with the reductions of the other HVAC systems because the base WUS had no mechanical OA and thus much higher IE. For a $4 \mathrm{~h}^{-1} \mathrm{PAC}$ in the classrooms, the NIEwus was reduced to an average of 0.08 . To achieve a similar NIEwUs, a $284 \mathrm{~L}^{-1} \mathrm{~s}^{-1}(600 \mathrm{cfm})$ exhaust fan would be required in both classrooms (average NIE $\mathrm{WUS}_{\mathbf{W}}=0.07$ ). 


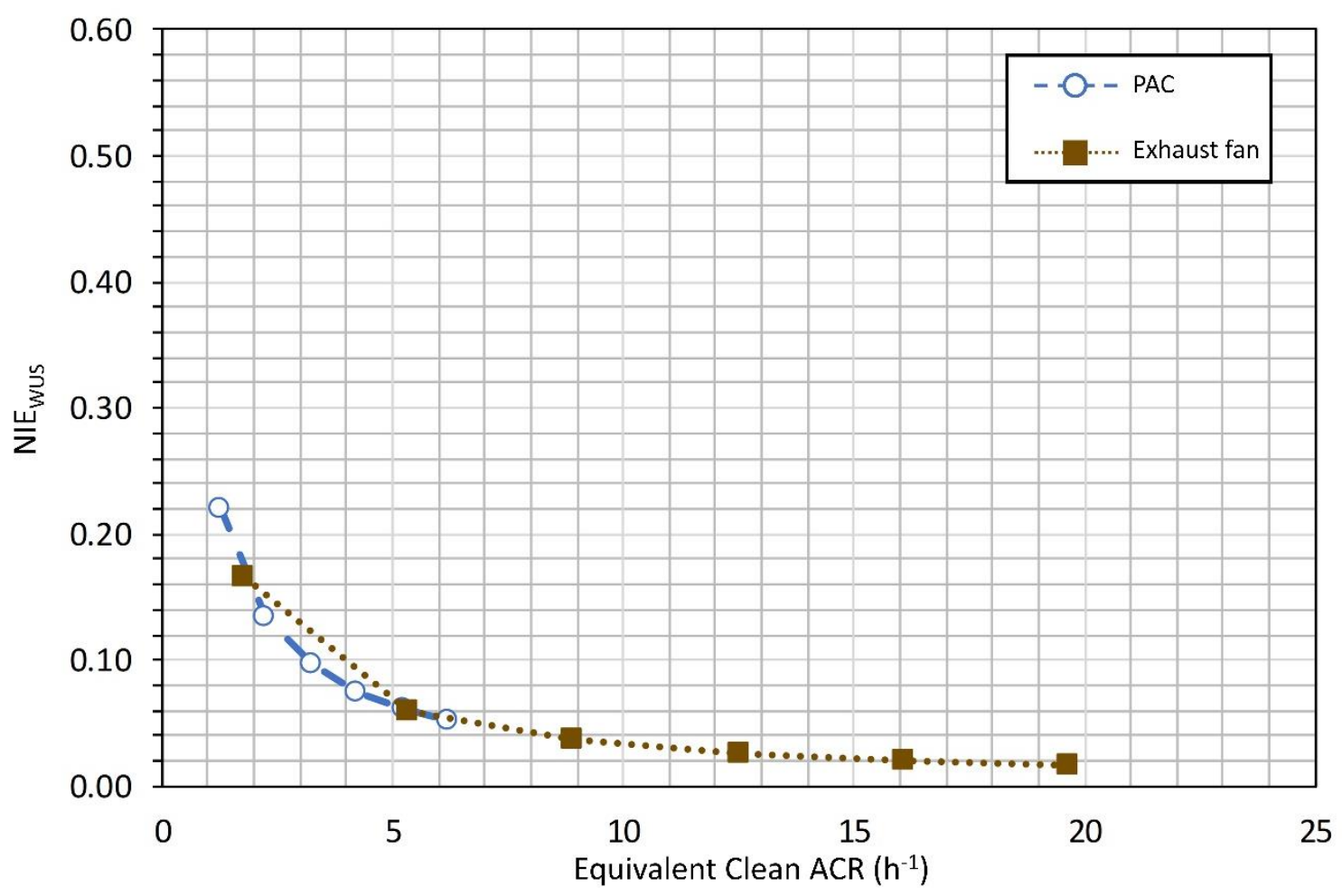

(a) Classroom

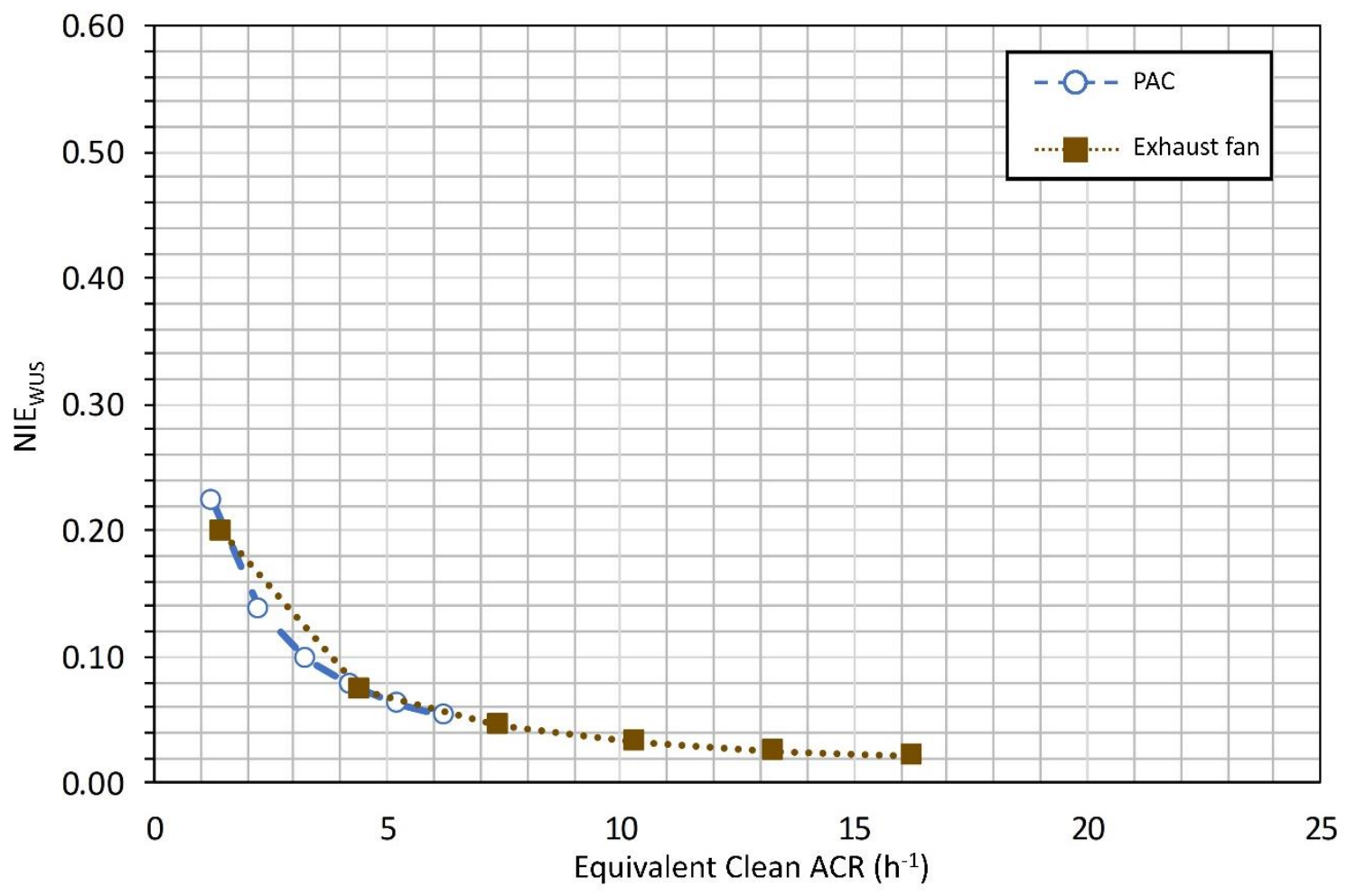

(b) Portable classroom

Figure 11. NIEwus with varying controls for (a) classroom and (b) portable classroom with masks 


\subsubsection{Factorial Analyses}

The results of the factorial analysis for the classroom are shown in Figure 12 for all HVAC types and in Figure 13 for the portable classroom. The DOAS and TUS had identical results. Masks alone with $25 \%$ inhalation and exhalation protection efficiencies (base level) yielded NIE HVAC of 0.56 for all HVAC systems and classrooms. With an inhalation protection efficiency of $90 \%$ and an exhalation efficiency of $85 \%$, the NIEHVAC was 0.01 . With an inhalation protection efficiency of $0 \%$ and an exhalation efficiency of $15 \%$, the NIEHVAC was 0.85 .

For the CAHS, DOAS, and TUS, MERV 13 filtration alone resulted in an average $\mathrm{NIE}_{\text {HVAC }}$ of 0.54 (0.74) across both classrooms. For the CAHS (Figure 12a and Figure 13a), $100 \%$ OA alone resulted in an average $\mathrm{NIE}_{\mathrm{CAHS}}$ of 0.57 (0.65), which was similar to the reduction using MERV 13 filtration.

The use of a 297 CADR PAC alone resulted in similar reductions for the CAHS, DOAS, and TUS. The average NIE $\mathrm{NVAC}_{\text {was }} 0.66$ (0.85). The PAC alone had the largest reduction for the WUS (NIEwUs of $0.21(0.45)$. The same size PAC reduced exposure more in the classroom due to its smaller volume compared to the portable classroom.

The $569 \mathrm{~L} \cdot \mathrm{s}^{-1}(1200 \mathrm{cfm})$ exhaust fan alone resulted in an average NIE HVAC of $0.40(0.43)$ for the CAHS, DOAS, and TUS in both classrooms. The exhaust fan had a larger reduction for the WUS (NIEwus of 0.05 (0.06) because it started with the highest base IE due to the lack of mechanical ventilation for this system. The same size exhaust fan reduced exposure more in the classroom due to its smaller volume relative to the portable classroom.

Of the individual controls simulated, the uncertainty in the effectiveness of the masks had the largest effects on NIE uncertainty as shown in Figure 12 (an uncertainty in NIE $\mathrm{HVAC}_{\mathrm{C}}$ of +0.29 when the (-) value mask was simulated and -0.55 when the (+) value mask was simulated). The uncertainty of implementation of the exhaust fans alone had the smallest effect (average uncertainty in NIEHVAC of +0.03 when the (-) value exhaust fan was simulated).

The average NIE ${ }_{\text {HVAC }}$ of each individual control (MERV 13 filtration, $100 \%$ OA, 297 CADR PAC, $569 \mathrm{~L} \cdot \mathrm{s}^{-1}(1200 \mathrm{cfm})$ exhaust fan) combined with the base masks was 0.28 across all HVAC systems and classrooms. With the (+) value masks, the average NIE HVAC was 0.01 . With the (-) value masks, the average NIE HVAC was 0.58 .

For all HVAC systems and classrooms, the combination of all controls resulted in an average NIE ${ }_{H V A C}$ of 0.11 with the base masks across all HVAC systems and classrooms. With the (+) value masks, the average NIE $\mathrm{HVAC}_{\mathrm{C}}$ with all controls was 0.003 . With the (-) value masks, the average NIEHVAC was 0.23 .

It should be noted that the reduction in exposure (and the uncertainty) reported here was dependent on the assumed effectiveness (and uncertainty) of each control. For example, this analysis showed that the exhaust fan had the smallest uncertainty because the (-) value was only $10 \%$ less than the (+) value. 


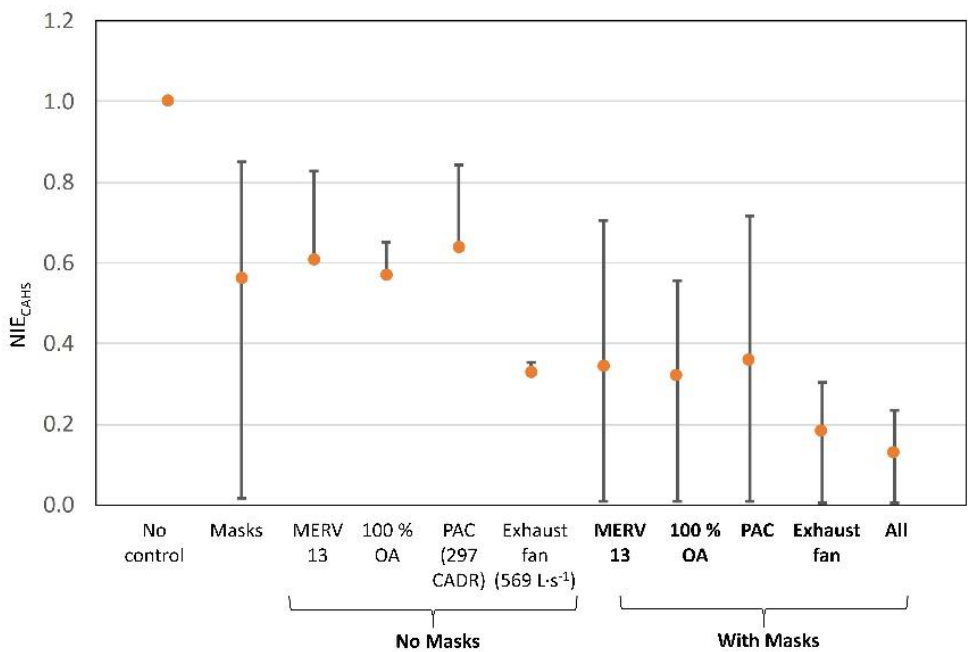

(a) CAHS

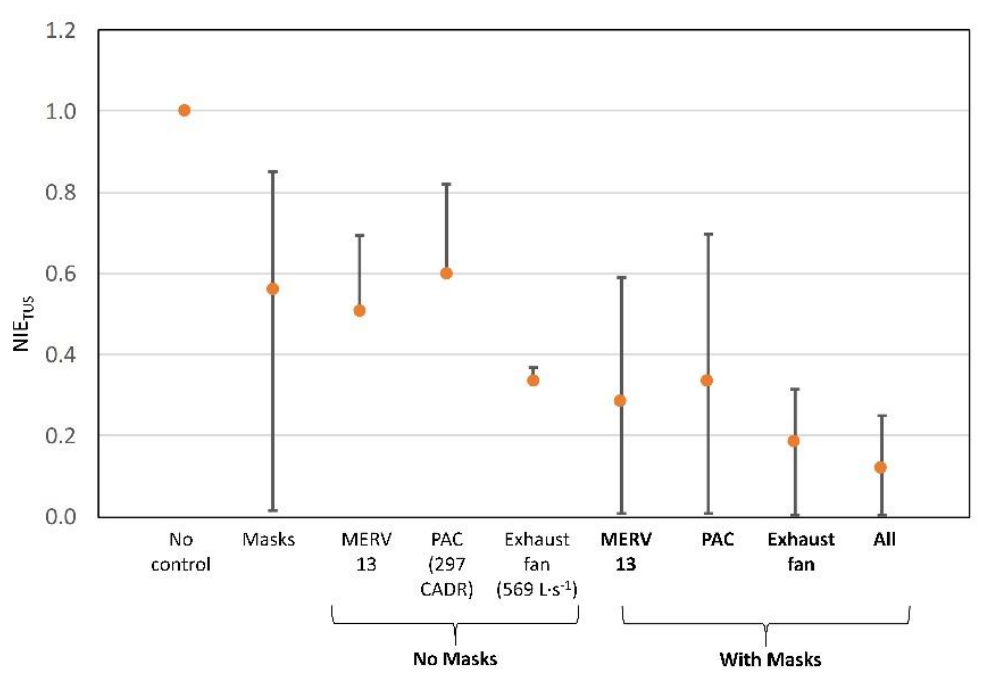

(c) TUS

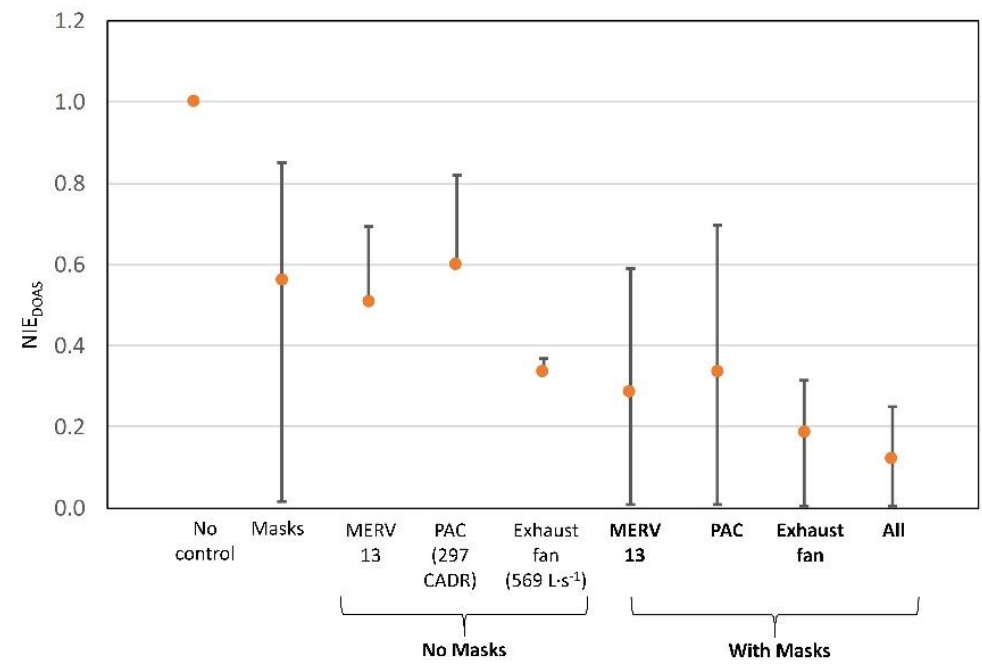

(b) DOAS

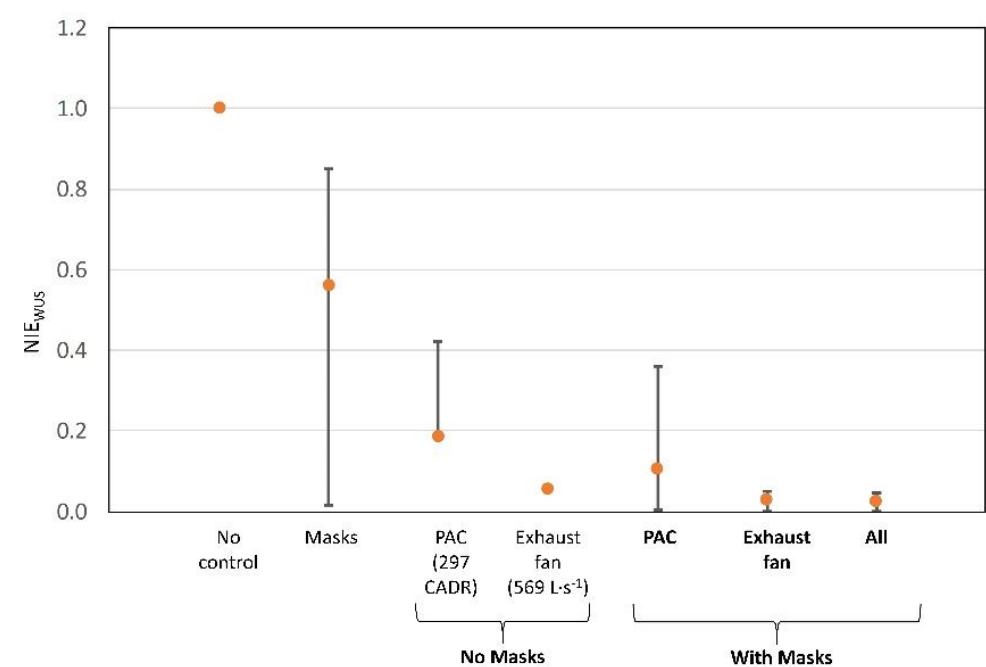

(d) WUS

Figure 12. Factorial analysis for classroom (all HVAC system types). For all controls except masks, solid circles show results at $(+)$ value, and top of the bar shows results at (-) value. For the masks, the base value is a solid circle, (+) value at the bottom, and (-) value at the top of the bar. 


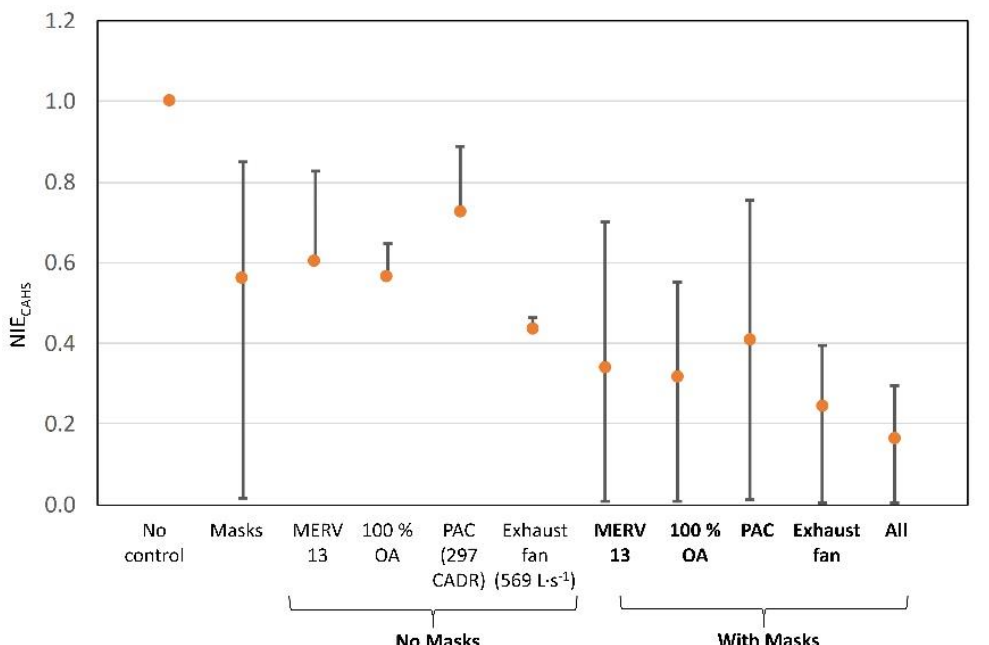

(a) CAHS

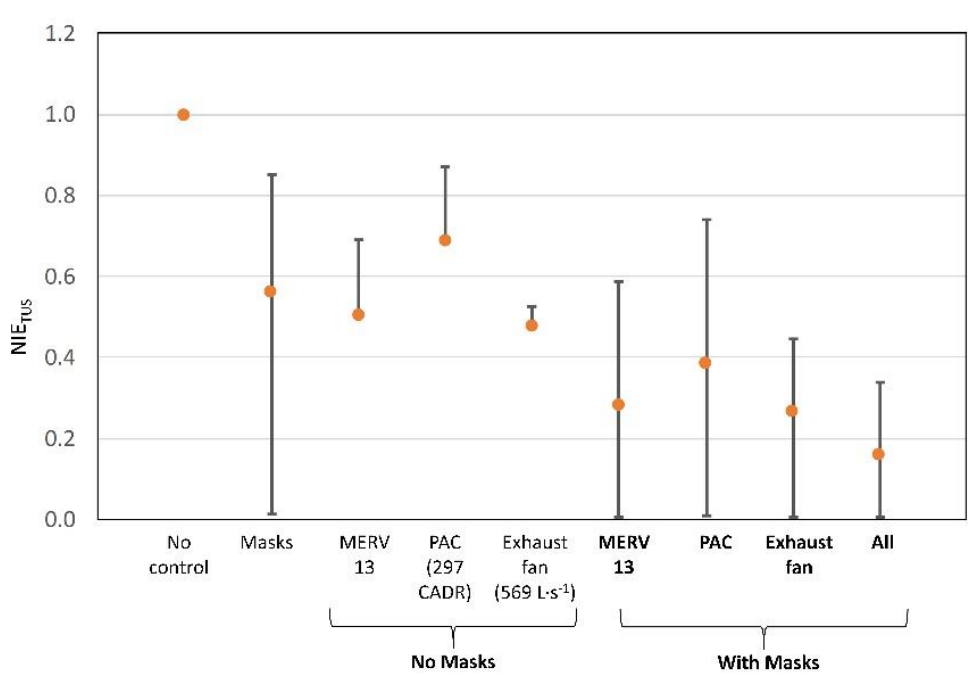

(c) TUS

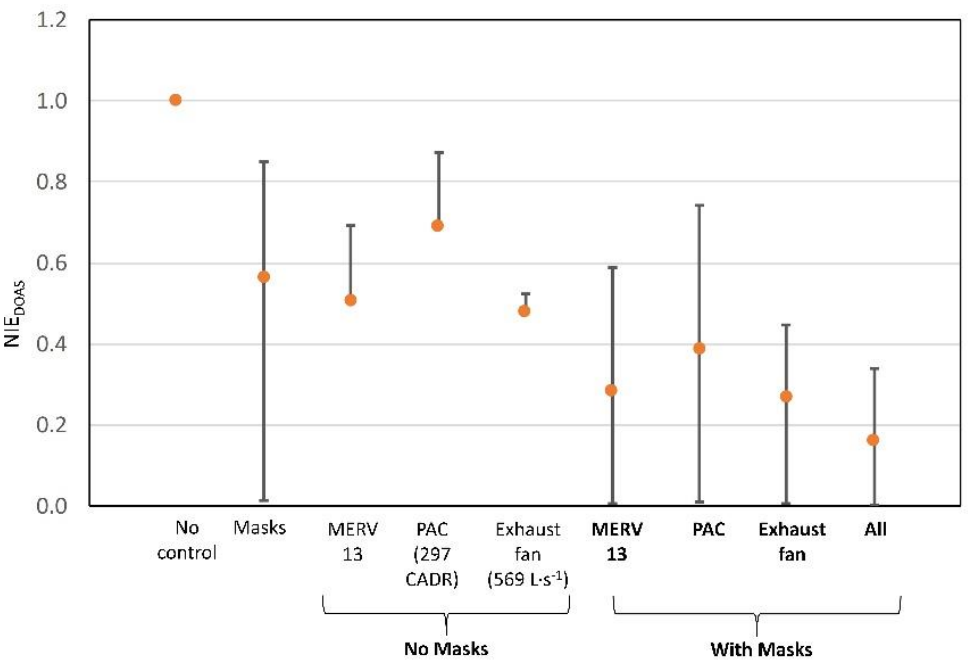

(b) DOAS

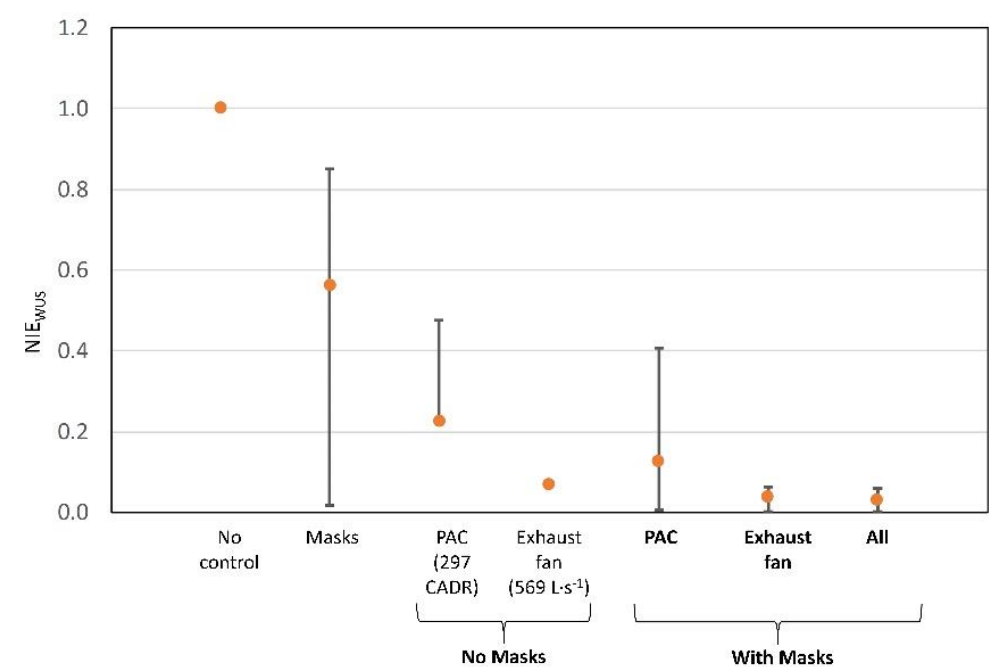

(d) WUS

Figure 13. Factorial analysis for portable classroom (all HVAC system types). For all controls except masks, solid circles show results at (+) value, and top of the bar shows results at (-) value. For the masks, the base value is a solid circle, (+) value at the bottom, and (-) value at the top of the bar. 


\subsection{Assembly room}

\subsubsection{Base Cases}

Figure 14 provides the IE of the base cases (no controls) for the assembly room and for each HVAC system type. These values are provided to point out that the base operation of the HVAC system type affected the base exposure. The base IE for the WUS was 20 times higher than for other HVAC systems. However, these values are not a direct metric of infection risk.

The results for the DOAS and TUS are similar because both systems have the same air balance as discussed in Sec. 6.3 and listed in Table 4. The IEs for the assembly room was on average $3 \%$ of the IE in the classroom. This was presumably because 1) the occupied interval for the receptor in the assembly room was only one hour compared to six hours in the classrooms and 2) there was only one infector simulated to be present in the assembly room, which had a volume that was eight to ten times larger than the classrooms and only represented $<1 \%$ of the full capacity. However, if the proportion of infectors to occupants was the same as that in the classroom (6\%) or portable classroom (3\%), the IE values would be impacted.

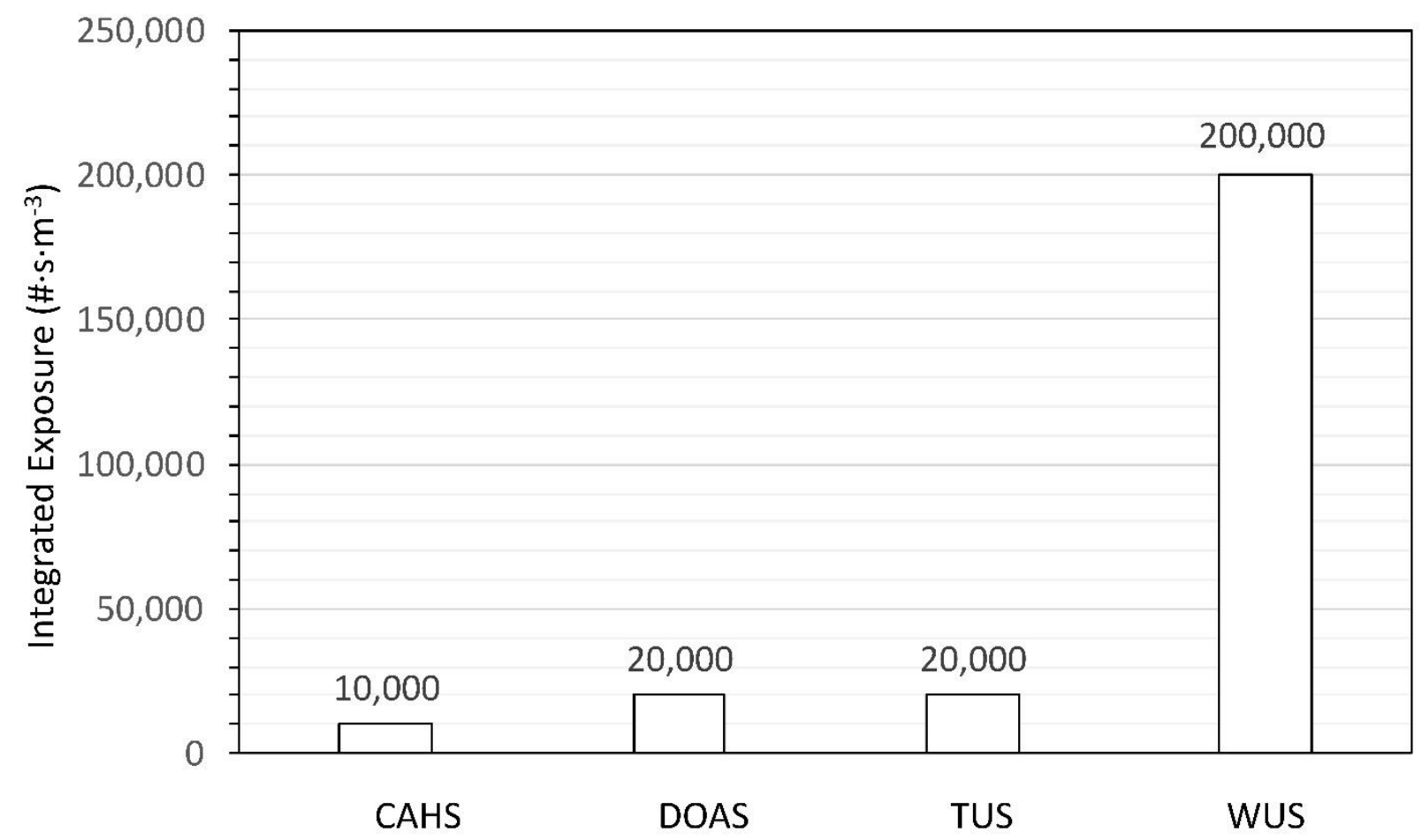

Figure 14. Base IE for assembly room 
Figure 15 shows the IE normalized to the results of the CAHS (NIE CAHS ), which had the lowest IE of the HVAC system types simulated. The effect of not having any mechanical OA ventilation is apparent in the WUS.

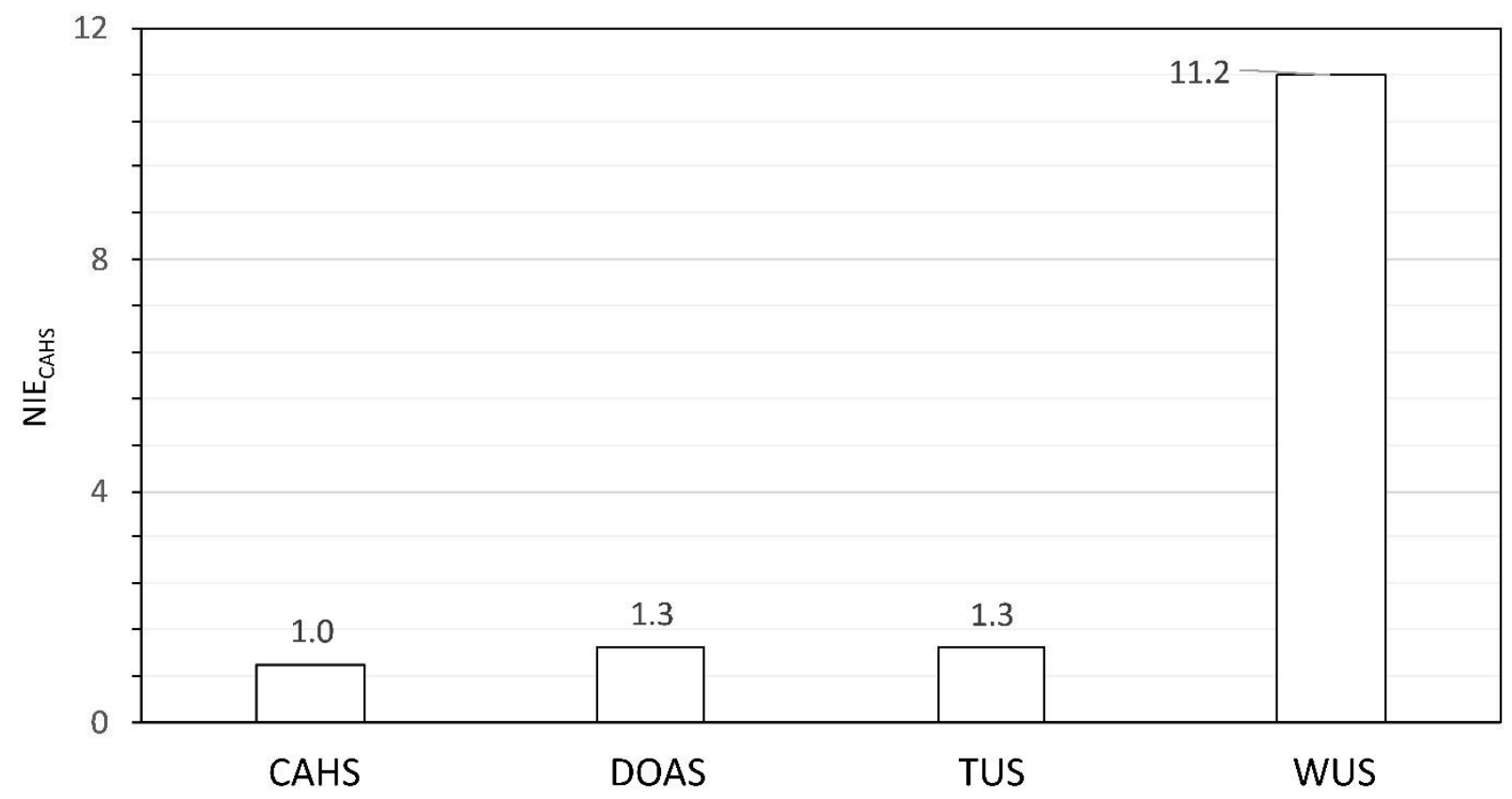

Figure 15. NIE ${ }_{\text {CAHS }}$ for HVAC system types (assembly room)

The NIE $\mathrm{NAHS}_{\text {for }}$ fore DOAS and TUS without any controls were both 1.3 for the assembly room, meaning that the DOAS and TUS had an exposure that was $30 \%$ greater than the exposure as a result of using the CAHS.

\subsubsection{Effectiveness of controls CAHS}

Figure 16 shows the effectiveness of four controls (filtration, OAF, PAC, and exhaust fan) with masks versus Equivalent Clean ACR for the assembly room with CAHS. Each level of control and the associated NIE ${ }_{\text {CAHS }}$ are listed in Sec. 11 in Table 26, where both Equivalent Clean ACR and per-person outdoor air ventilation rates are listed. 
The solid horizontal line indicates the NIE $E_{C A H S}$ at MERV 13 filtration. To achieve reductions equal to (or greater than) MERV 13 filtration $\left(\mathrm{NIE}_{\mathrm{CAHS}}=0.30\right)$ using other simulated controls individually would require:

- $\mathrm{OAF}$ of $83 \%^{5}$

or:

- An exhaust fan flow of more than $3982 \mathrm{~L} \cdot \mathrm{s}^{-1}(8400 \mathrm{cfm})$ (or Equivalent Clean ACR > $7.8 \mathrm{~h}^{-1}$ )

Unlike in the classrooms, the simulated PAC capacities in the assembly room were not large enough to deliver NIE ${ }_{\text {CAHS }}$ equivalent to MERV 13 filtration. Figure 16 shows that the Equivalent Clean ACR resulting from a single PAC was about $50 \%$ lower than that delivered by a single exhaust fan.

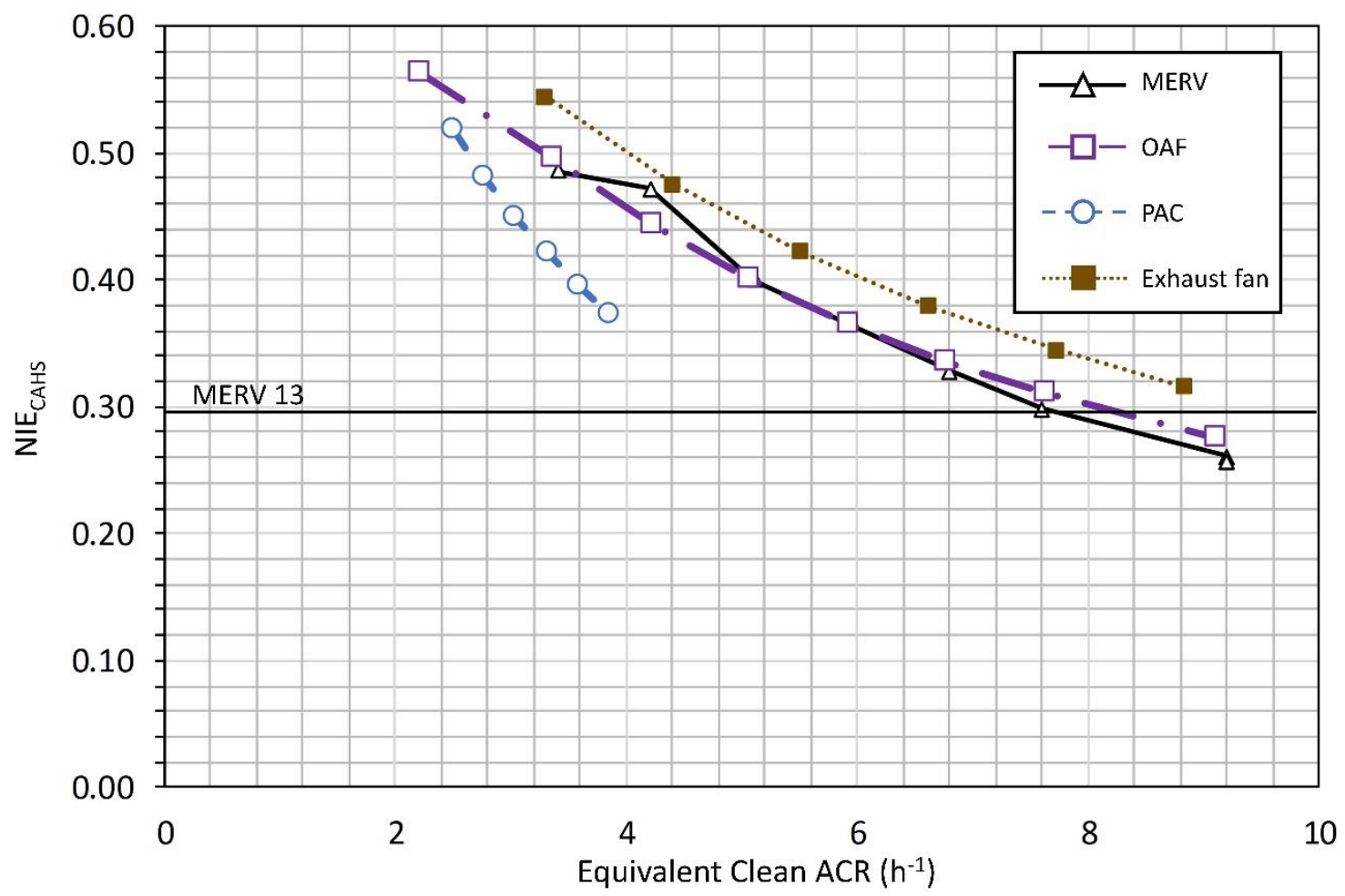

Figure 16. NIEcAHs with varying controls for assembly room with masks

\footnotetext{
5 The base OAF of the CAHS in the assembly room is 0.23 .
} 


\subsubsection{Effectiveness of controls DOAS}

Figure 17 shows the effectiveness of three controls (filtration, PAC, and exhaust fan) with masks versus Equivalent Clean ACR for the assembly room with DOAS. Each level of control and the associated NIE CAHS are listed in Sec. 11 in Table 27, where both Equivalent Clean ACR and perperson outdoor air ventilation rates are listed.

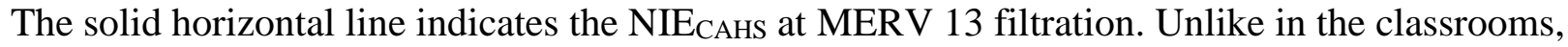
the simulated PAC and exhaust fan capacities in the assembly room would not be able to deliver NIE that was equivalent to MERV 13 filtration $\left(\mathrm{NIE}_{\mathrm{DOAS}}=0.23\right)$.

Even though Figure 17 shows that the two lowest exhaust fan capacities delivered different Equivalent Clean ACRs, there was very little reduction in NIEDOAS until the third-capacity value. This was because the air balance in the assembly room was $1142 \mathrm{~L} \cdot \mathrm{s}^{-1}$ and each incremental increase in exhaust fan capacity was $569 \mathrm{~L} \cdot \mathrm{s}^{-1}$, so more than two exhaust fans would be required to reduce the NIEDOAS.

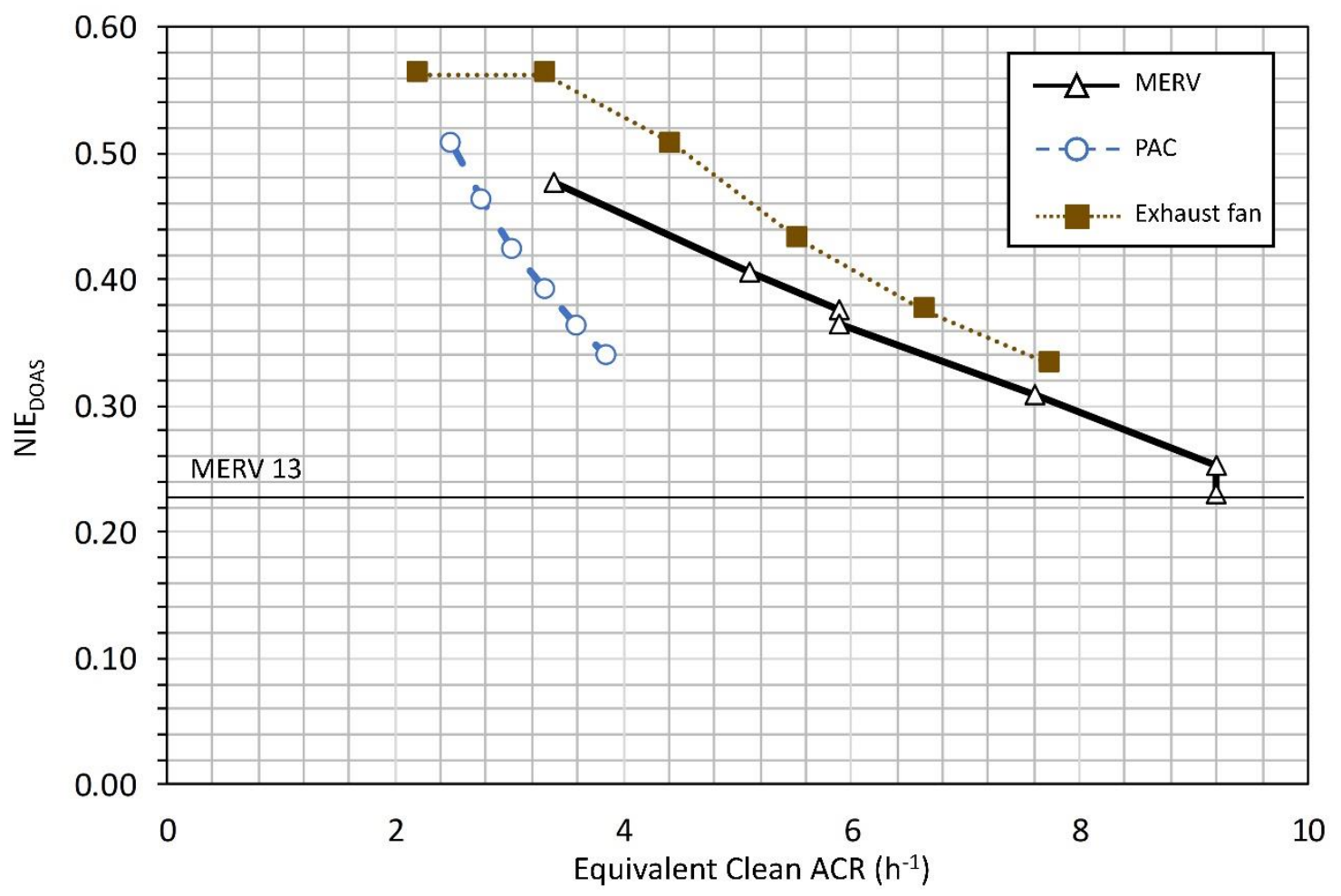

Figure 17. NIEdoAs varying controls for assembly room with masks 


\subsubsection{Effectiveness of controls TUS}

Figure 18 shows the effectiveness of three controls (filtration, PAC, and exhaust fan) with masks versus Equivalent Clean ACR for the assembly room with TUS. Each level of control and the associated NIE CAHS are listed in Sec. 11 in Table 27, where both Equivalent Clean ACR and perperson outdoor air ventilation rates are listed.

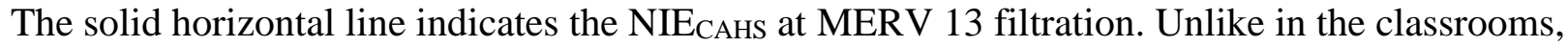
the simulated PAC and exhaust fan capacities in the assembly room would not be able to reduce the $\mathrm{NIE}_{\mathrm{TUS}}$ to a level equivalent to MERV 13 filtration $\left(\mathrm{NIE}_{\mathrm{TUS}}=0.23\right)$.

Even though Figure 18 shows that the lowest two simulated exhaust fan capacities delivered different Equivalent Clean ACRs, there was very little reduction in NIETus until the thirdsimulated capacity value. This was because the air balance in the assembly room was $1142 \mathrm{~L} \cdot \mathrm{s}^{-1}$ and each incremental increase in exhaust fan capacity was $569 \mathrm{~L} \cdot \mathrm{s}^{-1}$, so more than two exhaust fans would be required to reduce the NIETUs.

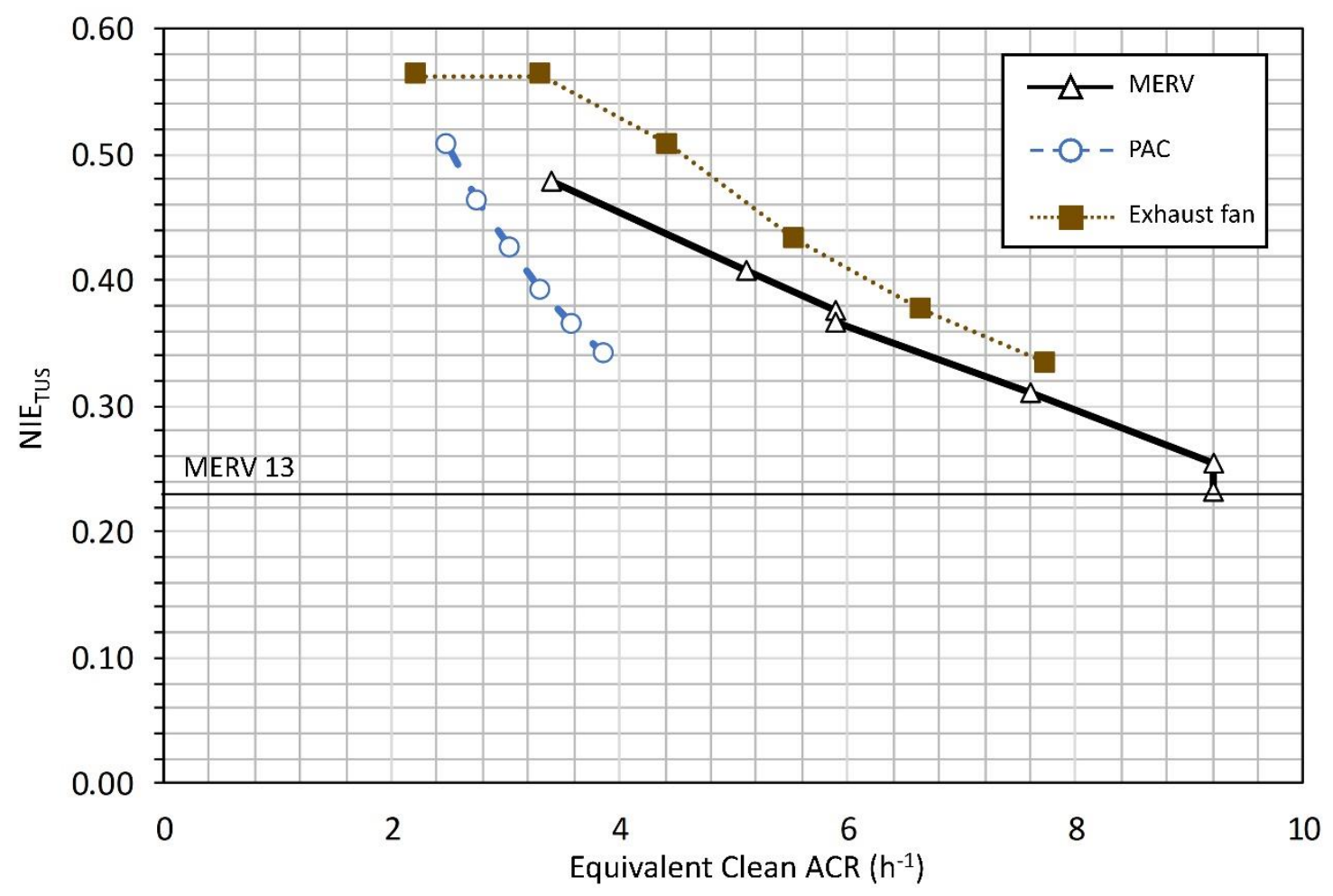

Figure 18. NIETus varying controls for assembly room with masks 


\subsubsection{Effectiveness of controls WUS}

Figure 19 shows the effectiveness of two controls (PAC and exhaust fan) with masks versus Equivalent Clean ACR for the assembly room with WUS. Each level of control and the

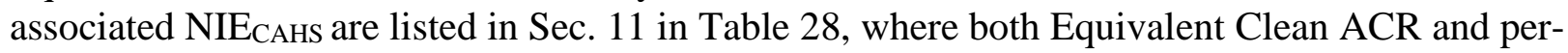
person outdoor air ventilation rates are listed.

The relative reduction in the assembly room with WUS were greater compared with the reductions of the other HVAC systems because the base WUS cases had no mechanical OA and thus much higher IEs.

Over the selected capacities, the PAC resulted in an average NIEwUs of 0.16 and the exhaust fan resulted in an average NIEwus of 0.09 .

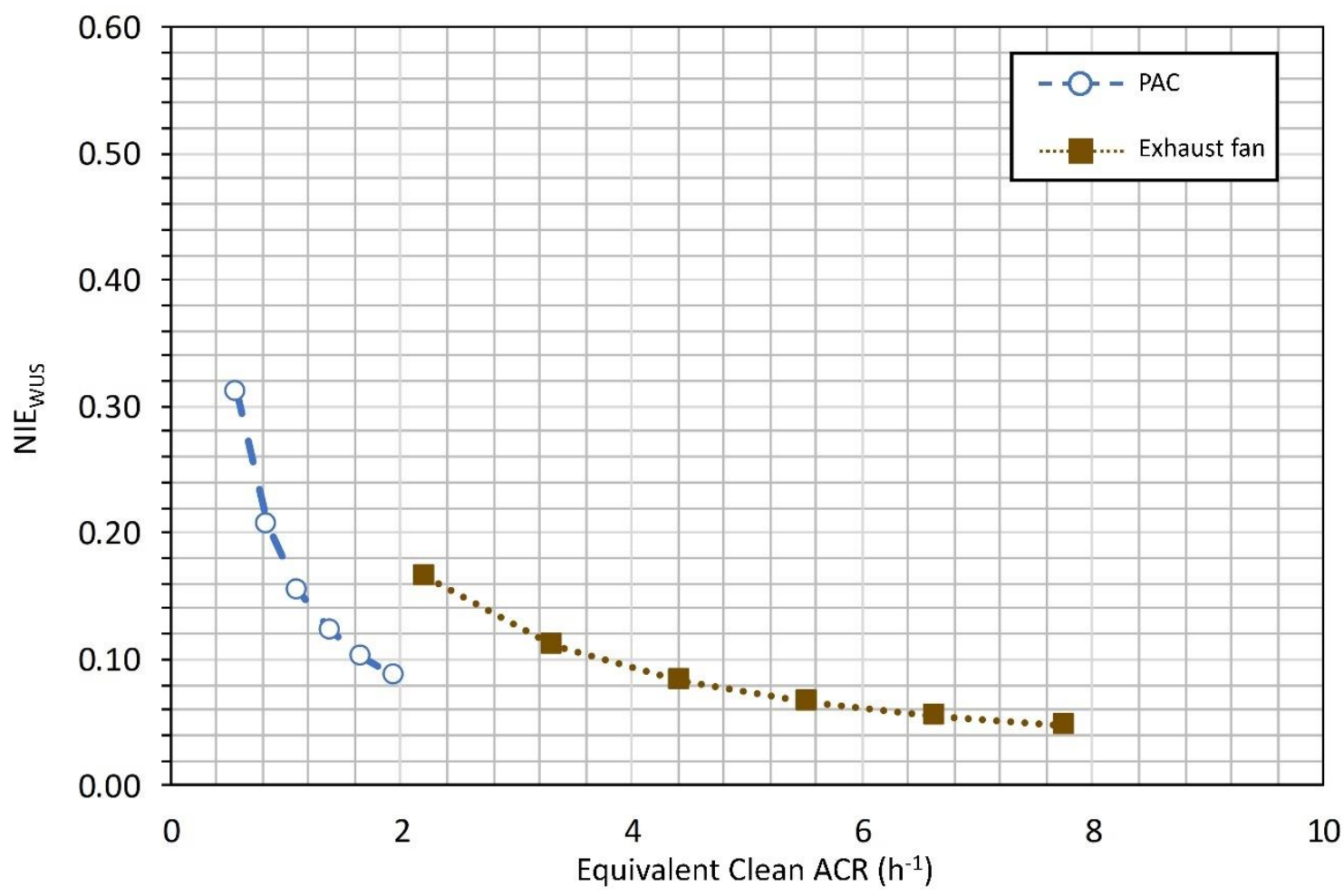

Figure 19. NIEwus varying controls for assembly room with masks 


\subsubsection{Factorial Analyses}

The results of the factorial analysis for the assembly room are shown in Figure 20 for all HVAC types. Masks alone with $25 \%$ inhalation and exhalation protection efficiencies (base level) yielded $\mathrm{NIE}_{\mathrm{HVAC}}$ of 0.56 for all HVAC systems in the assembly room. With an inhalation protection efficiency of $90 \%$ and an exhalation efficiency of $85 \%$, the NIE $\mathrm{HVAC}_{\mathrm{C}}$ was 0.02 . With an inhalation protection efficiency of $0 \%$ and an exhalation efficiency of $15 \%$, the NIE $\mathrm{HVAC}_{\mathrm{C}}$ was 0.85 .

For the CAHS, DOAS, and TUS, MERV 13 filtration alone resulted in an average NIEHVAC of $0.45(0.66)$ in the assembly room. For the CAHS (Figure 20a), $100 \%$ OA alone resulted in an average $\mathrm{NIE}_{\mathrm{C}}$ of $0.49(0.56)$ which was similar to the reduction using MERV 13 filtration.

The use of a 297 CADR PAC alone resulted in similar reductions for the CAHS, DOAS, and TUS. The average NIE $\mathrm{HVAC}_{\text {AC }} 0.93(0.98)$. This was approximately $27 \%$ lower than in the classrooms because the assembly room had a larger volume.

The PAC alone had the largest reduction for the WUS in the assembly room (NIEwUs of 0.63 (0.84). This reduction was approximately $42 \%$ lower than in the classrooms because the assembly room had a larger volume.

The $569 \mathrm{~L} \cdot \mathrm{s}^{-1}(1200 \mathrm{cfm})$ exhaust fan did not reduce the NIEHVAC for the CAHS, DOAS, and TUS because the size of exhaust fan was not large enough to overcome the air balance of $591 \mathrm{~L} \cdot \mathrm{s}^{-1}$ in the CAHS and $1142 \mathrm{~L} \cdot \mathrm{s}^{-1}$ in the DOAS and TUS (Sec. 6.3 and Table 4). The exhaust fan reduced the NIEwus for the WUS because the air balance for this HVAC system was $154 \mathrm{~L} \cdot \mathrm{s}^{-1}$. The NIEwus was $0.34(0.38)$.

Of the individual controls simulated, the uncertainty in the effectiveness of the masks had the largest effects on NIE $\mathrm{HVAC}_{\mathrm{C}}$ uncertainty as shown in Figure 20 (an uncertainty in $\mathrm{NIE}_{\mathrm{HVAC}}$ of +0.29 when the (-) value mask was simulated and -0.55 when the (+) value mask was simulated). The uncertainty of implementation of the exhaust fans alone had the smallest effect (average uncertainty in NIE of +0.01 when the (-) value exhaust fan was simulated).

The average NIEHVAC of each individual control (MERV 13 filtration, $100 \%$ OA, 297 CADR PAC, $569 \mathrm{~L} \cdot \mathrm{s}^{-1}(1200 \mathrm{cfm})$ exhaust fan) combined with the base masks was 0.37 across all HVAC systems in the assembly room. With the (+) value masks, the average NIEHVAC was 0.01 . With the (-) value masks, the average NIEHVAC was 0.64 .

For all HVAC systems in the assembly room, the combination of all controls resulted in an average NIE $\mathrm{HVAC}_{\text {AC }} 0.22$ with the base masks across all HVAC systems for the assembly room. With the (+) value masks, the average NIE $\mathrm{HVAC}_{\text {aC }}$ with all controls was 0.01 . With the (-) value masks, the average NIEHVAC was 0.44 . 


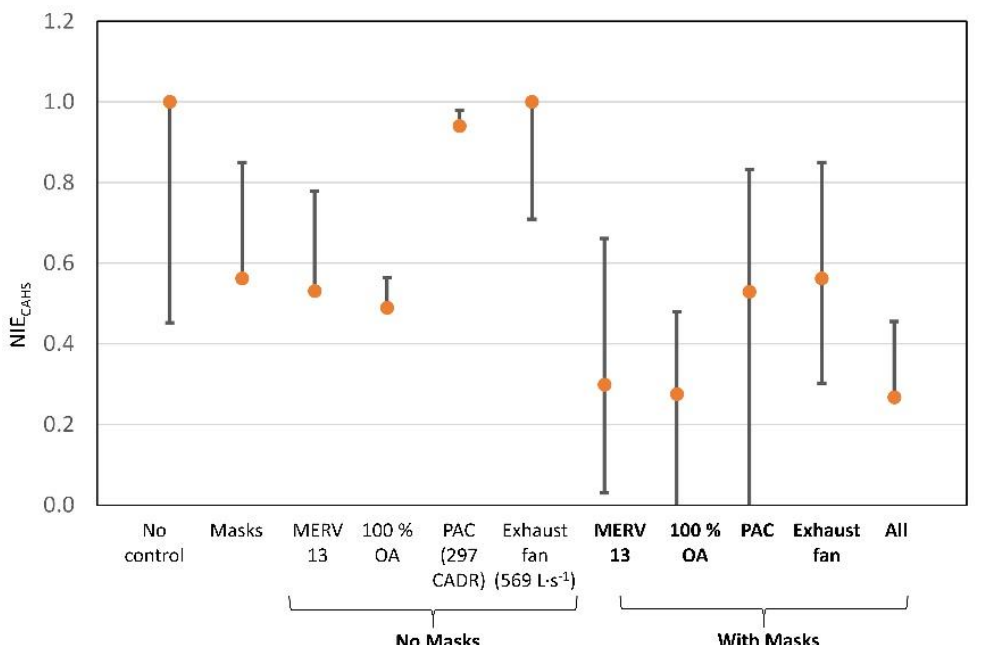

(a) CAHS

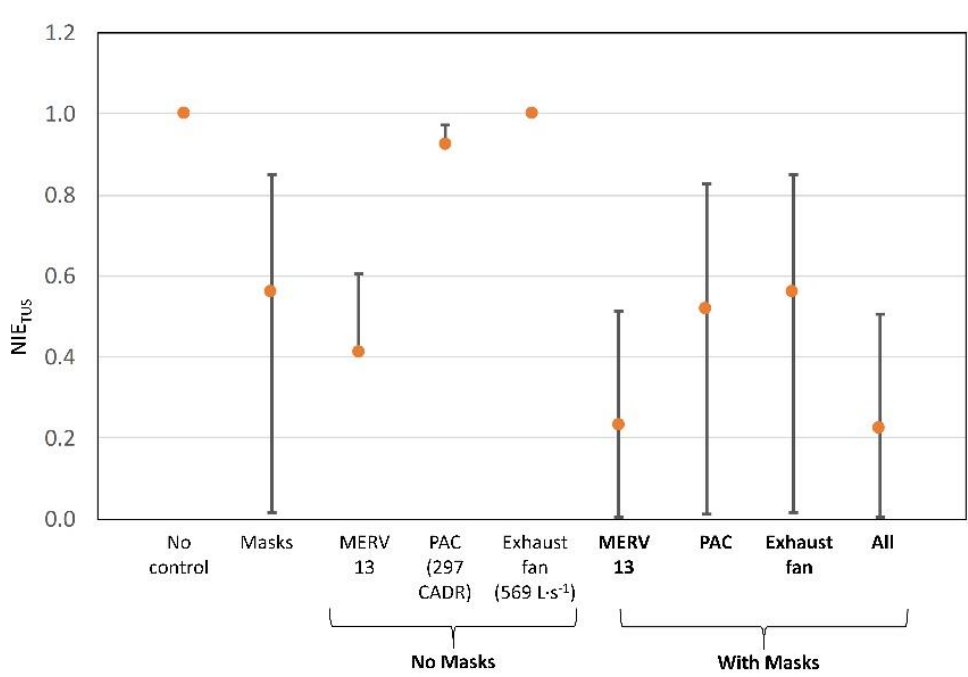

(c) TUS

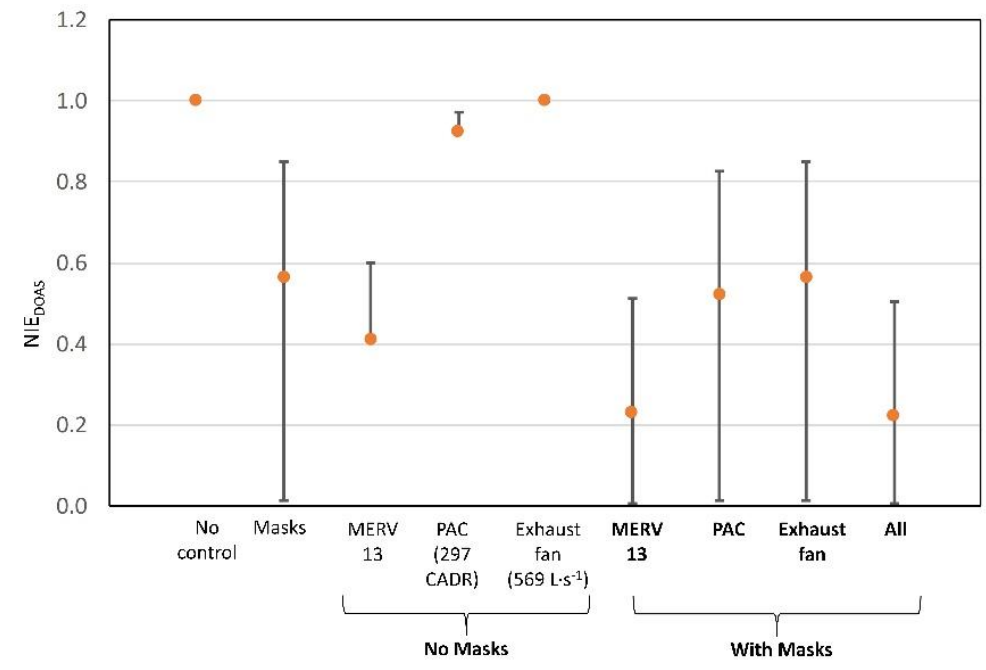

(b) DOAS

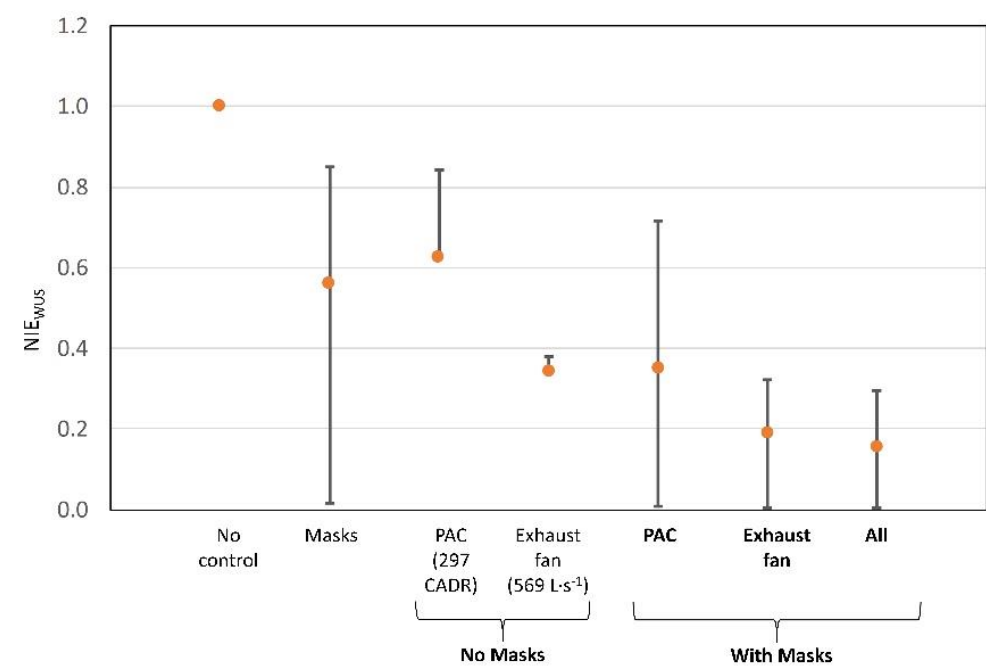

(d) WUS

Figure 20. Factorial analysis for assembly room (all HVAC system types). For all controls except masks, solid circles show results at (+) value, and top of the bar shows results at $(-)$ value. For the masks, the base value is a solid circle, (+) value at the bottom, and (-) value at the top of the bar. 


\section{Results Summary}

Table 18 and Table 19 summarize the NIEHVAC at selected levels for the classrooms (average for both classroom and portable classroom) and the assembly room, respectively. These values assumed the controls are performing at the level (+) discussed in the factorial analysis (Sec. 9). While these values are not a direct metric of infection risk, these results may be useful for understanding effectiveness of individual controls (without and with masks). In general, controls with masks resulted in lower NIEs than controls without masks.

MERV 13 filtration with the base masks in all spaces reduced NIEHVAC to an average value of 0.28. A single 297 CADR PAC with the base masks in all spaces reduced NIE HVAC $_{\text {to }}$ an average of 0.39 . A $569 \mathrm{~L} \cdot \mathrm{s}^{-1}(1200 \mathrm{cfm})$ exhaust fan with the base masks in all spaces reduced NIE $\mathrm{HVAC}_{\mathrm{H}}$

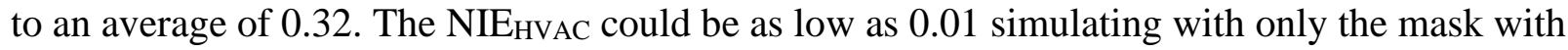
the higher protection efficiencies. The NIE $E_{H V A C}$ could be as high as 0.85 simulating only with the mask with the lower protection efficiencies.

The data in Figure 8 to Figure 11 for the classroom is summarized in Table 20 to Table 22. For the portable classrooms in these figures, the data is summarized in Table 23 to Table 25 . The data in Figure 16 to Figure 19 for the assembly is summarized in Table 26 to Table 28. The controls (filtration, OAF, PAC, and exhaust fan) and their respective simulated values are listed by row. The NIEHVAC is then listed by HVAC system type across the top (CAHS, DOAS/TUS, and WUS). The values for DOAS and TUS are listed together because they were the same. These values are not a direct metric of infection risk, but they may be useful in for understanding the effectiveness of individual controls with masks. 
Table 18. Summary of NIEHvac with controls at selected levels (classrooms)

\begin{tabular}{|c|c|c|c|c|c|c|c|c|c|}
\hline \multicolumn{3}{|c|}{ Average NIEhvac across classrooms } & \multicolumn{3}{|c|}{ No masks } & \multicolumn{4}{|c|}{$\begin{array}{l}\text { With base masks ( } 25 \% \text { inhalation and } \\
\text { exhalation protection efficiencies) }\end{array}$} \\
\hline $\begin{array}{l}\text { HVAC } \\
\text { system }\end{array}$ & $\begin{array}{l}\text { No } \\
\text { controls }\end{array}$ & $\begin{array}{l}\text { Masks } \\
\text { alone }\end{array}$ & MERV 13 & $\begin{array}{c}297 \\
\text { CADR } \\
\text { PAC }\end{array}$ & $\begin{array}{c}\text { Exhaust } \\
\text { fan } \\
(1200 \mathrm{cfm})\end{array}$ & $\begin{array}{l}\text { MERV } \\
13\end{array}$ & $\begin{array}{c}297 \\
\text { CADR } \\
\text { PAC }\end{array}$ & $\begin{array}{c}\text { Exhaust } \\
\text { fan } \\
(1200 \mathrm{cfm}) \\
\end{array}$ & $\begin{array}{c}\text { All } \\
\text { controls }\end{array}$ \\
\hline CAHS & 1.0 & 0.56 & 0.61 & 0.68 & 0.38 & 0.34 & 0.38 & 0.21 & 0.15 \\
\hline DOAS & 1.0 & 0.56 & 0.51 & 0.64 & 0.41 & 0.29 & 0.36 & 0.23 & 0.14 \\
\hline TUS & 1.0 & 0.56 & 0.51 & 0.64 & 0.41 & 0.29 & 0.36 & 0.23 & 0.14 \\
\hline WUS & 1.0 & 0.56 & N/A & 0.21 & 0.06 & N/A & 0.12 & 0.03 & 0.03 \\
\hline
\end{tabular}

a The NIE $E_{\text {HVAC }}$ could be as low as 0.004 simulating with the mask with the higher protection efficiencies. The NIE HVAC $_{\text {could be as }}$ high as 0.64 simulating with the mask with the lower protection efficiencies.

Table 19. Summary of NIEHvac with controls at selected levels (assembly room)

\begin{tabular}{|c|c|c|c|c|c|c|c|c|c|}
\hline \multicolumn{3}{|c|}{ Average NIEHVAC assembly room } & \multicolumn{3}{|c|}{ No masks } & \multicolumn{4}{|c|}{$\begin{array}{l}\text { With base masks (25\% inhalation and } \\
\text { exhalation protection efficiencies) }{ }^{a}\end{array}$} \\
\hline $\begin{array}{l}\text { HVAC } \\
\text { system }\end{array}$ & $\begin{array}{c}\text { No } \\
\text { controls }\end{array}$ & Masks alone & $\begin{array}{l}\text { MERV } \\
13\end{array}$ & $\begin{array}{c}297 \\
\text { CADR } \\
\text { PAC }\end{array}$ & $\begin{array}{l}\text { Exhaust fan } \\
(1200 \mathrm{cfm})\end{array}$ & $\begin{array}{l}\text { MERV } \\
13\end{array}$ & $\begin{array}{c}297 \\
\text { CADR } \\
\text { PAC }\end{array}$ & $\begin{array}{l}\text { Exhaust fan } \\
(1200 \mathrm{cfm})\end{array}$ & $\begin{array}{c}\text { All } \\
\text { controls }\end{array}$ \\
\hline CAHS & 1.0 & 0.56 & 0.53 & 0.94 & 1.00 & 0.30 & 0.53 & 0.56 & 0.27 \\
\hline DOAS & 1.0 & 0.56 & 0.41 & 0.92 & 1.00 & 0.23 & 0.52 & 0.56 & 0.22 \\
\hline TUS & 1.0 & 0.56 & 0.41 & 0.92 & 1.00 & 0.23 & 0.52 & 0.56 & 0.22 \\
\hline WUS & 1.0 & 0.56 & N/A & 0.63 & 0.34 & N/A & 0.35 & 0.19 & 0.15 \\
\hline
\end{tabular}

${ }^{a}$ The NIE ${ }_{H V A C}$ could be as low as 0.01 simulating with the mask with the higher protection efficiencies. The NIE ${ }_{H V A C}$ could be as high as 0.80 simulating with the mask with the lower protection efficiencies. 
Table 20. Summary of NIE

\begin{tabular}{|c|c|c|c|c|c|}
\hline \multicolumn{2}{|c|}{ Controls at various levels } & \multirow{2}{*}{$\begin{array}{c}\begin{array}{c}\text { Equivalent } \\
\text { Clean ACR } \\
\left(\mathbf{h}^{-1}\right)\end{array} \\
2.9\end{array}$} & \multirow{2}{*}{ 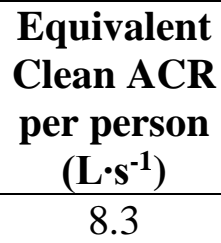 } & \multirow{2}{*}{$\begin{array}{c}\begin{array}{c}\text { Equivalent } \\
\text { Clean ACR } \\
\text { per person } \\
\text { (cfm) }\end{array} \\
17.5\end{array}$} & \multirow{2}{*}{$\begin{array}{c}\begin{array}{c}\text { Classroom } \\
\text { NIE }_{\text {CAHS }}\end{array} \\
0.56\end{array}$} \\
\hline Filtration & Base: 8 & & & & \\
\hline \multirow{7}{*}{$\begin{array}{l}\text { level } \\
\text { (MERV } \\
\text { rating,-) }\end{array}$} & 9 & 3.9 & 11.2 & 23.8 & 0.50 \\
\hline & 10 & 3.9 & 11.2 & 23.8 & 0.49 \\
\hline & 11 & 5.5 & 15.8 & 33.5 & 0.43 \\
\hline & 12 & 7.1 & 20.4 & 43.3 & 0.36 \\
\hline & 13 & 7.8 & 22.4 & 47.6 & 0.34 \\
\hline & 14 & 8.5 & 24.5 & 51.8 & 0.30 \\
\hline & 15 & 8.5 & 24.5 & 51.8 & 0.30 \\
\hline \multirow{8}{*}{$\begin{array}{l}\text { Outdoor } \\
\text { air } \\
\text { fraction } \\
\text { (OAF,-) }\end{array}$} & Base: 0.33 & 2.9 & 8.3 & 17.5 & 0.56 \\
\hline & 0.43 & 3.9 & 11.4 & 24.1 & 0.51 \\
\hline & 0.53 & 4.7 & 13.6 & 28.8 & 0.46 \\
\hline & 0.63 & 5.5 & 15.8 & 33.6 & 0.42 \\
\hline & 0.73 & 6.3 & 18.1 & 38.3 & 0.39 \\
\hline & 0.83 & 7.1 & 20.3 & 43.0 & 0.36 \\
\hline & 0.93 & 7.8 & 22.6 & 47.8 & 0.33 \\
\hline & 1.00 & 8.4 & 24.1 & 51.1 & 0.32 \\
\hline \multirow{7}{*}{\begin{tabular}{|l} 
PAC \\
Maximum \\
Airflow \\
Rate, \\
$\mathrm{L} \cdot \mathrm{s}^{-1}$ \\
$(\mathrm{CADR})$
\end{tabular}} & Base: 0 & 2.9 & 8.3 & 17.5 & 0.56 \\
\hline & $53(111)$ & 3.9 & 11.1 & 23.5 & 0.46 \\
\hline & $106(222)$ & 4.8 & 14.0 & 29.6 & 0.40 \\
\hline & $159(334)$ & 5.8 & 16.8 & 35.6 & 0.35 \\
\hline & $212(445)$ & 6.8 & 19.6 & 41.6 & 0.31 \\
\hline & $265(556)$ & 7.8 & 22.5 & 47.7 & 0.27 \\
\hline & $318(667)$ & 8.8 & 25.3 & 53.7 & 0.25 \\
\hline \multirow{7}{*}{$\begin{array}{l}\text { Exhaust } \\
\text { Fan, } \\
\mathrm{L} \cdot \mathrm{s}^{-1}(\mathrm{cfm})\end{array}$} & Base: 0 & 2.9 & 8.3 & 17.5 & 0.56 \\
\hline & $95(200)$ & 3.6 & 10.3 & 21.8 & 0.49 \\
\hline & $284(600)$ & 7.2 & 20.6 & 43.7 & 0.29 \\
\hline & $474(1000)$ & 10.7 & 30.9 & 65.5 & 0.21 \\
\hline & $664(1400)$ & 14.3 & 41.2 & 87.3 & 0.16 \\
\hline & $853(1800)$ & 17.9 & 51.5 & 109.1 & 0.13 \\
\hline & $1043(2200)$ & 21.5 & 61.8 & 130.9 & 0.11 \\
\hline
\end{tabular}


Table 21. Summary of NIEDoAs/Tus with controls at various levels (classroom with base masks)

\begin{tabular}{|c|c|c|c|c|c|}
\hline \multicolumn{2}{|c|}{ Controls at various levels } & \multirow{2}{*}{$\begin{array}{c}\begin{array}{c}\text { Equivalent } \\
\text { Clean ACR } \\
\left(\mathbf{h}^{-1}\right)\end{array} \\
2.9\end{array}$} & \multirow{2}{*}{$\begin{array}{c}\begin{array}{c}\text { Equivalent } \\
\text { Clean ACR } \\
\text { per person } \\
\left(\mathbf{L} \cdot \mathbf{s}^{-1}\right)\end{array} \\
8.3\end{array}$} & \multirow{2}{*}{ 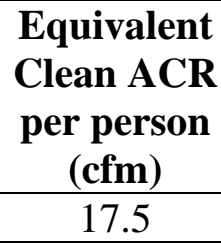 } & \multirow{2}{*}{$\begin{array}{c}\begin{array}{c}\text { Classroom } \\
\text { NIEDOAS/TuS }\end{array} \\
0.56\end{array}$} \\
\hline \multirow{8}{*}{$\begin{array}{l}\text { Filtration } \\
\text { level } \\
\text { (MERV } \\
\text { rating,-) }\end{array}$} & Base: 6 & & & & \\
\hline & 7 & 4.7 & 13.5 & 28.7 & 0.49 \\
\hline & 8 & 5.5 & 15.8 & 33.5 & 0.44 \\
\hline & 9 & 6.3 & 18.1 & 38.4 & 0.41 \\
\hline & 10 & 6.3 & 18.1 & 38.4 & 0.41 \\
\hline & 11 & 7.1 & 20.4 & 43.3 & 0.36 \\
\hline & 12 & 8.5 & 24.5 & 51.8 & 0.31 \\
\hline & 13 & 8.5 & 24.5 & 51.8 & 0.29 \\
\hline $\begin{array}{l}\text { Outdoor } \\
\text { air } \\
\text { fraction } \\
(\mathrm{OAF},-)\end{array}$ & N/A & N/A & N/A & N/A & N/A \\
\hline \multirow{7}{*}{$\begin{array}{l}\text { PAC } \\
\text { Maximum } \\
\text { Airflow } \\
\text { Rate, } \\
\mathrm{L} \cdot \mathrm{s}^{-1} \\
(\mathrm{CADR})\end{array}$} & Base: 0 & 2.9 & 8.3 & 17.5 & 0.56 \\
\hline & $53(111)$ & 3.9 & 3.9 & 23.5 & 0.45 \\
\hline & $106(222)$ & 4.8 & 4.8 & 29.6 & 0.37 \\
\hline & $159(334)$ & 5.8 & 5.8 & 35.6 & 0.32 \\
\hline & $212(445)$ & 6.8 & 6.8 & 41.6 & 0.28 \\
\hline & $265(556)$ & 7.8 & 7.8 & 47.7 & 0.25 \\
\hline & $318(667)$ & 8.8 & 8.8 & 53.7 & 0.22 \\
\hline \multirow{7}{*}{$\begin{array}{l}\text { Exhaust } \\
\text { Fan, } \\
\mathrm{L} \cdot \mathrm{s}^{-1}(\mathrm{cfm})\end{array}$} & Base: 0 & 2.9 & 8.3 & 17.5 & 0.56 \\
\hline & $95(200)$ & 2.9 & 2.9 & 17.5 & 0.56 \\
\hline & $284(600)$ & 5.4 & 5.4 & 32.7 & 0.34 \\
\hline & $474(1000)$ & 8.9 & 8.9 & 54.5 & 0.22 \\
\hline & $664(1400)$ & 12.5 & 12.5 & 76.3 & 0.16 \\
\hline & $853(1800)$ & 16.1 & 16.1 & 98.2 & 0.13 \\
\hline & $1043(2200)$ & 19.7 & 19.7 & 120.0 & 0.11 \\
\hline
\end{tabular}


Table 22. Summary of NIEwus with controls at various levels (classroom with base masks)

\begin{tabular}{|c|c|c|c|c|c|}
\hline \multicolumn{2}{|c|}{ Controls at various levels } & \multirow{2}{*}{$\begin{array}{c}\begin{array}{c}\text { Equivalent } \\
\text { Clean ACR } \\
\left(\mathbf{h}^{-1}\right)\end{array} \\
\text { N/A }\end{array}$} & \multirow{2}{*}{$\begin{array}{c}\begin{array}{c}\text { Equivalent } \\
\text { Clean ACR } \\
\text { per person } \\
\left(L \cdot \mathbf{s}^{-1}\right)\end{array} \\
\text { N/A }\end{array}$} & \multirow{2}{*}{$\begin{array}{c}\begin{array}{c}\text { Equivalent } \\
\text { Clean ACR } \\
\text { per person } \\
(\mathbf{c f m})\end{array} \\
\text { N/A }\end{array}$} & \multirow{2}{*}{$\begin{array}{c}\begin{array}{c}\text { Classroom } \\
\text { NIEwus }\end{array} \\
\text { N/A }\end{array}$} \\
\hline $\begin{array}{l}\text { Filtration } \\
\text { level } \\
\text { (MERV } \\
\text { rating,-) }\end{array}$ & N/A & & & & \\
\hline $\begin{array}{l}\text { Outdoor } \\
\text { air } \\
\text { fraction } \\
(\mathrm{OAF},-)\end{array}$ & N/A & N/A & N/A & N/A & N/A \\
\hline \multirow{7}{*}{$\begin{array}{l}\text { PAC } \\
\text { Maximum } \\
\text { Airflow } \\
\text { Rate, } \\
\mathrm{L} \cdot \mathrm{s}^{-1} \\
(\mathrm{CADR})\end{array}$} & Base: 0 & 0.3 & 0.9 & 1.8 & 0.56 \\
\hline & $53(111)$ & 1.3 & 3.7 & 7.8 & 0.22 \\
\hline & $106(222)$ & 2.3 & 6.6 & 13.9 & 0.13 \\
\hline & $159(334)$ & 3.3 & 9.4 & 19.9 & 0.10 \\
\hline & $212(445)$ & 4.3 & 12.2 & 26.0 & 0.07 \\
\hline & $265(556)$ & 5.2 & 15.1 & 32.0 & 0.06 \\
\hline & $318(667)$ & 6.2 & 17.9 & 38.0 & 0.05 \\
\hline \multirow{7}{*}{$\begin{array}{l}\text { Exhaust } \\
\text { Fan, } \\
\mathrm{L} \cdot \mathrm{s}^{-1}(\mathrm{cfm})\end{array}$} & Base: 0 & 0.3 & 0.9 & 1.8 & 0.56 \\
\hline & $95(200)$ & 1.8 & 5.1 & 10.9 & 0.17 \\
\hline & $284(600)$ & 5.4 & 15.4 & 32.7 & 0.06 \\
\hline & $474(1000)$ & 8.9 & 25.7 & 54.5 & 0.04 \\
\hline & $664(1400)$ & 12.5 & 36.0 & 76.3 & 0.03 \\
\hline & $853(1800)$ & 16.1 & 46.3 & 98.2 & 0.02 \\
\hline & $1043(2200)$ & 19.7 & 56.6 & 120.0 & 0.02 \\
\hline
\end{tabular}


Table 23. Summary of NIECAHS with controls at various levels (portable classroom with base masks)

\begin{tabular}{|c|c|c|c|c|c|}
\hline \multicolumn{2}{|c|}{ Controls at various levels } & \multirow{2}{*}{$\begin{array}{c}\begin{array}{c}\text { Equivalent } \\
\text { Clean ACR } \\
\left(\mathbf{h}^{-1}\right)\end{array} \\
3.6\end{array}$} & \multirow{2}{*}{$\begin{array}{c}\text { Equivalent } \\
\text { Clean ACR } \\
\text { per person } \\
\left(\mathbf{L} \cdot \mathbf{s}^{-1}\right)\end{array}$} & \multirow{2}{*}{$\begin{array}{c}\begin{array}{c}\text { Equivalent } \\
\text { Clean ACR } \\
\text { per person } \\
\text { (cfm) }\end{array} \\
15.5\end{array}$} & \multirow{2}{*}{$\begin{array}{c}\begin{array}{c}\text { Portable } \\
\text { Classroom } \\
\text { NIEcaHS }\end{array} \\
0.56\end{array}$} \\
\hline \multirow{8}{*}{$\begin{array}{l}\text { Filtration } \\
\text { level } \\
\text { (MERV } \\
\text { rating,-) }\end{array}$} & Base: 8 & & & & \\
\hline & 9 & 4.8 & 9.9 & 20.9 & 0.50 \\
\hline & 10 & 5.8 & 11.9 & 25.3 & 0.48 \\
\hline & 11 & 6.8 & 14.0 & 29.6 & 0.43 \\
\hline & 12 & 8.8 & 18.1 & 38.3 & 0.36 \\
\hline & 13 & 9.7 & 19.9 & 42.2 & 0.34 \\
\hline & 14 & 10.5 & 21.6 & 45.7 & 0.30 \\
\hline & 15 & 10.5 & 21.6 & 45.7 & 0.30 \\
\hline \multirow{8}{*}{$\begin{array}{l}\text { Outdoor air } \\
\text { fraction } \\
(\mathrm{OAF},-)\end{array}$} & Base: 0.33 & 3.6 & 7.3 & 15.5 & 0.56 \\
\hline & 0.43 & 4.8 & 10.0 & 21.1 & 0.50 \\
\hline & 0.53 & 5.8 & 12.0 & 25.4 & 0.46 \\
\hline & 0.63 & 6.8 & 14.0 & 29.6 & 0.42 \\
\hline & 0.73 & 7.8 & 16.0 & 33.9 & 0.38 \\
\hline & 0.83 & 8.8 & 18.0 & 38.2 & 0.36 \\
\hline & 0.93 & 9.7 & 20.0 & 42.4 & 0.33 \\
\hline & 1.00 & 10.4 & 21.4 & 45.3 & 0.32 \\
\hline \multirow{7}{*}{$\begin{array}{l}\text { PAC } \\
\text { Maximum } \\
\text { Airflow Rate, } \\
\mathrm{L} \cdot \mathrm{s}^{-1} \text { (CADR) }\end{array}$} & Base: 0 & 3.6 & 7.3 & 15.5 & 0.56 \\
\hline & $64(135)$ & 4.6 & 9.4 & 19.8 & 0.48 \\
\hline & $128(269)$ & 5.5 & 11.4 & 24.1 & 0.42 \\
\hline & $192(404)$ & 6.5 & 13.4 & 28.5 & 0.37 \\
\hline & $257(538)$ & 7.5 & 15.5 & 32.8 & 0.33 \\
\hline & $321(673)$ & 8.5 & 17.5 & 37.1 & 0.30 \\
\hline & $385(808)$ & 9.5 & 19.5 & 41.4 & 0.28 \\
\hline \multirow{7}{*}{$\begin{array}{l}\text { Exhaust Fan, } \\
\mathrm{L} \cdot \mathrm{s}^{-1}(\mathrm{cfm})\end{array}$} & Base: 0 & 3.6 & 7.3 & 15.5 & 0.56 \\
\hline & $95(200)$ & 3.8 & 7.7 & 16.4 & 0.54 \\
\hline & $284(600)$ & 6.7 & 13.8 & 29.3 & 0.36 \\
\hline & $474(1000)$ & 9.7 & 19.9 & 42.1 & 0.27 \\
\hline & $664(1400)$ & 12.6 & 26.0 & 55.0 & 0.22 \\
\hline & $853(1800)$ & 15.6 & 32.0 & 67.9 & 0.18 \\
\hline & $1043(2200)$ & 18.5 & 38.1 & 80.7 & 0.16 \\
\hline
\end{tabular}


Table 24. Summary of NIEDOAS/Tus with controls at various levels (portable classroom with base masks)

\begin{tabular}{|c|c|c|c|c|c|}
\hline \multicolumn{2}{|c|}{ Controls at various levels } & \multirow{2}{*}{$\begin{array}{c}\begin{array}{c}\text { Equivalent } \\
\text { Clean ACR } \\
\left(\mathbf{h}^{-1}\right)\end{array} \\
3.6 \\
\end{array}$} & \multirow{2}{*}{$\begin{array}{c}\begin{array}{c}\text { Equivalent } \\
\text { Clean ACR } \\
\text { per person } \\
\left(\mathbf{L} \cdot \mathbf{s}^{-1}\right)\end{array} \\
7.3\end{array}$} & \multirow{2}{*}{$\begin{array}{c}\begin{array}{c}\text { Equivalent } \\
\text { Clean ACR } \\
\text { per person } \\
\text { (cfm) }\end{array} \\
15.5 \\
\end{array}$} & \multirow{2}{*}{$\begin{array}{c}\begin{array}{c}\text { Portable } \\
\text { Classroom } \\
\text { NIEDOAS/Tus }\end{array} \\
0.56\end{array}$} \\
\hline \multirow{8}{*}{$\begin{array}{l}\text { Filtration } \\
\text { level } \\
\text { (MERV } \\
\text { rating,-) }\end{array}$} & Base: 6 & & & & \\
\hline & 7 & 4.8 & 9.9 & 20.9 & 0.49 \\
\hline & 8 & 6.8 & 14.0 & 29.6 & 0.44 \\
\hline & 9 & 7.8 & 16.0 & 34.0 & 0.41 \\
\hline & 10 & 7.8 & 16.0 & 34.0 & 0.40 \\
\hline & 11 & 8.8 & 18.1 & 38.3 & 0.36 \\
\hline & 12 & 10.5 & 21.6 & 45.7 & 0.30 \\
\hline & 13 & 10.5 & 21.6 & 45.7 & 0.28 \\
\hline $\begin{array}{l}\text { Outdoor air } \\
\text { fraction } \\
(\mathrm{OAF},-)\end{array}$ & N/A & N/A & N/A & N/A & N/A \\
\hline \multirow{7}{*}{$\begin{array}{l}\text { PAC } \\
\text { Maximum } \\
\text { Airflow Rate, } \\
\mathrm{L} \cdot \mathrm{s}^{-1}(\mathrm{CADR})\end{array}$} & Base: 0 & 3.6 & 7.3 & 15.5 & 0.56 \\
\hline & $64(135)$ & 4.6 & 4.6 & 19.8 & 0.47 \\
\hline & \begin{tabular}{|c|}
$128(269)$ \\
\end{tabular} & 5.5 & 5.5 & 24.1 & 0.40 \\
\hline & \begin{tabular}{|l|}
$192(404)$ \\
\end{tabular} & 6.5 & 6.5 & 28.5 & 0.35 \\
\hline & $257(538)$ & 7.5 & 7.5 & 32.8 & 0.31 \\
\hline & $321(673)$ & 8.5 & 8.5 & 37.1 & 0.28 \\
\hline & $385(808)$ & 9.5 & 9.5 & 41.4 & 0.25 \\
\hline \multirow{7}{*}{$\begin{array}{l}\text { Exhaust Fan, } \\
\mathrm{L} \cdot \mathrm{s}^{-1}(\mathrm{cfm})\end{array}$} & Base: 0 & 3.6 & 7.3 & 15.5 & 0.56 \\
\hline & $95(200)$ & 3.6 & 3.6 & 15.5 & 0.56 \\
\hline & $284(600)$ & 4.4 & 4.4 & 19.3 & 0.48 \\
\hline & $474(1000)$ & 7.4 & 7.4 & 32.2 & 0.32 \\
\hline & $664(1400)$ & 10.3 & 10.3 & 45.0 & 0.24 \\
\hline & $853(1800)$ & 13.3 & 13.3 & 57.9 & 0.19 \\
\hline & $1043(2200)$ & 16.3 & 16.3 & 70.8 & 0.16 \\
\hline
\end{tabular}


Table 25. Summary of NIEwus with controls at various levels (portable classroom with base masks)

\begin{tabular}{|c|c|c|c|c|c|}
\hline \multicolumn{2}{|c|}{ Controls at various levels } & \multirow{2}{*}{$\begin{array}{c}\begin{array}{c}\text { Equivalent } \\
\text { Clean ACR } \\
\left(\mathbf{h}^{-1}\right)\end{array} \\
\text { N/A }\end{array}$} & \multirow{2}{*}{$\begin{array}{c}\begin{array}{c}\text { Equivalent } \\
\text { Clean ACR } \\
\text { per person } \\
\left(\mathrm{L} \cdot \mathbf{s}^{-1}\right)\end{array} \\
\text { N/A }\end{array}$} & \multirow{2}{*}{$\begin{array}{c}\text { Equivalent } \\
\text { Clean ACR } \\
\text { per person } \\
(\mathbf{c f m})\end{array}$} & \multirow{2}{*}{$\begin{array}{c}\begin{array}{c}\text { Portable } \\
\text { Classroom } \\
\text { NIEwus }\end{array} \\
\text { N/A }\end{array}$} \\
\hline $\begin{array}{l}\text { Filtration } \\
\text { level } \\
\text { (MERV } \\
\text { rating,-) } \\
\end{array}$ & N/A & & & & \\
\hline $\begin{array}{l}\text { Outdoor } \\
\text { air } \\
\text { fraction } \\
(\mathrm{OAF},-) \\
\end{array}$ & N/A & N/A & N/A & & N/A \\
\hline \multirow{7}{*}{$\begin{array}{l}\text { PAC } \\
\text { Maximum } \\
\text { Airflow } \\
\text { Rate, } \\
\mathrm{L} \cdot \mathrm{s}^{-1} \\
(\mathrm{CADR})\end{array}$} & Base: 0 & 0.3 & 0.6 & 1.3 & 0.56 \\
\hline & $64(135)$ & 1.3 & 2.6 & 5.6 & 0.22 \\
\hline & $128(269)$ & 2.3 & 4.7 & 9.9 & 0.14 \\
\hline & \begin{tabular}{|l|}
$192(404)$ \\
\end{tabular} & 3.3 & 6.7 & 14.2 & 0.10 \\
\hline & 257 (538) & 4.3 & 8.7 & 18.5 & 0.08 \\
\hline & $321(673)$ & 5.2 & 10.8 & 22.9 & 0.06 \\
\hline & $385(808)$ & 6.2 & 12.8 & 27.2 & 0.05 \\
\hline \multirow{7}{*}{$\begin{array}{l}\text { Exhaust } \\
\text { Fan, } \\
\mathrm{L} \cdot \mathrm{s}^{-1}(\mathrm{cfm})\end{array}$} & Base: 0 & 0.3 & 0.6 & 1.3 & 0.56 \\
\hline & $95(200)$ & 1.5 & 3.0 & 6.4 & 0.20 \\
\hline & $284(600)$ & 4.4 & 9.1 & 19.3 & 0.07 \\
\hline & $474(1000)$ & 7.4 & 15.2 & 32.2 & 0.05 \\
\hline & $664(1400)$ & 10.3 & 21.3 & 45.0 & 0.03 \\
\hline & $853(1800)$ & 13.3 & 27.3 & 57.9 & 0.03 \\
\hline & $1043(2200)$ & 16.3 & 33.4 & 70.8 & 0.02 \\
\hline
\end{tabular}


Table 26. Summary of NIECAHS with controls at various levels (assembly room with base masks)

\begin{tabular}{|c|c|c|c|c|c|}
\hline \multicolumn{2}{|c|}{ Controls at various levels } & \multirow{2}{*}{$\begin{array}{c}\begin{array}{c}\text { Equivalent } \\
\text { Clean ACR } \\
\left(\mathbf{h}^{-1}\right)\end{array} \\
2.2\end{array}$} & \multirow{2}{*}{$\begin{array}{c}\begin{array}{c}\text { Equivalent } \\
\text { Clean ACR per } \\
\text { person } \\
\left(\mathbf{L} \cdot \mathbf{s}^{-1}\right)\end{array} \\
4.9\end{array}$} & \multirow{2}{*}{$\begin{array}{c}\begin{array}{c}\text { Equivalent } \\
\text { Clean ACR } \\
\text { per person } \\
\text { (cfm) }\end{array} \\
10.4 \\
\end{array}$} & \multirow{2}{*}{$\begin{array}{c}\begin{array}{c}\text { Assembly } \\
\text { room } \\
\text { NIECAHS }_{\text {CAH }}\end{array} \\
0.56\end{array}$} \\
\hline \multirow{8}{*}{$\begin{array}{l}\text { Filtration } \\
\text { level } \\
\text { (MERV } \\
\text { rating,-) }\end{array}$} & Base: 8 & & & & \\
\hline & 9 & 3.4 & 7.5 & 15.9 & 0.49 \\
\hline & 10 & 4.2 & 9.3 & 19.7 & 0.47 \\
\hline & 11 & 5.1 & 11.3 & 23.9 & 0.40 \\
\hline & 12 & 6.8 & 15.1 & 31.9 & 0.33 \\
\hline & 13 & 7.6 & 16.8 & 35.6 & 0.30 \\
\hline & 14 & 9.2 & 20.4 & 43.2 & 0.26 \\
\hline & 15 & 9.2 & 20.4 & 43.2 & 0.26 \\
\hline \multirow{8}{*}{$\begin{array}{l}\text { Outdoor air } \\
\text { fraction } \\
(\mathrm{OAF},-)\end{array}$} & Base: 0.23 & 2.2 & 4.9 & 10.4 & 0.56 \\
\hline & 0.33 & 3.4 & 7.5 & 15.8 & 0.50 \\
\hline & 0.43 & 4.2 & 9.4 & 19.8 & 0.44 \\
\hline & 0.53 & 5.1 & 11.2 & 23.8 & 0.40 \\
\hline & 0.63 & 5.9 & 13.1 & 27.8 & 0.36 \\
\hline & 0.73 & 6.8 & 15.0 & 31.8 & 0.34 \\
\hline & 0.83 & 7.6 & 16.9 & 35.8 & 0.31 \\
\hline & 1.00 & 9.1 & 20.2 & 42.7 & 0.28 \\
\hline \multirow{7}{*}{$\begin{array}{l}\text { PAC } \\
\text { Maximum } \\
\text { Airflow } \\
\text { Rate, } \\
\mathrm{L} \cdot \mathrm{s}^{-1} \\
\text { (CADR) }\end{array}$} & Base: 0 & 2.2 & 4.9 & 10.4 & 0.56 \\
\hline & $142(297)$ & 2.5 & 5.5 & 11.7 & 0.52 \\
\hline & $284(594)$ & 2.8 & 6.1 & 13.0 & 0.48 \\
\hline & $427(891)$ & 3.0 & 6.7 & 14.3 & 0.45 \\
\hline & $569(1188)$ & 3.3 & 7.3 & 15.6 & 0.42 \\
\hline & $711(1485)$ & 3.6 & 8.0 & 16.9 & 0.40 \\
\hline & $853(1782)$ & 3.9 & 8.6 & 18.1 & 0.37 \\
\hline \multirow{7}{*}{$\begin{array}{l}\text { Exhaust } \\
\text { Fan, } \\
\mathrm{L} \cdot \mathrm{s}^{-1}(\mathrm{cfm})\end{array}$} & Base: 0 & 2.2 & 4.9 & 10.4 & 0.56 \\
\hline & $1138(2400)$ & 3.3 & 7.3 & 15.4 & 0.54 \\
\hline & $1706(3600)$ & 4.4 & 9.7 & 20.6 & 0.48 \\
\hline & $2275(4800)$ & 5.5 & 12.2 & 25.8 & 0.42 \\
\hline & $2844(6000)$ & 6.6 & 14.6 & 31.0 & 0.38 \\
\hline & $3413(7200)$ & 7.7 & 17.1 & 36.2 & 0.34 \\
\hline & $3982(8400)$ & 8.8 & 19.5 & 41.4 & 0.32 \\
\hline
\end{tabular}


Table 27. Summary of NIEDOAS/Tus with controls at various levels (assembly room with base masks)

\begin{tabular}{|c|c|c|c|c|c|}
\hline \multicolumn{2}{|c|}{ Controls at various levels } & \multirow{2}{*}{$\begin{array}{c}\begin{array}{c}\text { Equivalent } \\
\text { Clean ACR } \\
\left(\mathbf{h}^{-1}\right)\end{array} \\
2.2\end{array}$} & \multirow{2}{*}{$\begin{array}{c}\begin{array}{c}\text { Equivalent } \\
\text { Clean ACR per } \\
\text { person } \\
\left(\mathbf{L} \cdot \mathbf{s}^{-1}\right)\end{array} \\
4.9 \\
\end{array}$} & \multirow{2}{*}{$\begin{array}{c}\begin{array}{c}\text { Equivalent } \\
\text { Clean ACR } \\
\text { per person } \\
\text { (cfm) }\end{array} \\
10.4 \\
\end{array}$} & \multirow{2}{*}{$\begin{array}{c}\begin{array}{c}\text { Assembly } \\
\text { room } \\
\text { NIEDOAS/TUS }\end{array} \\
0.56 \\
\end{array}$} \\
\hline Filtration & Base: 6 & & & & \\
\hline \multirow{7}{*}{$\begin{array}{l}\text { level } \\
\text { (MERV } \\
\text { rating,-) }\end{array}$} & 7 & 3.4 & 7.5 & 15.9 & 0.48 \\
\hline & 8 & 5.1 & 11.3 & 23.9 & 0.41 \\
\hline & 9 & 5.9 & 13.1 & 27.7 & 0.38 \\
\hline & 10 & 5.9 & 13.1 & 27.7 & 0.37 \\
\hline & 11 & 7.6 & 16.8 & 35.6 & 0.31 \\
\hline & 12 & 9.2 & 20.4 & 43.2 & 0.25 \\
\hline & 13 & 9.2 & 20.4 & 43.2 & 0.23 \\
\hline $\begin{array}{l}\text { Outdoor air } \\
\text { fraction } \\
(\mathrm{OAF},-)\end{array}$ & N/A & N/A & N/A & N/A & N/A \\
\hline \multirow{7}{*}{$\begin{array}{l}\text { PAC } \\
\text { Maximum } \\
\text { Airflow } \\
\text { Rate, } \\
\mathrm{L} \cdot \mathrm{s}^{-1} \\
(\mathrm{CADR})\end{array}$} & Base: 0 & 2.2 & 4.9 & 10.4 & 0.56 \\
\hline & $142(297)$ & 2.5 & 2.5 & 11.7 & 0.51 \\
\hline & $284(594)$ & 2.8 & 2.8 & 13.0 & 0.46 \\
\hline & $427(891)$ & 3.0 & 3.0 & 14.3 & 0.42 \\
\hline & $569(1188)$ & 3.3 & 3.3 & 15.6 & 0.39 \\
\hline & $711(1485)$ & 3.6 & 3.6 & 16.9 & 0.36 \\
\hline & $853(1782)$ & 3.9 & 3.9 & 18.1 & 0.34 \\
\hline \multirow{7}{*}{$\begin{array}{l}\text { Exhaust } \\
\text { Fan, } \\
\mathrm{L} \cdot \mathrm{s}^{-1}(\mathrm{cfm})\end{array}$} & Base: 0 & 2.2 & 4.9 & 10.4 & 0.56 \\
\hline & $1138(2400)$ & 2.2 & 2.2 & 10.4 & 0.56 \\
\hline & $1706(3600)$ & 3.3 & 3.3 & 15.6 & 0.56 \\
\hline & $2275(4800)$ & 4.4 & 4.4 & 20.8 & 0.51 \\
\hline & $2844(6000)$ & 5.5 & 5.5 & 26.0 & 0.43 \\
\hline & $3413(7200)$ & 6.6 & 6.6 & 31.2 & 0.38 \\
\hline & $3982(8400)$ & 7.8 & 7.8 & 36.4 & 0.33 \\
\hline
\end{tabular}


Table 28. Summary of NIEwus with controls at various levels (assembly room with base masks)

\begin{tabular}{|c|c|c|c|c|c|}
\hline \multicolumn{2}{|c|}{ Controls at various levels } & \multirow{2}{*}{$\begin{array}{c}\begin{array}{c}\text { Equivalent } \\
\text { Clean ACR } \\
\left(\mathbf{h}^{-1}\right)\end{array} \\
\text { N/A }\end{array}$} & \multirow{2}{*}{$\begin{array}{c}\begin{array}{c}\text { Equivalent } \\
\text { Clean ACR } \\
\text { per person } \\
\left(\mathrm{L} \cdot \mathrm{s}^{-1}\right)\end{array} \\
\text { N/A }\end{array}$} & \multirow{2}{*}{$\begin{array}{c}\begin{array}{c}\text { Equivalent } \\
\text { Clean ACR } \\
\text { per person } \\
\text { (cfm) }\end{array} \\
\text { N/A }\end{array}$} & \multirow{2}{*}{$\begin{array}{c}\begin{array}{c}\text { Assembly } \\
\text { room NIEwUS }\end{array} \\
\text { N/A }\end{array}$} \\
\hline $\begin{array}{l}\text { Filtration } \\
\text { level } \\
\text { (MERV } \\
\text { rating,-) }\end{array}$ & N/A & & & & \\
\hline $\begin{array}{l}\text { Outdoor } \\
\text { air } \\
\text { fraction } \\
(\mathrm{OAF},-)\end{array}$ & N/A & N/A & N/A & N/A & N/A \\
\hline \multirow{7}{*}{$\begin{array}{l}\text { PAC } \\
\text { Maximum } \\
\text { Airflow } \\
\text { Rate, } \\
\mathrm{L} \cdot \mathrm{s}^{-1} \\
(\mathrm{CADR})\end{array}$} & Base: 0 & 0.3 & 0.7 & 1.4 & 0.56 \\
\hline & $142(297)$ & 0.6 & 1.3 & 2.7 & 0.31 \\
\hline & $284(594)$ & 0.8 & 1.9 & 4.0 & 0.21 \\
\hline & $427(891)$ & 1.1 & 2.5 & 5.2 & 0.15 \\
\hline & $569(1188)$ & 1.4 & 3.1 & 6.5 & 0.12 \\
\hline & $711(1485)$ & 1.7 & 3.7 & 7.8 & 0.10 \\
\hline & $853(1782)$ & 1.9 & 4.3 & 9.1 & 0.09 \\
\hline \multirow{7}{*}{$\begin{array}{l}\text { Exhaust } \\
\text { Fan, } \\
\mathrm{L} \cdot \mathrm{s}^{-1}(\mathrm{cfm})\end{array}$} & Base: 0 & 0.3 & 0.7 & 1.4 & 0.56 \\
\hline & $1138(2400)$ & 2.2 & 4.9 & 10.4 & 0.17 \\
\hline & $1706(3600)$ & 3.3 & 7.4 & 15.6 & 0.11 \\
\hline & $2275(4800)$ & 4.4 & 9.8 & 20.8 & 0.08 \\
\hline & $2844(6000)$ & 5.5 & 12.3 & 26.0 & 0.07 \\
\hline & $3413(7200)$ & 6.6 & 14.7 & 31.2 & 0.06 \\
\hline & $3982(8400)$ & 7.8 & 17.2 & 36.4 & 0.05 \\
\hline
\end{tabular}




\section{Future Work}

This work could be expanded by combining pairs of controls, such as MERV 13 filtration with a PAC, and considering additional controls, such as UVGI. Additional space types, educational or other, and HVAC system types could also be evaluated. The impacts of poor ventilation system performance could also be explored in more detail.

FaTIMA implements a single zone, $24 \mathrm{~h}$ simulation. Future work could include multizone analyses using CONTAM. The infiltration rates could be varied by climate and building envelope airtightness. The effect of controls, such as exhaust fans, would also be affected by building envelope airtightness. CONTAM also allows the use of more flexible schedules, such as varying OA amounts at different times of the day, such as $2 \mathrm{~h}$ prior to and post-occupancy or with outdoor temperature.

\section{Conclusion}

Guidance for reoccupying school buildings includes wearing masks, increasing ventilation, increasing filtration, and using PACs. This analysis compared the relative reduction in aerosol exposure in selected educational spaces as a result of changes to the operation of HVAC systems and wearing of masks using FaTIMA. It also quantified some of the uncertainties associated with these controls. Aerosol exposure was evaluated in two classrooms and an assembly room with four different types of HVAC systems: CAHS, DOAS, TUS, and WUS. With no controls, it was found that the CAHS had the lowest exposure and the WUS had the highest exposure.

For all spaces and HVAC systems, masks with a protection efficiency of $25 \%$ reduced exposure by $44 \%$. Masks with higher protection efficiencies ( $85 \%$ to $90 \%$ ) reduced exposure by $99 \%$, and masks with lower protection efficiencies reduced exposure by $15 \%$. Controls combined with masks were more effective at reducing exposure than without masks. The rest of the findings summarized here are for the masks with $25 \%$ inhalation and exhalation protection efficiencies. For HVAC systems that could accommodate a MERV 13 filter (CAHS, DOAS, and TUS), the average NIE HVAC was 0.51 compared with no controls across space types. For HVAC systems that cannot accommodate a MERV 13 filter (WUS), a $569 \mathrm{~L} \cdot \mathrm{s}^{-1}$ (1200 cfm) exhaust fan was more effective than a single 297 CADR PAC in the classrooms simulated, but just as effective in the assembly room. These results assume all controls were performing as described in this report; the estimated exposure reductions would be different for different assumptions. Multiple controls can be implemented in spaces and HVAC systems to reduce exposure as part of a broader risk reduction strategy that might be pursued by a building owner or manager. As noted by ASHRAE, engineering and other controls should be part of a larger, layered risk reduction strategy that includes hand washing, surface cleaning, social distancing, and reduced occupant density (ASHRAE 2020). 


\section{Appendix A: Change Log}

The following change was made:

On page 63, Figure 20(a) was replaced with a corrected version. The previous Figure 20(a) was a duplicate of Figure 20(b). This change was made on September 2, 2021. 


\section{References}

AHAM (2006). ANSI/AHAM AC-1: Method for Measuring the Performance of Portable Household Electric Room Air Cleaners. Washington DC: Association of Home Appliance Manufacturers.

AHAM (2020). AHAM Verifide Directory of Certified Room Air Cleaners from https://ahamverifide.org/directory-of-air-cleaners/.

Ahlawat, A., A. Wiedensohler and S. K. Mishra (2020). An Overview on the Role of Relative Humidity in Airborne Transmission of SARS-CoV-2 in Indoor Environments. Aerosol and Air Quality Research 20(9): 1856-1861.

Allen, J., J. Cedeno-Laurent and S. Miller (2020). Harvard - CU Boulder Portable Air Cleaner Calculator For Schools v1.2 from https://tinyurl.com/portableaircleanertool.

Alsved, M., A. Matamis, R. Bohlin, M. Richter, P. E. Bengtsson, C. J. Fraenkel, P. Medstrand and J. Löndahl (2020). Exhaled respiratory particles during singing and talking. Aerosol Science and Technology 1-5.

Asadi, S., A. S. Wexler, C. D. Cappa, S. Barreda, N. M. Bouvier and W. D. Ristenpart (2019). Aerosol emission and superemission during human speech increase with voice loudness. Scientific Reports 9(1): 2348.

ASHRAE (2017). Standard 52.2-2017: Method of Testing General Ventilation Air-Cleaning Devices for Removal Efficiency by Particle Size. Atlanta: American Society of Heating, Refrigerating and Air-Conditioning Engineers.

ASHRAE (2019). ANSI/ASHRAE Standard 62.1-2019: Ventilation for Acceptable Indoor Air Quality. Atlanta, ASHRAE.

ASHRAE (2020). ASHRAE Epidemic Task Force: Re-Opening Schools and Universities

ASHRAE (2021). ASHRAE Epidemic Task Force: Core Recommendations for Reducing Airborne Infectious Aerosol Exposure

Buonanno, G., L. Morawska and L. Stabile (2020a). Quantitative assessment of the risk of airborne transmission of SARS-CoV-2 infection: Prospective and retrospective applications. Environ Int 145(106112.

Buonanno, G., L. Stabile and L. Morawska (2020b). Estimation of airborne viral emission: Quanta emission rate of SARS-CoV-2 for infection risk assessment. Environ Int 141(105794.

CDPH (2017). Standard method for the testing and evaluation of volatile organic chemical emissions from indoor sources using environmental chambers, version 1.2. Sacramento, CA: California Department of Public Health.

CDPH (2020). The Role of Building Ventilation and Filtration in Reducing Risk of Airborne Viral Transmission in Schools, Illustrated with SARS-CoV-2. Richmond, CA:

Dols, W. S. and B. Polidoro (2020). CONTAM User Guide and Program Documentation Version 3.4. Gaithersburg, MD: National Institute of Standards and Technology. Technical Note 1887 Revision 1.

Dols, W. S., B. J. Polidoro, D. Poppendieck and S. J. Emmerich (2020). A Tool to Model the Fate and Transport of Indoor Microbiological Aerosols (FaTIMA). Gaithersburg, MD: National Institute of Standards and Technology. 10.6028/nist.Tn.2095. TN2095.

Duguid, J. (1946). The size and the duration of air-carriage of respiratory droplets and dropletnuclei. Epidemiology \& Infection 44(6): 471-479. 
Haverinen-Shaughnessy, U., D. J. Moschandreas and R. J. Shaughnessy (2011). Association between substandard classroom ventilation rates and students' academic achievement. Indoor Air 21(2): 121-31.

Horve, P. F., L. Dietz, M. Fretz, D. A. Constant, A. Wilkes, J. M. Townes, R. G. Martindale, W. B. Messer and K. Van Den Wymelenberg (2020). Identification of SARS-CoV-2 RNA in Healthcare Heating, Ventilation, and Air Conditioning Units. under review 2020.06.26.20141085.

Jimenez, J. L. (2020). COVID-19 Aerosol Transmission Estimator from https://tinyurl.com/covid-estimator.

Jones, E., A. Young, K. Clevenger, P. Salimifard, E. Wu, M. L. Luna, M. Lahvis, J. Lang, M. Bliss, P. Azimi, J. Cedeno-Laurent, C. Wilson and J. Allen (2020). Schools for Health: Risk Reduction Strategies for Reopening SchoolsHarvard T.H. Chan School of Public Health Healthy Buildings Program.

Kowalski, W., W. P. Bahnfleth and T. Whittam (1999). Filtration of airborne microorganisms: Modeling and prediction. ASHRAE Transactions 105(4.

Kudo, E., E. Song, L. J. Yockey, T. Rakib, P. W. Wong, R. J. Homer and A. Iwasaki (2019). Low ambient humidity impairs barrier function and innate resistance against influenza infection. Proceedings of the National Academy of Sciences 116(22): 10905-10910.

Leconte, S., G. Liistro, P. Lebecque and J.-M. Degryse (2011). The objective assessment of cough frequency: accuracy of the LR102 device. Cough 7(1): 1-8.

Li, Y., G. M. Leung, J. W. Tang, X. Yang, C. Y. H. Chao, J. Z. Lin, J. W. Lu, P. V. Nielsen, J. Niu, H. Qian, A. C. Sleigh, H. J. J. Su, J. Sundell, T. W. Wong and P. L. Yuen (2007). Role of ventilation in airborne transmission of infectious agents in the built environment a multidisciplinary systematic review. Indoor Air 17(1): 2-18.

Lindsley, W. G., F. M. Blachere, D. H. Beezhold, B. F. Law, R. C. Derk, J. M. Hettick, K. Woodfork, W. T. Goldsmith, J. R. Harris, M. G. Duling, B. Boutin, T. Nurkiewicz and J. D. Noti (2021). A comparison of performance metrics for cloth face masks as source control devices for simulated cough and exhalation aerosols. medRxiv.

Liu, Y., Z. Ning, Y. Chen, M. Guo, Y. Liu, N. K. Gali, L. Sun, Y. Duan, J. Cai, D. Westerdahl, X. Liu, K. Xu, K.-f. Ho, H. Kan, Q. Fu and K. Lan (2020). Aerodynamic analysis of SARS-CoV-2 in two Wuhan hospitals. Nature 582(7813): 557-560.

Lu, J., J. Gu, K. Li, C. Xu, W. Su, Z. Lai, D. Zhou, C. Yu, B. Xu and Z. Yang (2020). COVID19 Outbreak Associated with Air Conditioning in Restaurant, Guangzhou, China, 2020. Emerg Infect Dis 26(7): 1628-1631.

Makison Booth, C., M. Clayton, B. Crook and J. M. Gawn (2013). Effectiveness of surgical masks against influenza bioaerosols. J Hosp Infect 84(1): 22-6.

Mecenas, P., R. T. d. R. M. Bastos, A. C. R. Vallinoto and D. Normando (2020). Effects of temperature and humidity on the spread of COVID-19: A systematic review. PLOS ONE 15(9): e0238339.

Miller, S. L., W. W. Nazaroff, J. L. Jimenez, A. Boerstra, G. Buonanno, S. J. Dancer, J. Kurnitski, L. C. Marr, L. Morawska and C. Noakes (2020). Transmission of SARS-CoV2 by inhalation of respiratory aerosol in the Skagit Valley Chorale superspreading event. Indoor Air 00(1-10.

Milton, D. K., M. P. Fabian, B. J. Cowling, M. L. Grantham and J. J. McDevitt (2013). Influenza virus aerosols in human exhaled breath: particle size, culturability, and effect of surgical masks. PLoS Pathog 9(3): e1003205. 
Morawska, L. and D. K. Milton (2020). It Is Time to Address Airborne Transmission of Coronavirus Disease 2019 (COVID-19). Clinical Infectious Diseases 71(9): 2311-2313.

Mueller, W., C. J. Horwell, A. Apsley, S. Steinle, S. McPherson, J. W. Cherrie and K. S. Galea (2018). The effectiveness of respiratory protection worn by communities to protect from volcanic ash inhalation. Part I: Filtration efficiency tests. Int J Hyg Environ Health 221(6): 967-976.

NASEM (2020). Reopening K-12 Schools During the COVID-19 Pandemic: Prioritizing Health, Equity, and Communities. Washington, DC: The National Academies Press

Ng, L. C., A. Musser, S. J. Emmerich and A. K. Persily (2019). Airflow and Indoor Air Quality Models of DOE Prototype Commercial Buildings. Gaithersburg, MD: National Institute of Standards and Technology. https://doi.org/10.6028/NIST.TN.2072. Technical Note 2072.

Ng, L. C., N. Ojeda Quiles, W. S. Dols and S. J. Emmerich (2018). Weather correlations to calculate infiltration rates for U. S. commercial building energy models. Building and Environment 127(Supplement C): 47-57.

Niazi, S., R. Groth, K. Spann and G. R. Johnson (2020). The role of respiratory droplet physicochemistry in limiting and promoting the airborne transmission of human coronaviruses: A critical review. Environmental Pollution 115767.

Noti, J. D., F. M. Blachere, C. M. McMillen, W. G. Lindsley, M. L. Kashon, D. R. Slaughter and D. H. Beezhold (2013). High humidity leads to loss of infectious influenza virus from simulated coughs. PLOS ONE 8(2): e57485.

Pan, J., C. Harb, W. Leng and L. C. Marr (2021). Inward and outward effectiveness of cloth masks, a surgical mask, and a face shield. Aerosol Science and Technology 1-16.

Park, S. Y., Y.-M. Kim, S. Yi, S. Lee, B.-J. Na, C. B. Kim, J.-i. Kim, H. S. Kim, Y. B. Kim, Y. Park, I. S. Huh, H. K. Kim, H. J. Yoon, H. Jang, K. Kim, Y. Chang, I. Kim, H. Lee, J. Gwack, S. S. Kim, M. Kim, S. Kweon, Y. J. Choe, O. Park, Y. J. Park and E. K. Jeong (2020). Coronavirus Disease Outbreak in Call Center, South Korea. Emerging Infectious Diseases 26(8): 1666-1670.

Persily, A. K. and L. C. Ng (2020). Presentation: Ventilation Impacts on Indoor Aerosol Transport and Current HVAC Recommendations for Re-Opening Buildings. Gaithersburg, MD, National Institute of Standards and Technology.

Rengasamy, S., B. Eimer and R. E. Shaffer (2010). Simple respiratory protection--evaluation of the filtration performance of cloth masks and common fabric materials against 20-1000 nm size particles. Ann Occup Hyg 54(7): 789-98.

Shrestha, S. S., A. Desjarlais, L. Dalgleish, L. Ng, D. Hun, S. Emmerich and G. Accawi (2019). Moisture Transfer in Commercial Buildings due to the Air Leakage: A New Feature in the Online Airtightness Savings Calculator. Thermal Performance of the Exterior Envelopes of Whole Buildings XIV International Conference, Clearwater, FL.

Thomas-Rees, S., D. Parker and J. Sherwin (2009). Lessons Learned in Portable Classrooms. ASHRAE Journal 51(30-41.

USGAO (2020). K-12 Education: School Districts Frequently Identified Multiple Building Systems Needing Updates or Replacement. Washington, D.C.: U. S. Government Accountability Office.

van der Sande, M., P. Teunis and R. Sabel (2008). Professional and home-made face masks reduce exposure to respiratory infections among the general population. PLoS One 3(7): e2618. 
Ward, M. P., S. Xiao and Z. Zhang (2020). Humidity is a consistent climatic factor contributing to SARS-CoV-2 transmission. Transboundary and Emerging Diseases n/a(n/a).

WHO (2020). WHO Director-General's opening remarks at the media briefing on COVID-19 11 March 2020. 